\section{OPEN ACCESS}

Edited by:

Martin G. Klotz,

Queens College, City University of

New York, USA

Reviewed by:

Eddie Cytryn,

Agricultural Research Organization,

Israel

John Phillip Bowman,

University of Tasmania, Australia

*Correspondence:

Markus Göker

markus.goeker@dsmz.de

${ }^{\dagger}$ These authors have contributed equally to this work.

Specialty section: This article was submitted to Evolutionary and Genomic Microbiology

a section of the journal

Frontiers in Microbiology

Received: 04 May 2016 Accepted: 30 November 2016 Published: 20 December 2016

Citation:

Hahnke RL, Meier-Kolthoff JP

García-López M, Mukherjee S, Huntemann M, Ivanova NN, Woyke T, Kyrpides NC, Klenk H-P and Göker M

(2016) Genome-Based Taxonomic

Classification of Bacteroidetes.

Front. Microbiol. 7:2003.

doi: 10.3389/fmicb.2016.02003

\title{
Genome-Based Taxonomic Classification of Bacteroidetes
}

\begin{abstract}
Richard L. Hahnke ${ }^{1 \dagger}$, Jan P. Meier-Kolthoff ${ }^{1 \dagger}$, Marina Garcia-López', Supratim Mukherjee ${ }^{2}$, Marcel Huntemann ${ }^{2}$, Natalia N. Ivanova ${ }^{2}$, Tanja Woyke ${ }^{2}$, Nikos C. Kyrpides ${ }^{2,3}$, Hans-Peter Klenk ${ }^{4}$ and Markus Göker ${ }^{1 *}$
\end{abstract}

${ }^{1}$ Department of Microorganisms, Leibniz Institute DSMZ-German Collection of Microorganisms and Cell Cultures, Braunschweig, Germany, ${ }^{2}$ Department of Energy Joint Genome Institute (DOE JGI), Walnut Creek, CA, USA, ${ }^{3}$ Department of Biological Sciences, Faculty of Science, King Abdulaziz University, Jeddah, Saudi Arabia, ${ }^{4}$ School of Biology, Newcastle University, Newcastle upon Tyne, UK

The bacterial phylum Bacteroidetes, characterized by a distinct gliding motility, occurs in a broad variety of ecosystems, habitats, life styles, and physiologies. Accordingly, taxonomic classification of the phylum, based on a limited number of features, proved difficult and controversial in the past, for example, when decisions were based on unresolved phylogenetic trees of the 16S rRNA gene sequence. Here we use a large collection of type-strain genomes from Bacteroidetes and closely related phyla for assessing their taxonomy based on the principles of phylogenetic classification and trees inferred from genome-scale data. No significant conflict between 16S rRNA gene and whole-genome phylogenetic analysis is found, whereas many but not all of the involved taxa are supported as monophyletic groups, particularly in the genome-scale trees. Phenotypic and phylogenomic features support the separation of Balneolaceae as new phylum Balneolaeota from Rhodothermaeota and of Saprospiraceae as new class Saprospiria from Chitinophagia. Epilithonimonas is nested within the older genus Chryseobacterium and without significant phenotypic differences; thus merging the two genera is proposed. Similarly, Vitellibacter is proposed to be included in Aequorivita. Flexibacter is confirmed as being heterogeneous and dissected, yielding six distinct genera. Hallella seregens is a later heterotypic synonym of Prevotella dentalis. Compared to values directly calculated from genome sequences, the $\mathrm{G}+\mathrm{C}$ content mentioned in many species descriptions is too imprecise; moreover, corrected $\mathrm{G}+\mathrm{C}$ content values have a significantly better fit to the phylogeny. Corresponding emendations of species descriptions are provided where necessary. Whereas most observed conflict with the current classification of Bacteroidetes is already visible in 16S rRNA gene trees, as expected whole-genome phylogenies are much better resolved.

\footnotetext{
Keywords: G+C content, genome BLAST distance phylogeny, gliding motility, gut microbiome, marine microbiology, one thousand microbial genomes project, phylogenetic classification, Bacteroidaeota-Rhodothermaeota-Balneolaeota-Chlorobaeota superphylum
}

\section{INTRODUCTION}

Bacteroidetes comprise bacteria widespread in the biosphere and isolated from many distinct habitats, including temperate, tropical and polar ecosystems (Krieg et al., 2010; Thomas et al., 2011). Bacteroides are anaerobic and mostly found in the gastrointestinal tract of animals and humans and, besides Firmicutes, even dominates the gut microflora of mammals (Smith et al., 2006; 
Ley et al., 2009; Thomas et al., 2011). Several Cytophagia were cultured from marine habitats, whereas Cytophaga was found in soils and Cyclobacteriaceae in (hyper-)saline environments only (Krieg et al., 2010). Flavobacteriaceae have colonized many different ecosystems such as soils, sediment, freshwater, brackish water, and seawater in temperate, tropical, and polar ecosystems (Bernardet, 2011). Some Flavobacteriaceae are even pathogenic for humans, other mammals, freshwater fish or marine fish. However, Blattabacteriaceae are endosymbiotic bacteria (e.g., in termites and cockroaches), whereas Cryomorphaceae mostly live in cold, marine environments (Bowman et al., 2003). The wide variety of habitats reflects the importance of Bacteroidetes in biogeochemical processes. For instance, aquatic, terrestrial and gut Bacteroidetes are well known for their functional specialization on the decomposition of peptides and polysaccharides (Kirchman, 2002; Bowman, 2006; Thomas et al., 2011; Fernández-Gómez et al., 2013). This feature is accompanied by a great number and diversity of carbohydrateactive enzymes (Cantarel et al., 2009) in Bacteroidetes genomes (Fernández-Gómez et al., 2013). The corresponding genes cluster together with TonB-dependent transporters in polysaccharideutilization loci (Martens et al., 2009; Sonnenburg et al., 2010; Fernández-Gómez et al., 2013). Genome sequences are expected to support investigating the evolutionary relationship of gut Bacteroidetes and the diet of their hosts, facilitated by lateral gene (carbohydrate-active enzymes) and gene cluster (polysaccharide utilization loci) transfer between environmental and gut Bacteroidetes (Thomas et al., 2011).

Bacteroidetes are Gram-stain-negative, chemo-organotrophic rods that do not form endospores and are either non-motile or motile by gliding (Woese, 1987; Paster et al., 1994). Before the phylum was called Bacteroidetes (Krieg et al., 2010), it had been referred to as Cytophaga-Flavobacteria-Bacteroides (Paster et al., 1994; Woese, 1987). The phylum comprises the classes Bacteroidia, Cytophagia, Flavobacteriia, and Sphingobacteriia (Krieg et al., 2010). Recently, the name Bacteroidaeota was proposed for this phylum by including the rank phylum in the International Code of Nomenclature of Prokaryotes (Oren et al., 2015). As Cytophaga, Flexibacter, and Flavobacterium have many phenotypic characteristics in common, their differentiation used to be based on the presence or absence of gliding motility (Bernardet et al., 1996). However, gliding motility is a common feature of many Bacteroidetes genera (McBride and Zhu, 2013). Cytophaga and Flexibacter were also delineated based on cell morphology, the $\mathrm{G}+\mathrm{C}$ content as well as the habitats they were isolated from Reichenbach (1989c). The anaerobic Bacteroidia used to be considered separate from the aerobic groups such as Flavobacteriia and Cytophagia, but 16S rRNA gene sequencing clarified their interconnections (Paster et al., 1985; Weisburg et al., 1985; Woese, 1987). Despite its usefulness in resolving such taxonomic questions, the 16S rRNA gene contains only a limited number of characters and thus usually yields only partially resolved phylogenies, i.e., trees with many statistically unsupported branches (Klenk and Göker, 2010; Breider et al., 2014). Recently, Munoz et al. (2016) revised the phylogeny of Bacteroidetes and removed the incertae sedis taxa from the Balneola group and Rhodothermaceae (Bacteroidetes Order II. incertae sedis) from the Bacteroidetes as the novel phylum Rhodothermaeota. Nevertheless, many unsatisfactory aspects of Bacteroidetes classification might still persist.

Indeed, only monophyletic taxa can be accepted in a taxonomic classification because its purpose is to summarize the phylogeny of the classified organisms (Hennig, 1965; Wiley and Lieberman, 2011), and genome-scale data are more promising than single genes, or multi-locus sequence analysis restricted to a low number of genes, to identify monophyletic and nonmonophyletic groups with high confidence (Klenk and Göker, 2010). The phenomenal increase in the number of publicly available whole-genome sequences further demands a genomebased classification system in today's genomic era.

The genomic $\mathrm{G}+\mathrm{C}$ content, i.e., the proportion of cytosines and guanines among all nucleotides in the genome, is one of the most frequently used taxonomic markers in microbiology (Mesbah et al., 1989; Rosselló-Mora and Amann, 2001). Within Bacteroidetes, it is strongly recommended to include the $\mathrm{G}+\mathrm{C}$ content especially when describing every species of Flavobacteriaceae (Bernardet et al., 2002). The rapid progress in sequencing technology (Liu et al., 2012; Mavromatis et al., 2012) allows not only for inferring genome-scale phylogenies (Klenk and Göker, 2010; Meier-Kolthoff et al., 2014a) but also for replacing traditional methods that indirectly determine the G+C content (Mesbah et al., 1989; Moreira et al., 2011) by calculating it directly from highly accurate genome sequences. For this reason, literature claims that the variation of the $\mathrm{G}+\mathrm{C}$ content within bacterial species is at most $3 \mathrm{~mol} \%$ (Mesbah et al., 1989) or even up to $5 \mathrm{~mol} \%$ (Rosselló-Mora and Amann, 2001) can be attributed to the imprecision of traditional methods (Meier-Kolthoff et al., 2014c). On the other hand, withinspecies variation is at most $1 \%$ when both species boundaries (Meier-Kolthoff et al., 2013a) and G+C contents are determined from genome sequences (Meier-Kolthoff et al., 2014c). These inconsistencies call for correcting species descriptions that include a conventionally determined $\mathrm{G}+\mathrm{C}$ content value that differs by more than $1 \%$ from the value calculated from the genome sequence of the type strain (Meier-Kolthoff et al., 2014c; Riedel et al., 2014). Apparently the same holds if a range of $\mathrm{G}+\mathrm{C}$ values was provided whose lower or upper bound deviates by more than $1 \%$ from the directly calculated $\mathrm{G}+\mathrm{C}$ value, but a species description should also be restricted if a range of $\mathrm{G}+\mathrm{C}$ values was provided that, unrealistically, exceeds $1 \%$. Taxa of higher rank should accordingly be emended if their presumed range of $\mathrm{G}+\mathrm{C}$ values turns out to be in conflict with the information from genome sequences (Scheuner et al., 2014).

The Genomic Encyclopedia of Bacteria and Archaea (GEBA) pilot phase as well as the One Thousand Microbial Genomes phase 1 (KMG-1) projects (Kyrpides et al., 2014) are ideal data sources for genome-scale taxonomic reasoning because these projects aimed at filling the genomic gaps in the bacterial and archaeal branches of the tree of life (Göker and Klenk, 2013) and included only type strains with a certified origin from a culture collection and thus a verifiable history. Using the Bacteroidetes genome sequences from these projects, we here address the following questions: (i) What 
is the relationship between the phylogenomic trees and the proposed taxonomic classifications or the 16S rRNA gene phylogenies? (ii) Which taxa need to be revised because they are evidently non-monophyletic? (iii) Which taxon descriptions that lack $\mathrm{G}+\mathrm{C}$ values should be augmented with information from genome sequences? (iv) Which taxon descriptions deviate from $\mathrm{G}+\mathrm{C}$ content values calculated from genome sequences and should now be emended accordingly? (v) Does the correction of $\mathrm{G}+\mathrm{C}$ values improve their fit to the phylogeny?

\section{MATERIALS AND METHODS}

The Bacteroidetes (ingroup), Chlorobi, Planctomycetes, and Verrucomicrobia (outgroup) type-strain genomes originating from the GEBA pilot phase and the KMG-1 (Kyrpides et al., 2014) project were downloaded from IMG (Markowitz et al., 2009) and augmented with additional type-strain genomes of taxonomic interest deposited in INSDC. The complete list is found in Supplementary Table 1. Genome-scale phylogenies were inferred from whole proteomes using the high-throughput version (Meier-Kolthoff et al., 2014a) of the Genome BLAST Distance Phylogeny (GBDP) approach (Henz et al., 2005; Auch et al., 2006). BLAST+ (v2.2.30) (Camacho et al., 2009) was run in BLASTP mode with default parameters except for an $e$-value filter of $10^{-8}$ (Meier-Kolthoff et al., 2014a). The greedy-with-trimming algorithm, which conducts a correction for non-orthologous hits, was applied in conjunction with formula $d_{5}$, which relates the (weighted) number of identities within BLAST hits (high-scoring segment pairs) to the overall length of these hits and thus is unaffected by incomplete genome sequencing, and subjected to 100 pseudo-bootstrap replicates (Meier-Kolthoff et al., 2013a, 2014a). Phylogenetic trees were inferred from the original and pseudo-bootstrapped intergenomic distance matrices using FastME (Lefort et al., 2015), and tree and support values visualized using ITOL (Letunic and Bork, 2011). Where species affiliations had to be clarified, digital DNA:DNA hybridization was conducted with the recommended settings of the GenomeTo-Genome Distance Calculator (GGDC) version 2.1 (MeierKolthoff et al., 2013a).

Comprehensive, aligned, near full-length 16S rRNA gene data for Bacteroidetes and the outgroup phyla were taken from version s123 of the All-Species Living Tree Project (LTP) (Yarza et al., 2008). Sequences of species of interest missing from LTP s123 (see Supplementary File 2) were added to the alignment using POA (Lee et al., 2002). Trees were inferred from the alignment with RAxML (Stamatakis, 2014) under the maximumlikelihood (ML) criterion in conjunction with the GTR-CAT model, fast bootstrapping, bootstopping (Pattengale et al., 2010) and subsequent search for the best tree, and with TNT (Goloboff et al., 2008) under the maximum-parsimony criterion (MP); here, new-technology search for the best tree was conducted as well as 1000 bootstrapping replicates in conjunction with tree-bisectionand-reconnection branch swapping and one random sequence addition replicate per bootstrap replicate. Further ML and MP trees were inferred in the same way but using the branches of the
GBDP tree with $\geq 95 \%$ support as backbone constraint. Finally, $16 \mathrm{~S}$ rRNA gene trees reduced to genome-sequenced strains were inferred.

All trees were compared to the current classification used in LTP version s123, which was cleaned from inconsistencies, such as mismatches between species and genus names, and subsequently modified manually in the case of taxonomic arrangements that could not be confirmed in the literature, of validly published synonyms that were in better agreement to the phylogenies, and of missing taxa such as the family for Saccharicrinis (Yang et al., 2014). The full list of changes is described in Supplementary File 2. Whether taxa were monophyletic, paraphyletic or polyphyletic (Farris, 1974; Wood, 1994) was determined using program code developed at DSMZ, which reports, in the case of taxa appearing non-monophyletic in a phylogeny, the highest support of all branches that conflict with the monophyly of that taxon as support against it (that can be displayed as negative support). In a rooted tree, these conflicting branches are the ones connected to subtrees that contain some but not all representatives of the taxon, as well as representatives of other taxa.

The (trivial) calculation of the $\mathrm{G}+\mathrm{C}$ content from genome sequences was done as in a previous study (Meier-Kolthoff et al., 2014c) and by the GGDC server version 2.1. The changes in the fit between phylogeny and $\mathrm{G}+\mathrm{C}$ content data when switching from conventionally calculated values to $\mathrm{G}+\mathrm{C}$ counts from genome sequences was assessed by calculating their MP score with TNT (Goloboff et al., 2008), which allows for treating continuous characters as such (Goloboff et al., 2006). The data were rescaled to fit in the range between 0 and 65 as necessary for TNT and exported using the opm package (Vaas et al., 2013) for R (R Development Core Team, 2015); species without a literature $\mathrm{G}+\mathrm{C}$ value were deactivated. To address phylogenetic uncertainty, the difference was re-calculated for each pseudobootstrap tree, and the resulting set of differences tested for its difference from zero using a $t$-test and Wilcoxon signed rank test as implemented in $\mathrm{R}$. Because some $\mathrm{G}+\mathrm{C}$ contents are given as ranges in the literature, we alternatively assessed minima, averages and maxima of the ranges, combined with the single $\mathrm{G}+\mathrm{C}$ values from the other sources. For each species, only the most recent emendation that included a $\mathrm{G}+\mathrm{C}$ content value was considered. Visualization was done with ggplot2 (Wickham, 2009). We further investigated the effect of incomplete genome sequencing on the calculation of $\mathrm{G}+\mathrm{C}$ content values using the simulation techniques from our earlier study (Auch et al., 2010); details are provided in Supplementary File 3.

\section{RESULTS}

\section{$\mathrm{G}+\mathrm{C}$ Content and Phylogeny}

Figure 1A shows the relationship between conventionally determined $\mathrm{G}+\mathrm{C}$ content values and those calculated from the genome sequences; Supplementary Table 1 contains all collected data. A total of 161 species descriptions could be confirmed regarding the $\mathrm{G}+\mathrm{C}$ content, for 45 it was obvious that they should be restricted because the provided $\mathrm{G}+\mathrm{C}$ content range was unrealistically broad, 119 deviated by more than $1 \%$ from the 

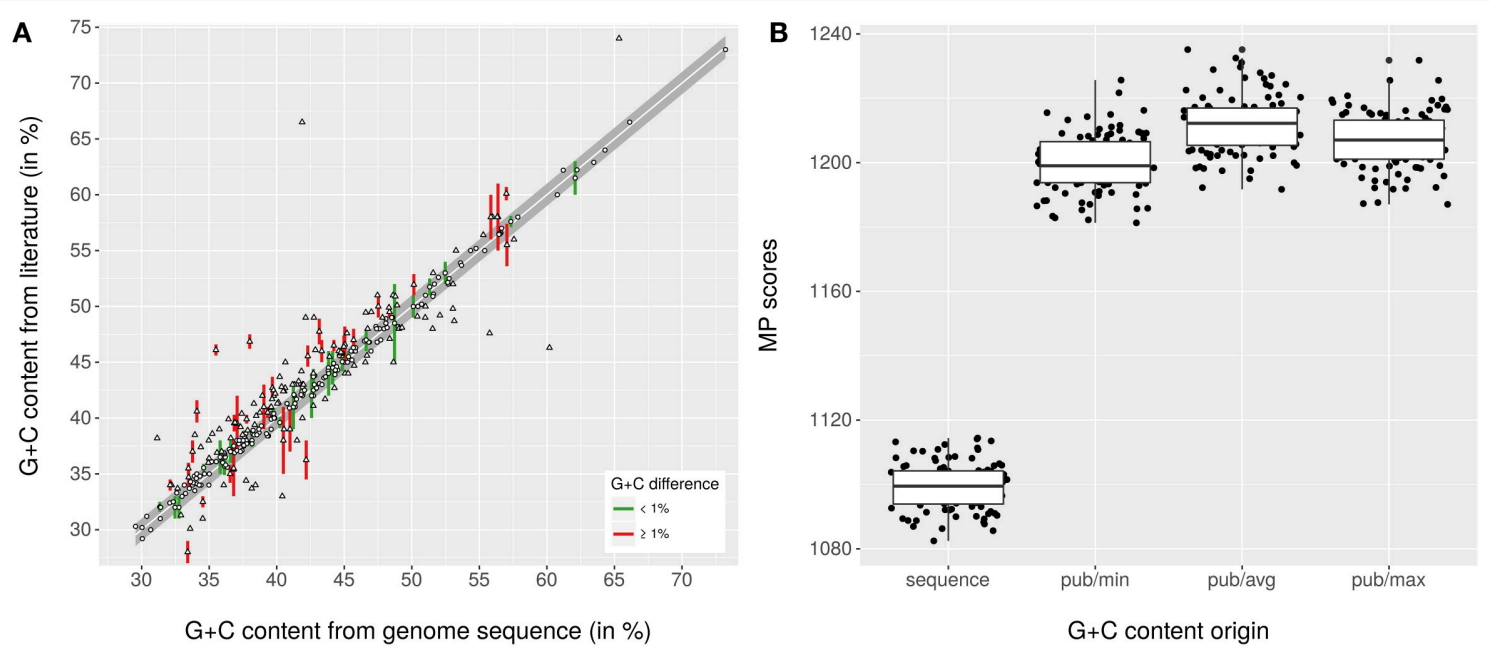

FIGURE 1 | Relationship between $\mathrm{G}+\mathrm{C}$ content values from species descriptions and those calculated from the genome sequences. (A) scatter plot showing the relationship between $\mathrm{G}+\mathrm{C}$ content values calculated from the genome sequences and those found in the respective last revision in the literature, mostly calculated traditionally. The gray band indicates the boundary of $1 \%$ deviation, green color (when ranges were provided) and circles indicate values within that range, red color and triangles indicate values outside that range. (B) box plots showing the MP scores calculated with TNT from the rescaled $\mathrm{G}+\mathrm{C}$ content values of distinct origin (pub, published; min, avg and max refer to whether the lower, average or upper value was used when a range was given) in conjunction with the 100 pseudo-bootstrapped GBDP trees. The values calculated from the genome sequences yield a significantly lower MP score (and thus a significantly better fit to the tree) than the ones from the respective last emendation in the literature.

genome sequence, and 24 lacked a $\mathrm{G}+\mathrm{C}$ content range or value altogether. The MP scores of the conventionally determined and genome-sequence based $\mathrm{G}+\mathrm{C}$ contents are shown in the Figure 1B. As confirmed by all tests conducted $(\alpha<0.001)$, it was obvious that the corrected $\mathrm{G}+\mathrm{C}$ content values display a significantly better fit to the phylogeny than the original ones, and that this progress can be detected even though a large number of the $\mathrm{G}+\mathrm{C}$ content values needed no correction. The results are in agreement with the simulations to assess the affect of incomplete genome sequencing on the calculation of the $\mathrm{G}+\mathrm{C}$ content, which showed that the expected deviation from the real value is significantly below $0.1 \%$ for the given sequencing quality (Supplementary File 3).

The underlying GDBP tree is shown in Figures 2-4 together with branch support values, taxonomic annotations and genomic $\mathrm{G}+\mathrm{C}$ content indicators. Figure 5 compares the positive or negative support values for each taxon implicit in the GBDP (average support over all branches, 92.00\%), 16S rRNA gene ML (69.47\%), and 16S rRNA gene MP (67.25\%) trees. The whole-genome tree supports more taxa than the 16S rRNA gene but also yields conflict in few cases where the 16S rRNA gene phylogeny is inconclusive, whereas several taxa are strongly supported as non-monophyletic by all approaches. However, in contrast to the classification, no well-supported (Taylor and Piel, 2004) discrepancies between the GBDP tree and the $16 \mathrm{~S}$ rRNA gene trees were detected, as evident from the empty upper left and lower right corners in Figure 5. The unconstrained comprehensive 16S rRNA gene ML and MP trees (UCT) as well as the backbone-constrained ones (CCT) are included in Supplementary File 4. Whereas the majority of taxa appeared monophyletic in our analyses, a couple of discrepancies between the phylogenomic tree and the classification were observed, which we report herein in decreasing order of taxonomic rank involved, along with according suggestions for reclassifications.

\section{Phyla, Classes, and Orders}

All phyla appeared as monophyletic in the GBDP tree (Figure 2). Given their separation from Bacteroidetes, the Balneolia and Rhodothermia could be assigned to a single phylum, Rhodothermaeota (Munoz et al., 2016). However, the 16S rRNA gene alone provides no support for their sistergroup relationship (albeit no significant conflict), and the two groups strongly differ in their genomic $\mathrm{G}+\mathrm{C}$ content (Figure 2), as previously noted (Urios et al., 2006); none of the remaining phyla show a comparable discrepancy in $\mathrm{G}+\mathrm{C}$ values. Exactly the same reasons argue against an inclusion of the two groups in the phylum Chlorobi (Figure 2). Moreover, there are considerable phenotypic and habitat differences between the Balneolia and Rhodothermia (Table 1). The Balneolia are mesophilic, whereas Rhodothermia are mostly either strongly thermophilic (Alfredsson et al., 1988) or extremely halophilic (Antón et al., 2002). Carotenoids were only reported from Rhodothermia (Makhdoumi-Kakhki et al., 2012) but not from the Balneolia. For these reasons, the Balneolia and Rhodothermia should not only be removed from Bacteroidetes but also classified in two separate phyla, Rhodothermaeota (Munoz et al., 2016) and Balneolaeota (this study), based on the priority of the respective genus names. A comparable situation has been solved recently for the Ignavibacteriaceae (Iino et al., 2010) and Melioribacteraceae (Podosokorskaya et al., 2013). These taxa have been separated from the Chlorobi as a new phylum Ignavibacteria (Podosokorskaya et al., 2013) based on their 


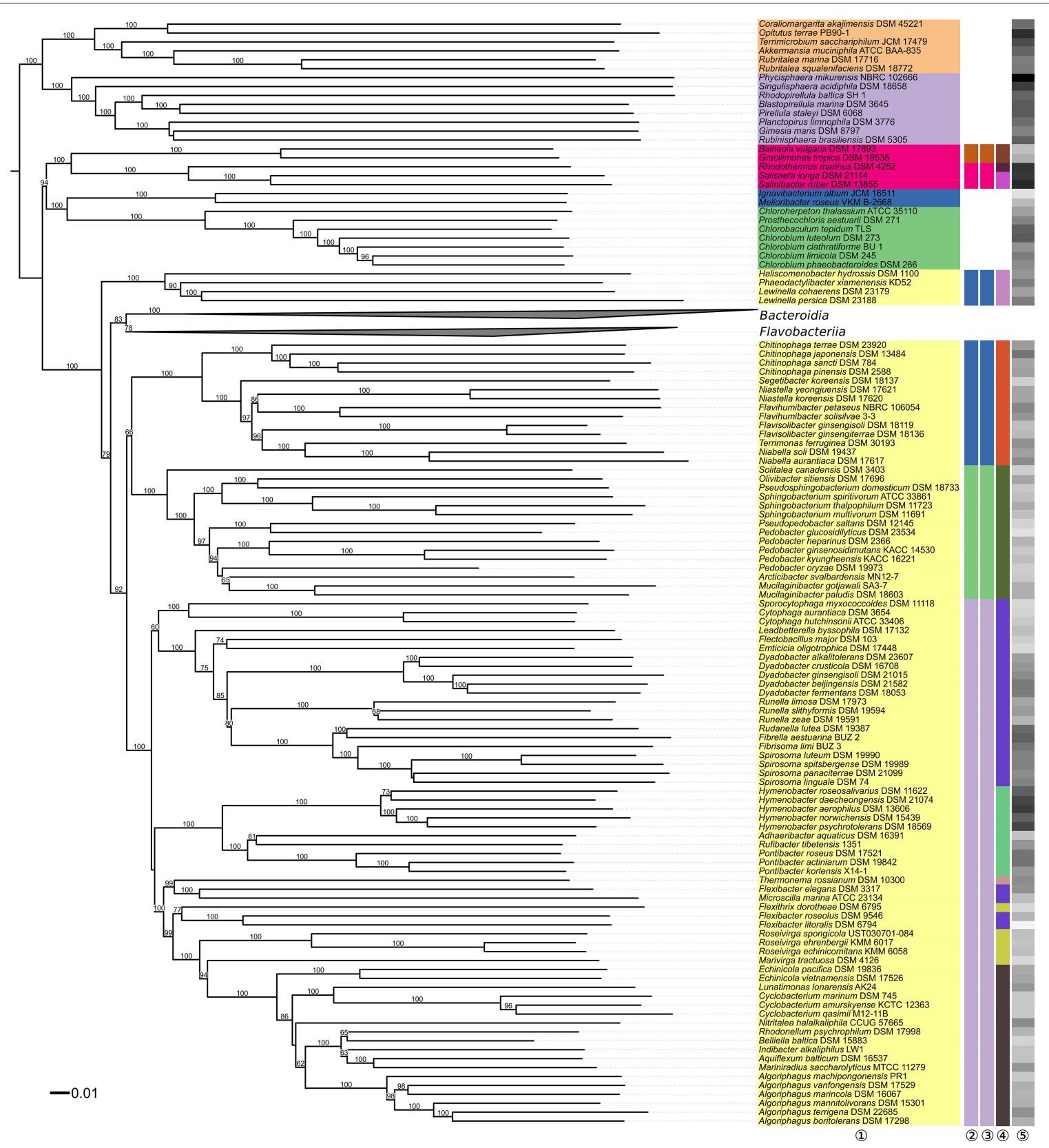

\begin{tabular}{|c|c|c|c|c|c|c|c|c|c|}
\hline \multicolumn{10}{|c|}{ Color legend: } \\
\hline (1) & Phylum: & (2) & Class: & (3) & Order: & (4) Family: & & & (5) $\mathrm{G}+\mathrm{C}$ content: \\
\hline & Verrucomicrobia & & Cytophagia & & Cytophagales & Flammeovirgaceae & Rhodothermaceae & Salinibacteraceae & Max.: $73.2 \%$ \\
\hline & Planctomycetes & & Rhodothermia & & Rhodothermales & Chitinophagaceae & Balneolaceae & Rikenellaceae & Avg:: $42.6 \%$ \\
\hline & Rhodothermaeota & & Sphingobacteriia & & Sphingobacteriales & Marinilabiliaceae & Cyclobacteriaceae & Cryomorphaceae & Min.: $29.5 \%$ \\
\hline & Chlorobi & & Flavobacteriia & & Flavobacteriales & Thermonemataceae & Prevotellaceae & Sphingobacteriaceae & 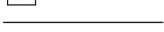 \\
\hline & Ignavibacteriae & & Bacteroidia & & Bacteroidales & Saprospiraceae & Prolixibacteraceae & Hymenobacteraceae & \\
\hline & Bacteroidetes & & Chitinophagia & & Chitinophagales & Odoribacteraceae & Porphyromonadaceae & Flavobacteriaceae & not discussed \\
\hline & & & Balneolia & & Balneolales & Cytophagaceae & Crocinitomicaceae & Bacteroidaceae & \\
\hline
\end{tabular}

FIGURE 2 | First part of the phylogenomic tree inferred with GBDP. Tree inferred with FastME from GBDP distances calculated from whole proteomes. The numbers above branches are GBDP pseudo-bootstrap support values from 100 replications. Tip colors indicate the phylum, colors to the right of the ingroup tips indicate, from left to right, class, order and family (see the embedded legend for details). Gray scale on the very right indicates the exact $\mathrm{G}+\mathrm{C}$ content as calculated from the genome sequences. The Bacteroidia and Flavobacteriia parts of the tree, which have been collapsed here, are shown in Figures $\mathbf{3}, \mathbf{4}$. 


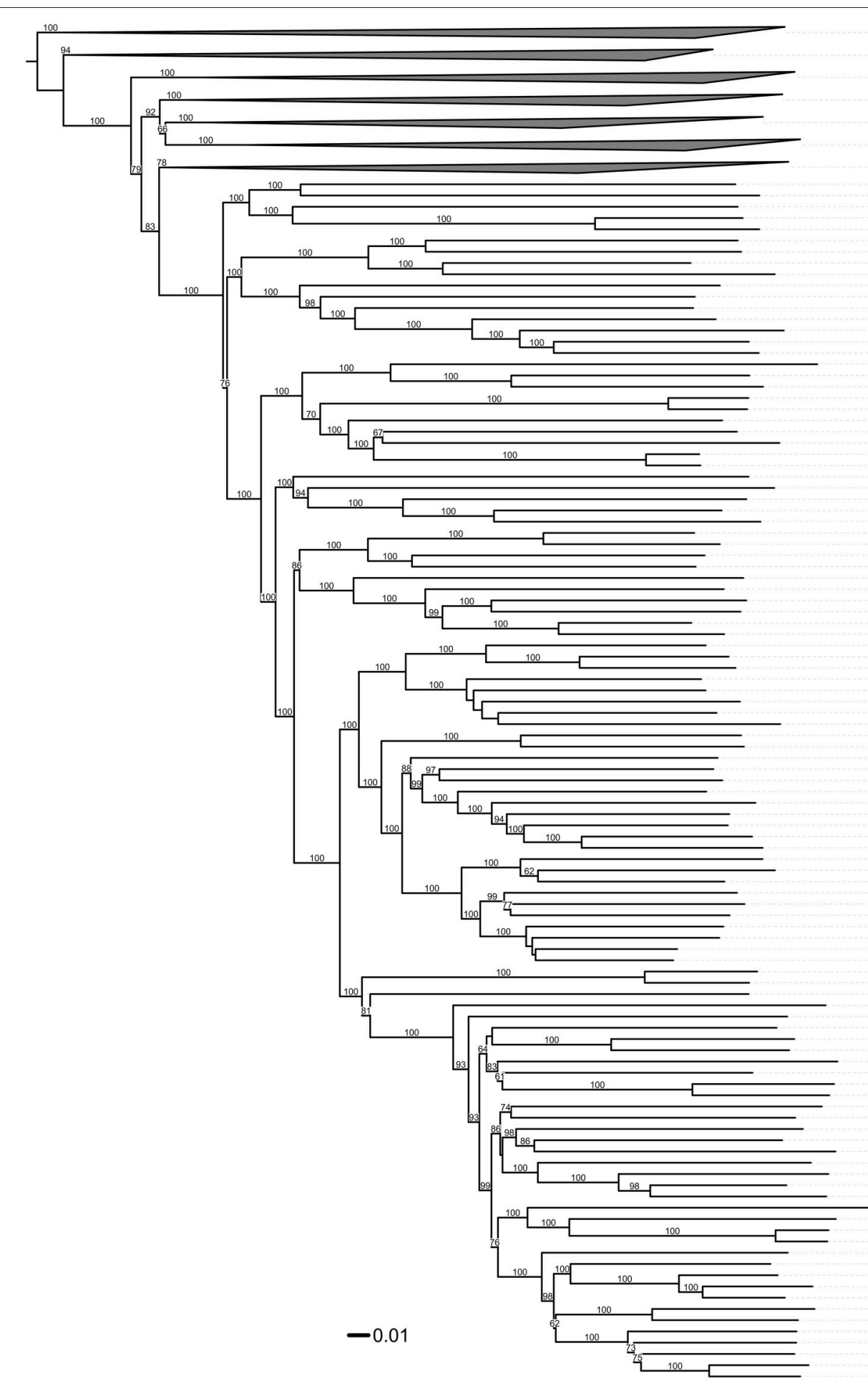

Outgroup (Verrucomicrobia and Planctomycetes) Chlorobi, Rhodothermaeota and Ignavibacteriae Chitinophagia p.p.

Cytophagia

Chitinophagia p.p.

Sphingobacteriia

Flavobacteriia

Alkaliflexus imshenetskii DSM 15055
Saccharicrinis formentans DSM 9555

ATCC BAA-1284

Draconibacterium orientale FH5
Draconibacterium sediminis JN14CK-3

Butyricimonas synergistica DSM 23225

Odoribacter laneus YIT 12061

Odoribacter splanchnicus DSM 20712

Alikenella microfusus DSM 15922

Alistipes inops 627

Alistipes putredinis DSM 17216

Alistipes Shahii WAL 8301

Alistipes finegoldii DSM 17242

Porphyromonas bennonis DSM 23058

Porphyyromononas somerae DSM 2338

Porphyromonas uenonis DSM 2338

Porphyromonas asaccharolytica DSM 20707

Porphyromonas endodontalis ATCC 35406

Porphyromonas catoniae ATCC 51270

Porphyromonas gulae DSM 15663

Porphyromonas gingivalis ATCC 33277

Proteiniphilum acetatigenes DSM 18083

Dysgonomonas capnocytophagoides DSM 22835

Dysgonomonas gadei ATCC BAA-280

Barnesiella viscericola DSM 18177

Barnesiella intestinihominis YIT 11860

Coprobacter fastidiosus DSM 26242

Tannerella forsythia ATCC 43037
Parabacteroides distasonis ATCC 8503

Parabacteroides distadonidi DSM 23371

Parabacteroides goldsteinii WAL 12034
Parabacteroides merdae ATCC 43184

Parabacteroides johnsonii DSM 18315

Bacteroides vulgatus ATCC 8482

Bacteroides dorei DSM 17855

Bacteroides bamesiae DSM 18169

Bacteroides plebeius DSM 17135

Bacteroides coprocola DSM 17136

Bacteroldes salanitronis DSM 18170

Bacteroides coprosuis DSM 18011

Bacteroides graminisolvens DSM 1998

Bacteroides salyersiae WAL 10018

Bacteroides pyogenes DSM 20611

Bacteroides thetaiotaomicron VPI 5482

Bacteroides caccae ATCC 43185
Bacteroides finegoldii DSM 17565

Bacteroides ovatus ATCC 8483

Bacteroides xylanisolvens XB1A

Bacteroides oleiciplenus YIIT 12058

Bacteroides intestinalis DSM 17393

Bacteroides uniformis ATCC 8492
Bacteroides helcogenes DSM 20613

Bacteroides helcogenes DSM 20613
Bacteroides fluxus YII 12057
Bacteroides gallinarum DSM 18171

Bacteroides gallinarum DSM 18171
Bacteroides eggerthii DSM 20697

Bacteroides eggerthii DSM 20697
Bacteroides stercoris ATCC 43183

Bacteroides clarus YIT 12056

Paraprevotella clara YIT 11840
Paraprevotella xylaniphila YTT 11841

Alloprevotella tannerae ATCC 5125

Prevotella stercorea DSM 18206

Prevotella oralis ATCC 33269

Prevotella buccalis ATCC 35310

Prevotella nanceiensis DSM 1912

Prevotella marshii DSM 16973

Prevotella shahii DSM 15611

Prevotella baroniae DSM 16972

Prevotella buccae ATCC 33574

Prevotella albensis DSM 11370

Prevotellia bryantii B14

Prevotella paludivivens DSM 17968

Prevotella oris DSM 18711

Prevotella salivae DSM 15606
Prevotella multisaccharivorax DSM 17128

Prevotella multisaccharivorax DSM

Hallella seregens ATCC 51272

Prevotella dentalis DSM 3688

Prevotella micans DSM 21469

Prevotella intermedia DSM 20706

Prevotella pallens ATCC 700821

Prevotella nigrescens ATCC 335

Prevotella bivia DSM 20514

Prevotella veroralis DSM 1955

Prevotella melaninogenica ATCC 25845

Prevotella melaninogenica ATCC
Prevotella denticola DSM 20614

Prevotella multiformis DSM 16608

(1)

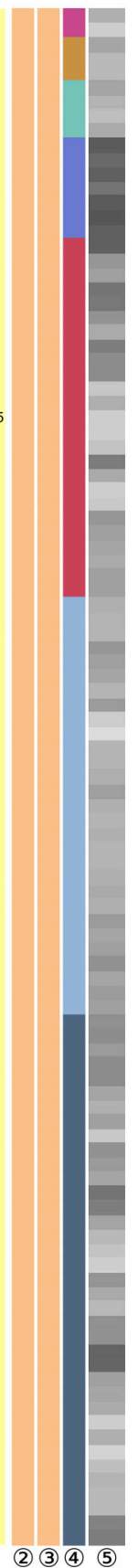

FIGURE 3 | Second part of the phylogenomic tree inferred with GBDP. Tree inferred with FastME from GBDP distances calculated from whole proteomes. The numbers above branches are GBDP pseudo-bootstrap support values from 100 replications. Tip colors indicate the phylum, colors to the right of the ingroup tips indicate, from left to right, class, order and family (see the legend embedded in Figure $\mathbf{2}$ for details). Gray scale on the very right indicates the exact $\mathrm{G}+\mathrm{C}$ content as calculated from the genome sequences. The non-Bacteroidia parts of the tree, which have been collapsed here, are shown in Figures $2,4$. 


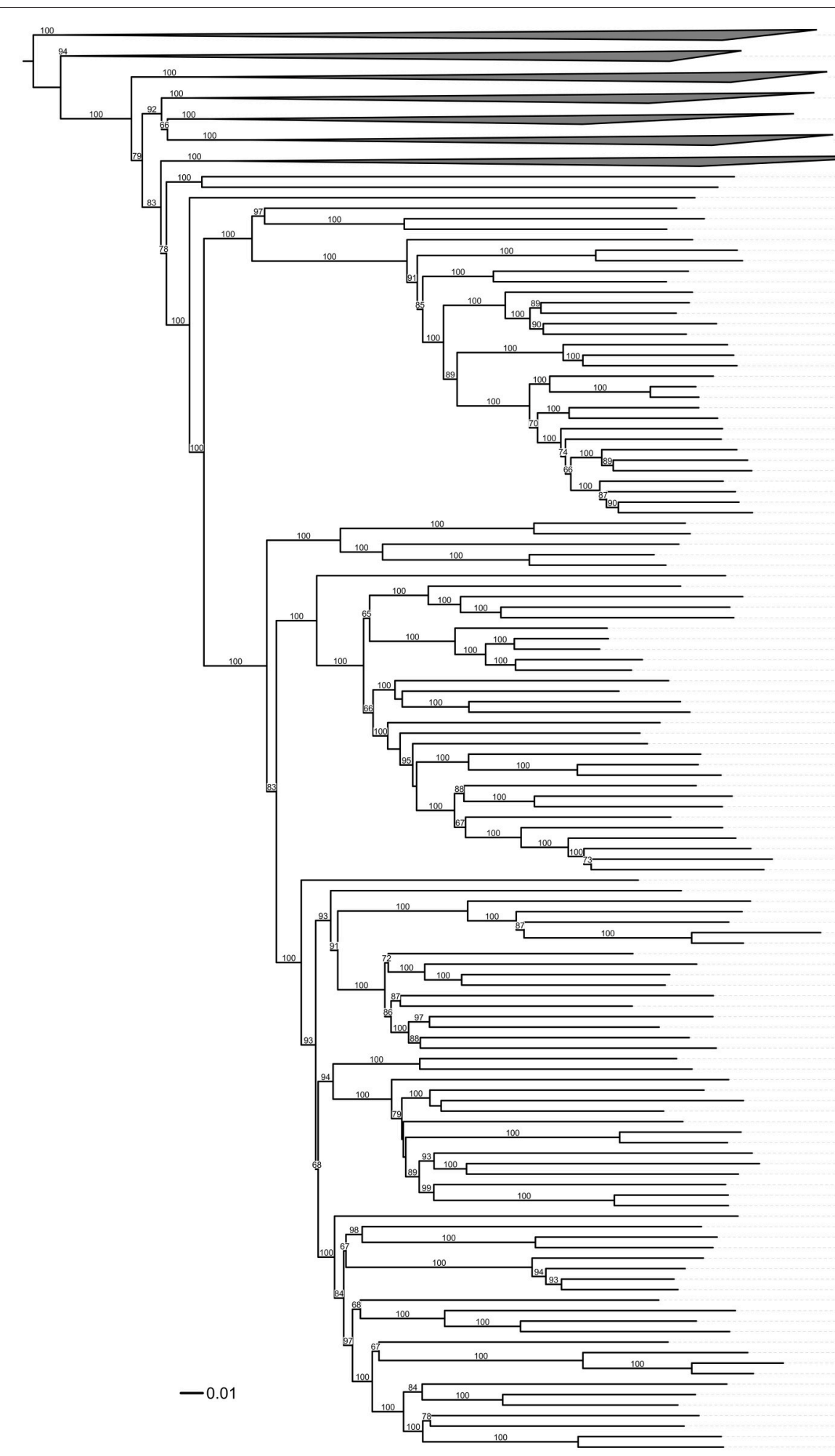

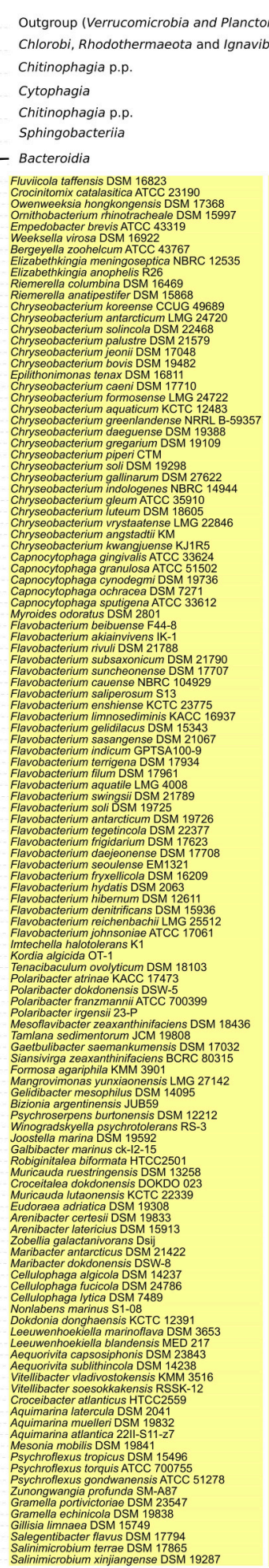

(1)

FIGURE 4 | Third part of the phylogenomic tree inferred with GBDP. Tree inferred with FastME from GBDP distances calculated from whole proteomes. The numbers above branches are GBDP pseudo-bootstrap support values from 100 replications. Tip colors indicate the phylum, colors to the right of the ingroup tips indicate, from left to right, class, order and family (see the legend embedded in Figure $\mathbf{2}$ for details). Gray scale on the very right indicates the exact $\mathrm{G}+\mathrm{C}$ content as calculated from the genome sequences. The non-Flavobacteriia parts of the tree, which have been collapsed here, are shown in Figures 2, $\mathbf{3}$. 

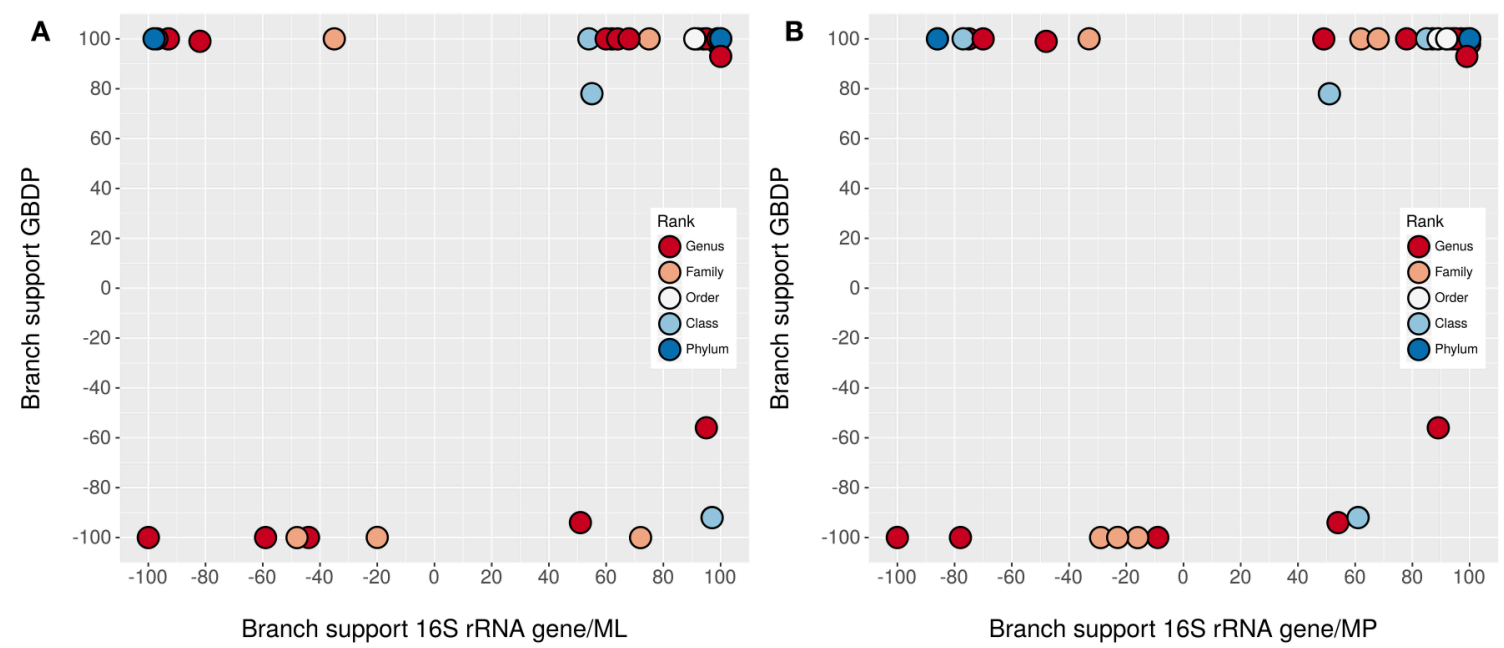

FIGURE 5 | Comparison of branch support. Shown are the negative or positive branch support values for each taxon inferred from whole genomes with GBDP in comparison to those inferred from 16S rRNA gene sequences with ML (A) and MP (B). The colors indicate the taxonomic rank. The upper right corner contains the taxa significantly supported by all methods, the lower left corner those significantly opposed by all methods. The other two corners, which would indicate a significant conflict between the methods, are empty. Jitter was used to avoid overplotting.

physiological distinction and their large phylogenetic distance to Chlorobi.

The Balneolaeota (Munoz et al., 2016) and Rhodothermaeota (as suggested here) differ from Bacteroidetes by a considerable number of phenotypic characters. The large amount of phospholipids [diphosphatidylglycerol (DPG), phosphatidylethanolamine (PE), phosphatidylglycerol (PG) and phosphatidylcholine (PC)] found in Rhodothermus (and its relatives) is unusual for aerobic Bacteroidetes (Nolan et al., 2009). Polar lipids of Bacteroides comprise largely PE and small amounts of PG and phosphatidylserine (Wardle et al., 1996), whereas polar lipids of the phylum Bacteroidetes usually comprise significant amounts of amide-linked lipids (aminolipids) rather than ester-linked polar lipids (Bernardet, 2010). The most significant difference between the Balneolaeota and Rhodothermaeota on the one hand and Bacteroidetes on the other hand can be attributed to the composition of fatty acids. Characteristic fatty acids of Bacteroidetes are 2-hydroxy and 3-hydroxy fatty acids, predominantly iso- $\mathrm{C}_{17: 0} 3-\mathrm{OH}$, iso- $\mathrm{C}_{15: 0}$ 3-OH and iso- $\mathrm{C}_{16: 0}$ 3-OH (Mayberry, 1980; Krieg et al., 2010), whereas strains of the Balneolaeota and Rhodothermaeota do not possess 2-hydroxy and 3-hydroxy fatty acids (Table 1). Flagella in conjunction with motility were observed in Balneola vulgaris (Urios et al., 2006) and Salinibacter ruber (Antón et al., 2002) but are unusual in Bacteroidetes; conversely, neither gliding motility nor flexirubin, a pigment common in Bacteroidetes (Krieg et al., 2010), were reported for the Balneolaeota and Rhodothermaeota. We suggest according emendations of taxon descriptions.

With the Balneolaeota and Rhodothermaeota removed from Bacteroidetes, the classes and orders of Bacteroidetes appeared as monophyletic in the GBDP phylogeny (Figure 2) with the sole exception of Chitinophagia and Chitinophagales, which were shown as paraphyletic due to the early branching of Haliscomenobacter, Phaeodactylibacter, and Lewinella (Saprospiraceae). Three branches with weak to moderate (79, 92, and 66\%) support, respectively, would need to be wrong to obtain monophyletic Chitinophagia and Chitinophagales. The UCT and CCT show a distinct picture with a monophyletic Chitinophagia and Chitinophagales with 94-99\% support under ML and $<60-79 \%$ support under MP. Thus, regarding the monophyly criterion, it might or might not be adequate to place Saprospiraceae in Chitinophagales according to our analyses. The monophyly of the family itself, including the type genus Saprospira, is supported by the 16S rRNA gene trees with 95-100\%. Thus, given its uncertain position relative to the remaining Chitinophagia and Chitinophagales, the taxonomic placement of Saprospiraceae should be reconsidered.

The family Saprospiraceae has been proposed first in Bergey's manual (Garrity and Holt, 2001) and was suggested to represent a sister lineage, without confirmatory evidence, to the family Sphingobacteriaceae. Saprospiraceae was later on placed in Chitinophagales but without relevant branch support (Munoz et al., 2016). In contrast to both Sphingobacteriaceae and Chitinophagaceae, Saprospiraceae are long rods (up to 5 $\mu \mathrm{m}$ ) that form long filaments (up to $500 \mu \mathrm{m}$ ) and do not possess sphingophospholipids. Moreover, the 16S rRNA gene trees indicate that the group comprising both Saprospiraceae and Chitinophagaceae (which is not even monophyletic in Figure 2) is quite divergent. Based on these results, we propose to classify the family Saprospiraceae into the new order Saprospirales, of the new class Saprospiria. Moreover, some noticeable phenotypical characteristics in agreement with the branching order (Figure 2, Supplementary File 4) call for a split of the family Saprospiraceae into three families (Saprospiraceae, Lewinellaceae, and Haliscomenobacteraceae). Lewinella, Saprospira and Aureispira exhibit gliding motility, but 


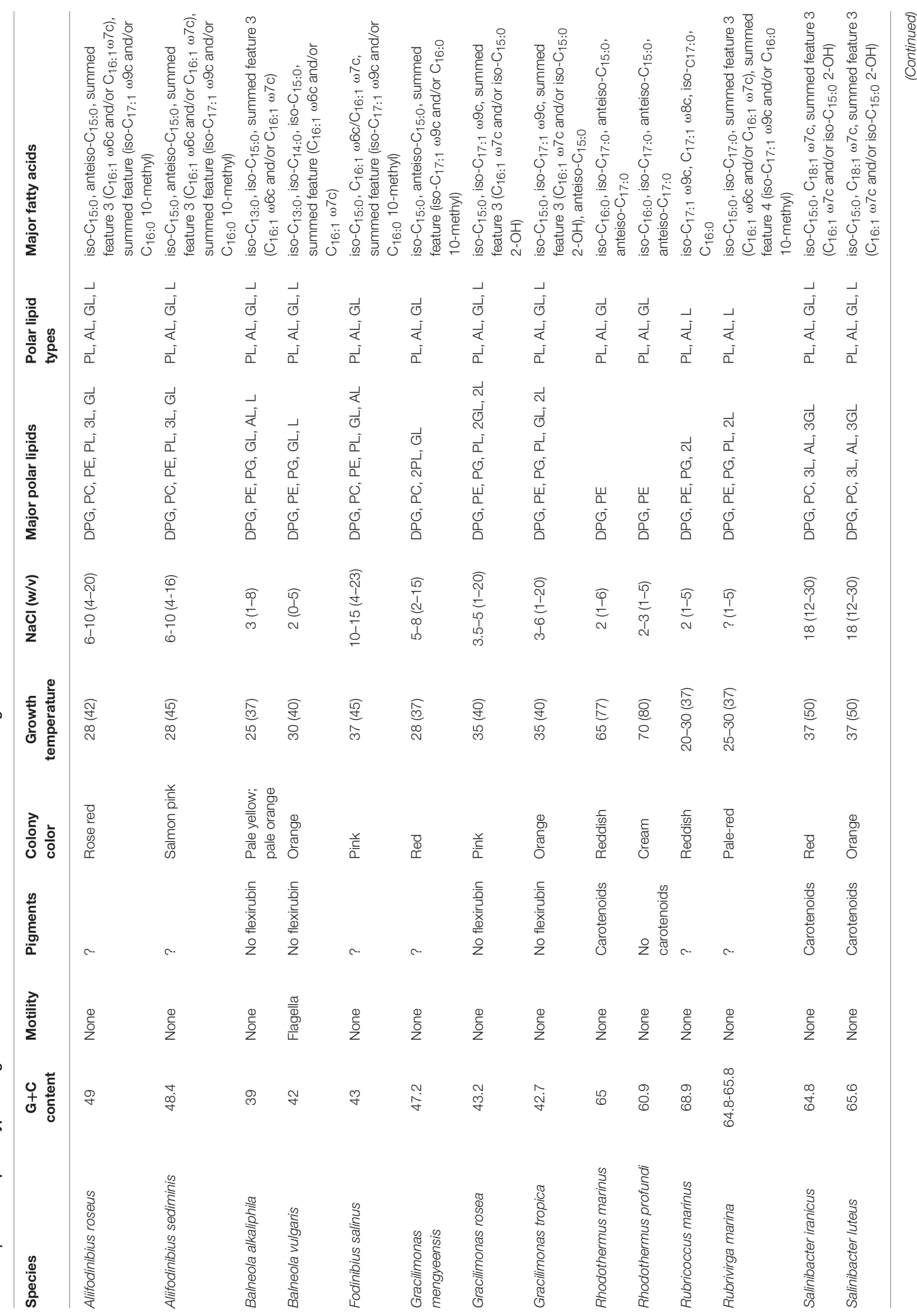


only Saprospira and Aureispira form helical filaments (Krieg et al., 2012). In contrast, Haliscomenobacter, Phaeodactylibacter, and Portibacter are non-motile straight filaments.

A noticeable feature of the current classification of Bacteroidetes is that each class contains only a single order and thus the classification into orders provides no additional information. As this is not an issue of non-monophyly, we suggest addressing it once an even more comprehensive genome-scale phylogeny might help making more sense from these Linnaean ranks.

\section{Families}

The recently revised (Munoz et al., 2016) Rhodothermales families appeared as monophyletic (Figure 2) but turned out to differ significantly by some key physiological characteristics. Rhodothermus (Rhodothermaceae) tolerates up to $6 \% \mathrm{NaCl}$ and $70^{\circ} \mathrm{C}$ (Table 1). In contrast, Salinibacter and Salisaeta (Salinibacteraceae) thrive in salt lakes and crystallizer ponds and grow at maximum temperatures of $50^{\circ} \mathrm{C}$ in medium with at least $5 \% \mathrm{NaCl}$ and up to saturation (Table 1). Additionally, the polar lipids of Rhodothermus comprise mainly DPG and PE whereas Salinibacter, Salinivenus, and Salisaeta additionally contain PC, glycolipids and halocapnines, while Rubricoccus and Rubrivirga (Rubricoccaceae) contain PG, but no glycolipids (Table 1). Rhodothermus mainly displays saturated fatty acids, whereas Salinibacter, Salinivenus, and Salisaeta contain unsaturated and $\mathrm{C}_{18}$ fatty acids (Table $\mathbf{1}$ ). We thus suggest according emendations.

The families within Sphingobacteriales appeared monophyletic throughout with maximum support in the GBDP tree (Figure 2). Within Cytophagales, the situation seems more complex. Cytophagaceae were not shown as monophyletic, since strong conflicting support was present regarding the positioning of Flexibacter and Microscilla, which are currently placed in that family (Nakagawa, 2011b) but here Flexibacter appeared problematic per se and thus is discussed below in more detail.

Flexithrix is placed apart from the remaining Flammeovirgaceae (Marivirga, Roseivirga) with 99\% support in the GBDP analysis. Flexithrix and Rapidithrix formed a clade with reasonable bootstrap support (always $>90 \%$ ) in the UCT and CCT. Marivirga and Roseivirga did not form a clade either, with a conflicting branch supported by $94 \%$ in the GBDP tree. Because of their overall lower resolution, the 16S rRNA gene trees do not indicate in which of these three distinct groups of Flammeovirgaceae its type genus, Flammeovirga, is placed. For this reason, further revisions of Flammeovirgaceae have to be postponed until more genome sequences are available. Based on phylogenetic results (Nakagawa et al., 2002) and a polyphasic approach (Nedashkovskaya et al., 2010), the genus Marivirga was proposed to comprise of $M$. sericea and $M$. tractuosa (Nedashkovskaya et al., 2010). However, the physiological differentiation in that study only included Flammeovirgaceae genera (Fabibacter, Fulvivirga, Marinoscillum, Reichenbachiella, Roseivirga), and Thermonema lapsum (Flammeovirgaceae) was used as an outgroup for the 16S rRNA gene sequence-based phylogeny. A similar set of strains was investigated in the 
description of the two other Marivirga species, M. lumbricoides (Xu et al., 2015) and M. atlantica (Lin C.-Y. et al., 2015). Thus, the strain samplings in those earlier studies did not allow for detecting a closer affiliation of Marivirga to another family, which might explain the conflicting result obtained here.

Within Bacteroidia, Porphyromonadaceae appeared paraphyletic with maximum support against their monophyly in the GBDP analysis (Figure 3), as all other genera were placed in clades distinct from the one harboring Porphyromonas. According to the GBDP phylogeny, three families should be separated from Porphyromonadaceae, each corresponding to a maximally support clade. A revision of the family is currently already conducted (Hugenholtz, pers. comm.), hence no taxonomic consequences will be undertaken in our study.

The recent removal of Butyricimonas and Odoribacter from Porphyromonadaceae to place them in the new family Odoribacteraceae (Munoz et al., 2016) also requires some attention. The features of the genera that used to be included in Porphyromonadaceae have been reviewed in 2009 (Sakamoto et al., 2009); the statements below also extend to the more recently added genera Falsiporphyromonas (Wagener et al., 2014), Macellibacteroides (Jabari et al., 2012), and Petrimonas (Grabowski et al., 2005). (An issue with Falsiporphyromonas and Macellibacteroides that is beyond the scope of the current study is that these genera are nested with strong support within Porphyromonas and Parabacteroides, respectively; see Supplementary File 4.) Butyricimonas and Odoribacter (Hardham et al., 2008) differ from each other, but not clearly from the other genera, by their major metabolic end products; however, this feature does not unambiguously differentiate between the other genera either. Butyricimonas and Odoribacter differ from all other genera except Porphyromonas by containing iso- $\mathrm{C}_{15: 0}$ as major fatty acid, with a low ratio of anteiso$\mathrm{C}_{15: 0}$ to iso- $\mathrm{C}_{15: 0}$. Butyricimonas and Odoribacter differ from Falsiporphyromonas and Porphyromonas by their fermentative metabolism (Sakamoto et al., 2009) and partially by their lack of pigments (Nagai et al., 2010). To reflect this distribution of phenotypic features, we propose to emend the family Odoribacteraceae accordingly.

\section{Genera}

Six genera were found to be non-monophyletic in the phylogenomic analysis. Pedobacter (Sphingobacteriaceae) appeared paraphyletic because Pseudopedobacter saltans was placed as sister group of Pedobacter glucosidilyticus with $100 \%$ support and Pedobacter oryzae as sister group of Arcticibacter svalbardensis and Mucilaginibacter paludis with $<50 \%$ support (Figure 2). The UCT and CCT also showed Pedobacter distributed over several clades but without significant support against its monophyly. Due to the size of the genera Mucilaginibacter and Pedobacter we suggest sampling more genomes from these groups prior to drawing taxonomic conclusions.

Flexibacter (Cytophagaceae) appeared paraphyletic with high confidence in the phylogenomic tree because the clade comprising $F$. litoralis and $F$. roseolus (separated by long branches) occurred in clades with 77 and $99 \%$ support together with other genera, to the exclusion of F. elegans, which formed the sister group of Microscilla marina with maximum support (Figure 2). A paraphyletic Flexibacter also occurred in the UCT and CCT, with strong support against its monophyly, as F. elegans was also highly supported as sister group of Microscilla marina. F. ruber formed the sister group of that clade without significant support, whereas Flexibacter flexilis Soriano 1945 , the type species of the genus (Nakagawa, 2011c), was indeed placed within the Cytophagaceae, with Arcicella, Flectobacillus, and Pseudarcicella as most closely related genera, without much support. Flexibacter litoralis, F. polymorphus, and F. roseolus formed a clade with reasonable bootstrap support ( $>90 \%$ in the CCT), which was placed in an uncertain position. Apart from tree topology, the branch lengths in the whole-genome and 16S rRNA gene tree indicated that the Flexibacter species are too divergent to be placed in a single genus. Additionally, Microscilla marina and F. elegans appear to be too divergent to be placed in a single genus (Figure 2).

Since its description, eleven of 17 originally supposed Flexibacter species were reclassified into a variety of genera (Chitinophaga, Flavobacterium, Marivirga, Solitalea, and Tenacibaculum), but it was emphasized that Flexibacter is still heterogeneous and should be subdivided based on additional molecular taxonomic data (Nakagawa, 2011c). Furthermore, this author mentioned that the type species, Flecibacter flexilis, is isolated from all other species of the genus and that Flexibacter should be restricted to it. The current sole distinction between the definitions of Microscilla and Flexibacter is their habitat (marine vs. terrestrial) (Reichenbach, 1989a), whereas F. elegans showed the same morphology and physiology as M. marina in previous studies (Lewin, 1969); F. roseolus differed from $M$. marina regarding its pigmentation and $F$. ruber by its ability to digest starch. F. flexilis differs from M. marina and F. elegans regarding cell length and $\mathrm{H}_{2} \mathrm{~S}$ production, whereas the other species differ from $F$. flexilis regarding pigmentation, cell length and in the case of $F$. roseolus also $\mathrm{H}_{2} \mathrm{~S}$ production. Thus, the Flexibacter species are approximately equidistant from each other regarding morphology and physiology. This also holds for Flexibacter litoralis and F. polymorphus; whereas they form sister groups with high support, their level of divergence is higher than between many other pairs of genera, as obvious from the branch lengths in the trees (Figures 2, 3; Supplementary File 4), and their morphology and physiology also differs (Lewin, 1969, 1974). Thus, based on phylogenetic position (Supplementary File 4) and phenotype, we propose to classify $F$. elegans, $F$. litoralis, F. polymorphus, F. roseolus, and F. ruber into the new genera Eisenibacter, Bernardetia, Garritya, Hugenholtzia, and Thermoflexibacter, respectively. Further, we propose the new family Microscillaceae to accomodate Bernardetia and Eisenibacter as well as the new family Bernardetiaceae to accommodate Bernardetia, Hugenholtzia and tentatively also Garritya.

Within Prevotellaceae, Prevotella (Shah and Collins, 1990; Willems and Collins, 1995a; Sakamoto and Ohkuma, 2012) appeared paraphyletic because Hallella seregens (Moore and Moore, 1994) was included within, placed as sister group of $P$. dentalis with strong support (Figure 3). This problem was 
also obvious in 16S rRNA gene data and was indeed noted two decades ago (Willems and Collins, 1995a). These authors refrained from taxonomic consequences, however, because they observed a $16 \mathrm{~S}$ rRNA gene similarity of $99.8 \%$ between the type strains of $H$. seregens and $P$. dentalis; hence it could not be excluded that the two species are heterotypic synonyms (MeierKolthoff et al., 2013b). Furthermore, the $\mathrm{G}+\mathrm{C}$ values calculated from the genomes of $H$. seregens and $P$. dentalis are almost identical, with 56.0 and $55.9 \%$, respectively, even though this is not currently reflected in the species descriptions. Digital DNA:DNA hybridization between the genome sequences of H. seregens ATCC $51272^{\mathrm{T}}$ and P. dentalis DSM $3688^{\mathrm{T}}$ conducted with the recommended settings of the GGDC yielded $87.40 \pm$ $2.36 \% \mathrm{DDH}$ similarity and thus indicated identical species, even identical subspecies (Meier-Kolthoff et al., 2014b). We conclude that $H$. seregens is a later heterotypic synonym of $P$. dentalis.

Within Flavobacteriaceae, Chryseobacterium appeared paraphyletic because Epilithonimonas tenax was clearly nested within a well-supported branch of 21 Chryseobacterium species (Figure 4). Whereas support was maximal in the phylogenomic analysis, the UCT and CCT showed Epilithonimonas nested within a paraphyletic Chryseobacterium, too, but without any branch support. In the original description of Epilithonimonas (O'Sullivan et al., 2006) only 75\% bootstrap support was obtained for the separation of Epilithonimonas from Chryseobacterium, based on a simplistic evolutionary model (Felsenstein, 2004). The most recent description of an Epilithonimonas species (Ge et al., 2015), still based on that model, showed moderate support for Epilithonimonas monophyly but none for Chryseobacterium monophyly; hence 16S rRNA gene analyses did not rule out that Epilithonimonas is nested within Chryseobacterium, as revealed by phylogenomic analysis. As evident from Figure 4, retaining Epilithonimonas by including certain Chryseobacterium species would require the establishment of a third genus for at least the upper branch including six Chryseobacterium species (C. koreense, C. antarcticum, C. solincola, C. palustre, C. jeonii, C. bovis) to obtain monophyletic groups. The solution to merge the two genera is thus more conservative. Moreover, the overall divergence of the clade comprising the two genera is lower than the divergence of other clades comprising only a single genus (Figures 2-4). Chryseobacterium has priority over Epilithonimonas (Vandamme et al., 1994). Chryseobacterium was recently emended because some summed features of MIDIsystem fatty-acids profiles appeared to have frequently been misinterpreted in the literature, and a specific pattern of polar lipids remained mostly unnoticed (Montero-Calasanz et al., 2014). In detail, iso- $\mathrm{C}_{15: 0} 2-\mathrm{OH}$ is present in Chryseobacterium as part of summed feature 3 or 4 instead of $\mathrm{C}_{16: 1} \omega 7 \mathrm{t}, \mathrm{C}_{16: 1} \omega 6 \mathrm{c}$ and $C_{16: 1} \omega 7 c$; iso- $C_{17: 1} \omega 7 c$ is present instead of iso- $C_{17: 1} \omega 9 c$; and the major polar lipids contain three common unknown lipids and two common unknown aminolipids.

Thus, the question arises whether the reported differences regarding the lipid profiles between Epilithonimonas and the description of Chryseobacterium can be traced back to misidentified fatty acids or were real differences. Table 2 shows the potentially conflicting phenotypic features. The only real difference in fatty-acid profiles appeared to be the presence of iso$\mathrm{C}_{16: 0}$ 3-OH, which was not explicitly mentioned for the genus Chryseobacterium (Montero-Calasanz et al., 2014). However, it was reported for a variety of Chryseobacterium species (Hugo et al., 2003; Kämpfer et al., 2003, 2011; Li et al., 2003; Kim et al., 2005; Shen et al., 2005; Young et al., 2005; Park et al., 2006; Behrendt et al., 2007, 2008; Hantsis-Zacharov and Halpern, 2007; Quan et al., 2007; Vaneechoutte et al., 2007; Szoboszlay et al., 2008; Ilardi et al., 2009; Benmalek et al., 2010; Pires et al., 2010; Wu et al., 2013) in concentrations up to $9 \%$ and thus does not constitute a real difference either. Additionally, anteiso- $\mathrm{C}_{15: 0}$ as reported for Epilithonimonas is not mentioned in the description of Chryseobacterium but known to occur in the genus from traces to up to $8.2 \%$ (Montero-Calasanz et al., 2014). The polar-lipid patterns of Epilithonimonas also fit very well to that revision of Chryseobacterium (Table 2); the sole exception is E. psychrophila, for which only phosphatidylethanolamine and a single unknown lipid were reported; given its well-supported position within a core group of four Epilithonimonas species and the general faintness of the published thin-layer chromatogram ( $\mathrm{Ge}$ et al., 2015), this can hardly be regarded as an argument against the unification of the genera. Moreover, the two genera have overlapping habitats and other interesting features in common, such as the production of indole-3-acetic acid for promoting plant growth (Montero-Calasanz et al., 2014; Hoang et al., 2015). Thus, the three physiological features that conflict between the original description of Chryseobacterium (Vandamme et al., 1994) and some or all of the Epilithonimonas species rather call for an emendation of Chryseobacterium.

Muricauda (Flavobacteriaceae) appeared paraphyletic in the phylogenomic tree because Croceitalea dokdonensis was placed as sister group of $M$. lutaonensis. Support was weak $(<60 \%)$, however, and in the UCT and CCT Croceitalea and Muricauda appear as separate groups with moderate support. Thus, even though in the description of the moderate thermophile M. lutaonens the genus Croceitalea was not considered (Arun et al., 2009), our analyses do not indicate a need to revise the classification of the two genera.

Aequorivita (Flavobacteriaceae) also appeared paraphyletic in the phylogenomic tree because two Vitellibacter species were placed as sister group of Aequorivita sublithincola with $94 \%$ support. In the UCT and CCT the clade comprising both genera is maximally supported, but within the clade the two genera are intermixed without much support. The genomic divergence of the clade comprising both genera appears as lower than the divergences of many clades that contain only a single genus (Figure 3). When the genus Vitellibacter was introduced (Nedashkovskaya et al., 2003), type strains from the previously suggested genus Aequorivita (Bowman and Nichols, 2002) were not considered. The phenotypic features reported in the literature (Bowman and Nichols, 2002; Nedashkovskaya et al., 2003; Bowman, 2006; Park et al., 2009, 2014; Kim et al., 2010; Liu et al., 2013; Lin S. Y. et al., 2015; Rajasabapathy et al., 2015) for the species of two genera considerably overlap. The only stable difference is whether the cells are oxidase-positive or negative, but this alone can hardly justify two separate genera. For this 
TABLE 2 | Comparison of relevant phenotypic features between Epilithonimonas species and the description of Chryseobacterium.

\begin{tabular}{|c|c|c|c|c|c|c|}
\hline Feature & Maybe provided as & Chryseobacterium & E. tenax & E. lactis & E. ginsengisoli & E. xixisoli \\
\hline iso- $\mathrm{C}_{15: 0}$ & & Major & (20) & 23.7 & 17.9 & 29.6 \\
\hline iso- $\mathrm{C}_{15: 0} 2-\mathrm{OH}$ & summed feature 3 & Major & $\left(21.1^{\star}\right)$ & $26.7^{*}$ & $33.1^{* *}$ & $23^{\star}$ \\
\hline iso- $\mathrm{C}_{17: 0} 3-\mathrm{OH}$ & & Major & $(9.8)$ & 10 & 10 & $(4.6)$ \\
\hline iso- $\mathrm{C}_{17: 1} \omega 7 \mathrm{c}$ & iso- $\mathrm{C}_{17: 1} \omega 9 \mathrm{c}$ & Major & $\left(1.0^{* \star}\right)$ & $\left(1.1^{\star \star}\right)$ & $(0.0)$ & $\left(<1.0^{\star \star}\right)$ \\
\hline anteiso- $\mathrm{C}_{15: 0}$ & & Traces/major & $(14.5)$ & $(8.2)$ & (9.3) & 12.9 \\
\hline iso- $\mathrm{C}_{16: 0} 3-\mathrm{OH}$ & & Missing/traces & $(1.9)$ & $(1.5)$ & $(1.4)$ & $(2.7)$ \\
\hline Phosphatidylethanolamine & & Major & $?$ & $?$ & Present & Major \\
\hline Unknown lipids & & Three major & $?$ & $?$ & One to five & Four major, five in total \\
\hline Unknown aminolipids & & Two major & $?$ & $?$ & three to six & Three major \\
\hline Growth at $30^{\circ} \mathrm{C}$ & & Yes & Yes & Yes & Yes & Yes \\
\hline Oxidation of glycerol & & Yes & No & No & $?$ & No \\
\hline Oxidation of trehalose & & Yes & Yes & Yes & $?$ & No \\
\hline
\end{tabular}

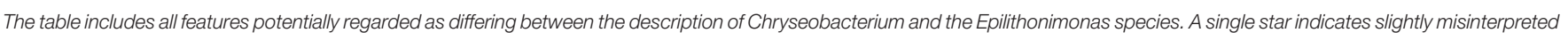
summed features according to the corrected description of Chryseobacterium (Montero-Calasanz et al., 2014); two stars indicate more strongly misinterpreted summed features. Values in parentheses are those not included in the respective species descriptions (O'Sullivan et al., 2006; Shakéd et al., 2010; Feng et al., 2014; Ge et al., 2015; Hoang et al., 2015). Physiological data for Chryseobacterium are from its original description (Vandamme et al., 1994). Question marks indicate missing information.

reason, we propose to place Vitellibacter in Aequorivita and to emend the description of Aequorivita accordingly.

\section{DISCUSSION}

Our phylogenetic analysis revealed much agreement between genome-scale data and the current classification of Bacteroidetes, particularly due to the most recent revision (Munoz et al., 2016), but also a number of instances which still call for reclassifications or emendations of taxon descriptions. Prokaryotic taxonomy is not "written by taxonomists for taxonomists" (Cowan, 1971) but directly influences all microbiological disciplines. In microbial ecology, the name of a given taxon gets linked to observed characteristics of its described representatives and, further, to its inferred function in the environment. For example, in the Bacteroidetes-Chlorobi "superphylum," Chlorobi (Garrity and Holt, 2001), now Chlorobaeota (Oren et al., 2015), are known as the obligate anaerobic green sulfur bacteria, whereas Bacteroidetes, now Bacteroidaeota (Oren et al., 2015), are known as polymer-decomposing microorganisms in the environment and the intestinal tract (Thomas et al., 2011). Currently Halomonadaceae, some Bacteroidetes (Rhodothermaceae, Salinibacter) and Chlostridia are considered as halotolerant or halophilic Bacteria (Oren, 2002, 2008; Bakermans, 2015). The reclassifications of the Rhodothermia and the Balneolia into separated phyla suggest that some Bacteroidetes remain thermotolerant (e.g., Schleiferia and Thermonema, growth at $30-60^{\circ} \mathrm{C}$ ) or halotolerant [e.g., Anaerophaga, Fabibacter, and Dyadobacter, growth at 1$12 \% \mathrm{NaCl}(\mathrm{w} / \mathrm{v})$ ] (Krieg et al., 2010), but not thermophilic (Rhodothermus, growth at $50-70^{\circ} \mathrm{C}$ ) or halophilic [Salinibacter, growth at $15-30 \% \mathrm{NaCl}(\mathrm{w} / \mathrm{v})]$.

In other areas such as medicine and industry, the risk classification of a prokaryotic species to cause infectious diseases is based on its taxonomic classification (ABAS, 2015; ABSA, 2016). Given the peculiar ecological preferences of particularly Rhodothermaeota and Balneolaeota, but also of other groups reclassified here, it is likely that ecological studies using metagenomic binning or similar techniques will benefit from the further improved classification. Studies that do not distinguish between Rhodothermaeota, Balneolaeota, and Bacteroidetes may insufficiently describe microbial compositions of environmental habitats and perhaps make misleading assumptions on environmental conditions (Tsiamis et al., 2008; Baati et al., 2010; Çinar and Mutlu, 2016). A more profound effect of the proposed reclassifications might be on a potentially misleading proposal of an origin for horizontal-gene-transfer (Nelson-Sathi et al., 2015). In contrast, the CARD-FISH probes CF968 (Acinas et al., 2015) and CFB319 (Manz et al., 1996) will not hybridize with 16S rRNA gene sequences of Rhodothermaeota and the Balneolaeota (both probes have two mismatches), and thus environmental studies using this probe are not influenced by the mentioned reclassifications.

Our analysis has shown that a large proportion of $\mathrm{G}+\mathrm{C}$ content values in Bacteroidetes species descriptions needs to be corrected. The according emendations proposed below are numerous but by no means excessive. Indeed, we do not propose to correct all $\mathrm{G}+\mathrm{C}$ content values whose precision or accuracy could be improved but only those that are too imprecise or inaccurate given that the within-species deviation in $\mathrm{G}+\mathrm{C}$ content is at most $1 \%$ (Meier-Kolthoff et al., 2014c). G+C content values provided in species descriptions that deviate more than $1 \%$ from the value calculated from the genome sequence, or display a range of more than $1 \%$, obscure species affiliations and should be corrected (Riedel et al., 2014). Emendations of higher taxa regarding their $\mathrm{G}+\mathrm{C}$ content have also been conducted (Scheuner et al., 2014) but we abstain from accordingly redefining Bacteroidetes genera here because we opine that more type-strain genome sequences per genus would be needed. Moreover, the emendation of Flavobacterium suncheonense has recently been conducted (Panschin et al., 2016) and needs not be considered here. For the emendations conducted below we round all $\mathrm{G}+\mathrm{C}$ 
content values to a single decimal place to accommodate for incompletely sequenced genomes (see Supplementary File 3 for details).

Whereas conflict with the monophyly of several taxa was obvious in our genome-scale analysis, cases where a taxon was strongly supported in the proteome tree and strongly in conflict with the 16S rRNA gene, or vice versa, were not observed (Figure 5). This is crucial since the promise of phylogenomics is to yield more strongly resolved trees (which fully succeeded in this study), but this might in theory also increase the topological conflict between analyses based on distinct large sets of characters or distinct phylogenetic methods (Jeffroy et al., 2006; Klenk and Göker, 2010). For instance, horizontal gene transfer is known as a cause of topological conflict between analyses of single genes and has even been be used to argue against hierarchical classification (Bapteste and Boucher, 2009; Klenk and Göker, 2010). However, adding more genes, up to virtually all genes available in a genome, increases support in phylogenomic analyses (Breider et al., 2014), indicating that there is a strong hierarchical signal. In contrast, selection of few genes (or any number of characters not on the same order of magnitude as the overall number of genomic characters) can hardly be called genome-scale and also depends on assumptions about the relative suitability of genes for the analysis (Lienau and DeSalle, 2009; Klenk and Göker, 2010). Whole-genome methods such as GBDP avoid this issue and have the potential to yield a truly genomebased classification, but then the question arises how to avoid overestimating phylogenetic confidence (Taylor and Piel, 2004). Bootstrapping entire genes instead of single alignment positions was suggested to reduce conflict and provide more realistic support values in phylogenomic analysis (Siddall, 2010). GBDP pseudo-bootstrapping in conjunction with the greedy-withtrimming algorithm (Meier-Kolthoff et al., 2014a) is indeed conceptually closer to this partition bootstrap than to standard bootstrapping. Compared to analyses of concatenated alignments of orthologs, GBDP yielded the same topology but slightly lower support values (Riley et al., 2016). This might explain why we did not identify significant conflict with the 16S rRNA gene in this study.

We neither identified any significant conflict between phenotypic information and reclassifications suggested by genome-scale trees; rather, these called for a distinct interpretation of the available information, or highlighted known problems that just had not yet been taxonomically fixed. Many of the taxonomic problems had also been visible in the $16 \mathrm{~S}$ rRNA gene sequence analysis in the past, provided a sufficient taxon sampling had been used. For instance, sampling Chlorobi was also necessary in previous (Munoz et al., 2016) and the current phylogenetic analyses to fully recognize the problematic placement of the Balneola clade and Rhodothermaceae. In other cases, missing genomes did not hinder recognizing taxonomic problems. For instance, whereas the genome sequence of the type strain of the type species of Flexibacter was not available to us, the need to split the genus into several genera is already visible in the unconstrained 16S rRNA gene analysis. Moreover, applying a backbone constraint is a valuable means for augmenting comprehensible sampled single-gene data with information from analyses of more genes but fewer organisms (Liu et al., 2015).

The high resolution provided by whole-genome phylogenies and the apparent lack of conflicts with data from other sources renders genome-based approaches quite promising for shaping the future of Bacteroidetes taxonomy. This holds even though the present study led to a number of changes in taxonomic opinion, listed below in the order of decreasing Linnaean ranks and with proposed names first, followed by the emendations. We additionally propose to rephrase the "Bacteroidetes-Chlorobi superphylum" to "Bacteroidaeota-Rhodothermaeota-Balneolaeota-Chlorobaeota (BRBC) superphylum," considering the recent proposal to include the phylum rank in taxonomy (Oren et al., 2015), and considering the new phyla Rhodothermaeota and Balneolaeota as part of the former "Bacteroidetes-Chlorobi superphylum" (Figure 2).

\section{Taxonomic Consequences}

\section{Description of Balneolaeota, phyl. nov.}

Bal.ne.o.lae.o'ta (N.L. fem. n. Balneola, type genus of the type order of the phylum, -aeota ending to denote phylum; N.L. neut. pl. n. Balneolaeeota, the phylum of the class Balneolia).

The description is the same as for the class Balneolia.

This phylum is described on the basis of $16 \mathrm{~S}$ rRNA gene and whole-genome phylogenetic analysis. The type (and currently sole) order of the phylum is Balneolales. The phylum currently contains a sole class, Balneolia.

\section{Emended Description of Rhodothermaeota, Munoz et al. 2016}

The description is the same as given by Munoz et al. (2016) with the following modification. Cells are aerobic. The phylum has been additionally circumscribed on the basis of whole-genome phylogenetic analysis.

This change was necessary due to the removal of Balneolia from the phylum Rhodothermaeota.

\section{Emended Description of Balneolia Munoz et al. 2016}

The description is the same as given by Munoz et al. (2016) with the following modification. The class Balneolia is part of the phylum Balneolaeota and has been additionally circumscribed on the basis of whole-genome phylogenetic analysis.

This change was necessary due to the removal of Balneolia from the phylum Rhodothermaeota. The description is the same as for the order Balneolales.

\section{Emended Description of Cytophagia Nakagawa 2012}

The description is the same as given by Nakagawa (2011a) with the following modification. Flagella are not found.

This change was necessary due to the removal of Balneola from Cytophagia.

\section{Description of Saprospiria, class. nov.}

Sa.pros.pi'ri.a (N.L. fem. n. Saprospira, type genus of the type order of the class, -ia ending to denote a class; N.L. fem. pl. n. Saprospiria, the class of the order Saprospirales).

The description is the same as for the order Saprospirales. 
This class is described on the basis of 16S rRNA gene and whole-genome phylogenetic analysis. The type and currently sole order of the class is Saprospirales.

\section{Description of Saprospirales, ord. nov.}

Sa.pro.spi.ra'les (N.L. fem. n. Saprospira, type genus of the order, suff. -ales ending to denote order; N.L. fem. pl. n. Saprospirales, the order of the genus Saprospira).

The description is the same as for the family Saprospiraceae.

This order is described on the basis of $16 \mathrm{~S}$ rRNA gene and whole-genome phylogenetic analysis. The type genus is Saprospira. The currently sole family of the order is Saprospiraceae.

\section{Emended description of Chitinophagales Munoz et al. 2016}

The description is as given by Munoz et al. (2016), with the following changes. Currently encompasses only the family Chitinophagaceae. This change was necessary due to the removal of Saprospiraceae from the order Chitinophagales.

\section{Description of Lewinellaceae, fam. nov.}

Le.wi.nel.la'ce.ae (L. fem. n. Lewinella type genus of the family; aceae ending to denote a family; N.L. fem. pl. n. Lewinellaceae the Lewinella family).

Cells are ensheathed, Gram-stain negative flexible rods (up to $3 \mu \mathrm{m}$ ) that form long filaments (up to $150 \mu \mathrm{m}$ ) and are motile by gliding. Typical fatty acids are iso- $\mathrm{C}_{15: 0}$, iso- $\mathrm{C}_{15: 1}$, iso$\mathrm{C}_{17: 0} 3-\mathrm{OH}$ and summed feature 3 (either $\mathrm{C}_{16: 1} \omega 7 \mathrm{c} / \mathrm{C}_{16: 1} \omega 6 \mathrm{c}$ or $\mathrm{C}_{16: 1} \omega 7 \mathrm{c} /$ iso- $\left.\mathrm{C}_{15: 0} 2-\mathrm{OH}\right)$. Seawater is required for growth. Flexirubin-type pigments are not produced. Carotenoid-type pigments are produced. The respiratory quinone is MK-7. The genomic $\mathrm{G}+\mathrm{C}$ content is around $45-53 \%$.

This family belongs to the phylum Bacteroidetes, order Saprospirales ord. nov., class Saprospiria class. nov., and currently comprises only the type genus, Lewinella.

\section{Description of Haliscomenobacteraceae, fam. nov.}

Ha.lis.co.me.no.bac.te.ra'ce.ae (L. fem. n. Haliscomenobacter type genus of the family; -aceae ending to denote a family; N.L. fem. pl. n. Haliscomenobacteraceae the Haliscomenobacter family).

Cells are Gram-stain negative, non-motile long rods (up to $5 \mu \mathrm{m}$ ) that form long needle-like filaments (up to $300 \mu \mathrm{m}$ ). Some are enclosed by a narrow, hardly visible hyaline sheath (Haliscomenobacter). Typical fatty acids are iso- $\mathrm{C}_{15: 0}$, summed feature 3 (either $\mathrm{C}_{16: 1} \quad \omega 7 \mathrm{c} / \mathrm{C}_{16: 1} \omega 6 \mathrm{c}$ or $\mathrm{C}_{16: 1} \omega 7 \mathrm{c} /$ iso$\mathrm{C}_{15: 0}$ 2-OH) and either iso- $\mathrm{C}_{17: 0} 3-\mathrm{OH}$ or iso- $\mathrm{C}_{15: 0} 3-\mathrm{OH}$. Flexirubin-type pigments are not produced. Carotenoid-type pigments are produced. The respiratory quinone is MK-7. Cells are oxidase-positive. The genomic $\mathrm{G}+\mathrm{C}$ content is around 47-54\%.

This family belongs to the phylum Bacteroidetes, order Saprospirales ord. nov., class Saprospiria class. nov., and currently comprises the genera Haliscomenobacter (the type genus), Phaeodactylibacter and Portibacter.

\section{Description of Microscillaceae, fam. nov.}

Mi.cros.cil.la'ce.ae (L. fem. n. Microscilla type genus of the family; -aceae ending to denote a family; N.L. fem. pl. n. Microscillaceae the Microscilla family).

Cells are Gram-stain negative, chemoorganotrophs and strict aerobes. Cells are flexible threads motile by gliding. Gelatin is degraded, but not agar, alginate, or carboxymethyl cellulose. The major respiratory quinone is $\mathrm{MK}-7$. The genomic $\mathrm{G}+\mathrm{C}$ content is around $40-50 \%$.

This family belongs to the phylum Bacteroidetes, order Cytophagales, class Cytophagia, and comprises currently the genera Microscilla (the type genus) and Eisenibacter gen. nov.

\section{Description of Bernardetiaceae, fam. nov.}

Ber.nar.de.ti.a'ce.ae (L. fem. n. Bernardetia type genus of the family; -aceae ending to denote a family; N.L. fem. pl. n. Bernardetiaceae the Bernardetia family).

Cells are Gram-stain negative, chemoorganotrophs and strict aerobes that are motile by gliding. Threads are formed, with and without cross-walls. Carotenoids, saproxanthin or flexixanthin, are produced. Oxidase activity is present, catalase activity is absent. Gelatin is hydrolyzed, but neither cellulose nor agar. The major respiratory quinone is $\mathrm{MK}-7$. The genomic $\mathrm{G}+\mathrm{C}$ content is $29-38 \%$.

This family belongs to the phylum Bacteroidetes, order Cytophagales, class Cytophagia, and currently comprises the genera Bernardetia (the type genus), Hugenholtzia, and tentatively also Garritya.

\section{Emended Description of Balneolaceae Munoz et al. 2016}

The description is the same as given by Munoz et al. (2016) with the following modification.

Cells are non-motile or motile by means of flagella. The dominant fatty acids are iso- $\mathrm{C}_{15: 0}$ and other nonhydroxy branched-chain fatty acids. Major polar lipids are diphosphatidylglycerol, phosphatidylethanolamine and either phosphatidylglycerol (Balneola, Gracilimonas) or phosphatidylcholine (Aliifodinibius, Fodinibius). The major menaquinone is MK-7. The genomic $\mathrm{G}+\mathrm{C}$ content varies around $45 \%$.

\section{Emended Description of Salinibacteraceae Munoz et al. 2016}

The description is the same as given by Munoz et al. (2016) with the following modification.

Major polar lipids are diphosphatidylglycerol (cardiolipid) and diphosphatidylcholin. Some species possess halocapnines. The major fatty acids are iso- $C_{15: 0}, C_{18: 1} \omega 7 c$, summed feature 3 ( $\mathrm{C}_{16: 1} \omega 6 \mathrm{c}$ and/or $\left.\mathrm{C}_{16: 1} \omega 7 \mathrm{c}\right)$.

\section{Emended Description of Rhodothermaceae Ludwig et al. 2012}

The description is the same as given by Ludwig et al. (2012) with the following modification.

Major polar lipids are diphosphatidylglycerol, phosphatidylethanolamine and phosphatidylglycerol. The 
major fatty acids are iso- $\mathrm{C}_{16: 0}$, iso- $\mathrm{C}_{17: 0}$, anteiso- $\mathrm{C}_{17: 0}$. The genomic $\mathrm{G}+\mathrm{C}$ content varies around $65 \%$.

\section{Emended Description of Odoribacteraceae Munoz et al. 2016}

The description is the same as given by Munoz et al. (2016) with the following modification.

Cells are non-motile. Metabolism fermentative, major end products are diverse organic acids. Major menaquinones are MK-9 and MK-10. Major fatty acid iso- $\mathrm{C}_{15: 0}$, with a low ratio of anteiso- $\mathrm{C}_{15: 0}$ to iso- $\mathrm{C}_{15: 0}$. The genomic $\mathrm{G}+\mathrm{C}$ content varies around $40-50 \%$.

\section{Emended description of Saprospiraceae Krieg et al. 2012}

The description is as given by Krieg et al. (2012), with the following changes.

Cells are long rods (up to $3.5 \mu \mathrm{m}$ ) that form long helical filaments (up to $500 \mu \mathrm{m}$ ) and are motile by gliding. $\mathrm{NaCl}$ is required for growth and some can be tolerate $\mathrm{NaCl}$ at a concentration of up to $9 \%(\mathrm{w} / \mathrm{v})$. Cytochrome oxidase and catalase activities are variable. Flexirubin-type pigments are not produced. Carotenoid-type pigments are produced. The respiratory quinone is $\mathrm{MK}-7$. The genomic $\mathrm{G}+\mathrm{C}$ content is around $33-48 \%$.

This family belongs to the phylum Bacteroidetes, order Saprospirales ord. nov., class Saprospiria class. nov., and currently comprises the genera Saprospira (the type genus) and Aureispira.

\section{Description of Bernardetia, gen. nov.}

Ber.nar.de'ti.a (N.L. masc. n. Bernardet named after JeanFrançois Bernardet, researcher at INRA Research Center, Jouyen-Josas, France, and chairman of ICSP subcommittee on the taxonomy of aerobic Bacteroidetes; N.L. fem. n. Bernardetia a genus named after Jean-François Bernardet).

On the basis of 16S rRNA gene sequence analysis, the genus represents a separate branch within the order Cytophagales. With moderate support it forms a clade together with Hugenholtzia gen. nov. and perhaps also Garritya gen. nov. but the three type species, respectively, are comparatively distant from each other in terms of sequence divergence, morphology and physiology. The type species of the genus is Bernardetia litoralis comb. nov.

\section{Description of Bernardetia litoralis, comb. nov.}

B. li.to.ra'lis (L. masc. adj. litoralis, belonging to the sea shore).

Basonym: Flexibacter litoralis Lewin 1969

The description is the same as for Flexibacter litoralis (Lewin, 1969). The type strain is ATCC $23117=$ DSM 6794.

\section{Description of Garritya, gen. nov.}

Gar.ri'ty.a (N.L. masc. n. Garrity named after George M. Garrity, professor at Michigan State University, East Lansing, MI, USA, the former editor of Bergey's manual and current chief editor of Standards in Genomic Sciences; N.L. fem. n. Garritya a genus named after George M. Garrity).

The description is the same as for the species Garritya polymorpha, comb. nov., as its known features, while scarce, already differentiate at the genus level.
On the basis of 16S rRNA gene sequence and phylogenomic analysis, the genus represents a separate branch within the order Cytophagales with an uncertain affiliation to a family. It potentially forms a clade together with Bernardetia gen. nov. and Hugenholtzia gen. nov. but the three type species, respectively, are comparatively distant from each other in terms of sequence divergence, morphology and physiology. The type (and currently sole) species of the genus is Garritya polymorpha.

\section{Description of Garritya polymorpha, comb. nov.}

G. po.ly.mor'pha (N.L. fem. adj. polymorpha, variable in form).

Basonym: Flexibacter polymorphus Lewin 1974

The description is the same as for Flexibacter polymorphus (Lewin, 1974). The type strain is ATCC $27820=$ DSM 9678.

\section{Description of Hugenholtzia, gen. nov.}

Hu.gen.hol'tzi.a (N.L. masc. n. Hugenholtz named after Philip Hugenholtz, Professor at University of Queensland, Brisbane, Qld, Australia, who played a decisive role in starting the GEBA project; N.L. fem. n. Hugenholtzia a genus named after Philip Hugenholtz).

The description is the same as for the species Hugenholtzia roseola, comb. nov., as its known features, while scarce, already differentiate at the genus level.

On the basis of 16S rRNA gene sequence and phylogenomic analysis, the genus represents a separate branch within the order Cytophagales. With moderate support it forms a clade together with Bernardetia gen. nov. and perhaps also Garritya gen. nov. but the three type species, respectively, are comparatively distant from each other in terms of sequence divergence, morphology and physiology. The type species of the genus is Hugenholtzia roseola.

\section{Description of Hugenholtzia roseola, comb. nov.}

H. ro.se'o.la (N.L. fem. dim. adj. roseola, with a rosy shading).

Basonym: Flexibacter roseolus Lewin 1969

The description is the same as for Flexibacter roseolus (Lewin, $1969)$ with the following restriction. The genomic G+C content is $42.2 \%$. The type strain is ATCC $23088=$ DSM 9546.

\section{Description of Thermoflexibacter, gen. nov.}

Ther.mo.fle.xi.bac'ter (Gr. adj. thermos hot; L. part. adj. flexus bent, winding; N.L. masc. n. bacter from Gr. neut. n. baktron little stick or rod; N.L. masc. n. Thermoflexibacter a thermophilic flexible rod. The type strain GEY was isolated from a Geysir in Iceland, can grow in freshwater medium of up to $45^{\circ} \mathrm{C}$ and forms very long threads of more than $50 \mu \mathrm{m}$ length.

The description is the same as for the species Thermoflexibacter ruber, comb. nov., as its known features, while scarce, already differentiate at the genus level.

On the basis of 16S rRNA gene sequence analysis as well as previously published physiological and morphological data, the genus represents a branch of uncertain affiliation within the order Cytophagales. The 16S rRNA gene quite weakly supports a sister-group relationship of this genus and the new family Microscillaceae. The type (and currently sole) species of the genus is Thermoflexibacter ruber. 
Description of Thermoflexibacter ruber, comb. nov.

T. ru'bra (L. fem. adj. rubra, red).

Basonym: Flexibacter ruber Lewin 1969

The description is the same as for Flexibacter ruber (Lewin, 1969). The type strain is GEY = ATCC $23103=$ DSM 9560.

Description of Eisenibacter, gen. nov.

Ei.se.ni.bac'ter (N.L. masc. n. Eisen named after Jonathan A. Eisen, professor at University of California, Davis, CA, USA, who played a decisive role in starting the GEBA project; N.L. masc. n. bacter a rod; N.L. masc. n. Eisenibacter a rod named after Jonathan A. Eisen).

The description is the same as for the species Eisenibacter elegans, comb. nov., as its known features, while scarce, already differentiate at the genus level.

On the basis of 16S rRNA gene sequence analysis as well as previously published physiological and morphological data, the genus represents a separate branch within the order Cytophagales. The 16S rRNA gene strongly supports a sister-group relationship of this genus and Microscilla. The type (and currently sole) species of the genus is Eisenibacter elegans.

Description of Eisenibacter elegans, comb. nov.

E. e'le.gans (L. masc. adj. elegans refined, fashionable, elegant).

Basonym: Flexibacter elegans (ex Lewin 1969, non Soriano, 1945) Reichenbach 1989b, 2067 ${ }^{\mathrm{AL}}$

The description is the same as for Flexibacter elegans (Reichenbach, 1989a). The type strain is ATCC $23112=$ DSM $3317=$ JCM $21159=$ LMG $10750=$ NBRC $15055=$ Lewin NZ-1.

\section{Emended Description of Aequorivita (Bowman and Nichols 2002) Park et al. 2009}

The description is as given by Park et al. (2009) with the following modifications. Gliding motility is present or absent, flexirubin production is variable, oxidase reaction is positive or negative. The genomic $\mathrm{G}+\mathrm{C}$ content varies around $37 \%$.

This change was necessary due to the inclusion of the Vitellibacter species in Aequorivita.

\section{Description of Aequorivita aestuarii, comb. nov.}

A. aes.tu.a'ri.i (L. gen. n. aestuarii, of a tidal flat).

Basonym: Vitellibacter aestuarii Kim et al. 2010

The description is the same as for Vitellibacter aestuarii (Kim et al., 2010). The type strain is JC2436 = IMSNU $14137=$ KACC 13727.

Description of Aequorivita echinoideorum, comb. nov.

A. e.chi.no.i.de.o'rum (N.L. gen. n. echinoideorum, of Echinoidea, sea urchins).

Basonym: Vitellibacter echinoideorum Lin et al. 2015

The description is the same as for Vitellibacter echinoideorum (Lin S. Y. et al., 2015). The type strain is CC-CZW007 = BCRC $80886=$ JCM 30378 .

Description of Aequorivita nionensis, comb. nov.

A. ni.o.nen'sis (N.L. adj. nionensis, derived from the acronym of the National Institute of Oceanography, NIO).
Basonym: Vitellibacter nionensis Rajasabapathy et al., 2015

The description is the same as for Vitellibacter nionensis (Rajasabapathy et al., 2015). The type strain is VBW088 = KCTC $32420=$ MCC 2354

\section{Description of Aequorivita soesokkakensis, comb.} nov.

A. soe.sok.ka.ken'sis (N.L. adj. soesokkakensis, pertaining to the Soesokkak area)

Basonym: Vitellibacter soesokkakensis Park et al., 2014

The description is the same as for Vitellibacter soesokkakensis (Park et al., 2014) with the following modification. The genomic $\mathrm{G}+\mathrm{C}$ content of the type strain is $37.8 \%$. The type strain is RSSK-12 = KCTC $32536=$ CECT 8398.

\section{Description of Aequorivita vladivostokensis, comb. nov.}

A. vla.di.vos.to.ken'sis (N.L. adj. vladivostokensis, pertaining to the city of Vladivostok)

Basonym: Vitellibacter vladivostokensis Nedashkovskaya et al. 2003

The description is the same as for Vitellibacter vladivostokensis (Nedashkovskaya et al., 2003). The type strain is KMM $3516=$ NBRC 16718.

\section{Emended Description of Aliifodinibius Wang et al. 2013}

The description is the same as given by Wang et al. (2013a) with the following modification. The genus Aliifodinibius is a member of the phylum Balneolaeota.

This change was necessary due to the removal of Aliifodinibius from Rhodothermaeota.

\section{Emended Description of Chryseobacterium} (Vandamme et al. 1994) Montero-Calasanz et al. 2014 The description is as given by Montero-Calasanz et al. (2014) with the following modification. Almost all strains grow at $30^{\circ} \mathrm{C}$. Most, but not all, strains oxidize glycerol and trehalose.

On the basis of phylogenomic analysis and a re-assessment of 16S rRNA gene sequence analyses and phenotypic features published earlier, the genus Epilithonimonas should be included in Chryseobacterium.

\section{Description of Chryseobacterium ginsengiterrae, nom. nov.}

C. gin.sen.gi.ter'rae (N.L. n. ginsengum ginseng; L. n. terra soil; N.L. gen. n. ginsengiterrae of soil from a ginseng field).

Basonym: Epilithonimonas ginsengisoli Hoang et al. 2015 (the name Chryseobacterium ginsengisoli has already been validly published, hence a new epithet must be chosen to avoid homonyms)

The description is the same as for Epilithonimonas ginsengisoli (Hoang et al., 2015) with the following modification. Summed feature 3 should be interpreted as iso- $\mathrm{C}_{15: 0}$ 2-OH (MonteroCalasanz et al., 2014). The type strain is DCY78 = JCM 19896 $=$ KCTC 32174 . 


\section{Description of Chryseobacterium halperniae, nom.}

nov.

C. hal.per'ni.ae (N.L. gen. n. halperniae of Halpern, named after Malka Halpern, Professor at University of Haifa, Haifa, Israel, whose team isolated E. lactis).

Basonym: Epilithonimonas lactis Shakéd et al. 2010 (the name Chryseobacterium lactis has already been validly published, hence a new epithet must be chosen to avoid homonyms)

The description is the same as for Epilithonimonas lactis (Shakéd et al., 2010). The type strain is DSM $19921=\mathrm{H} 1=\mathrm{LMG}$ 24401.

\section{Description of Chryseobacterium psychrotolerans,} comb. nov.

C. psy.chro.to'le.rans. (Gr. adj. psychros cold; L. pres. part. tolerans tolerating; N.L. part. adj. psychrotolerans cold-tolerating).

Basonym: Epilithonimonas psychrotolerans $\mathrm{Ge}$ et al. 2015

The description is the same as for Epilithonimonas psychrotolerans (Ge et al., 2015) with the following modification. Summed feature 3 should be interpreted as iso- $\mathrm{C}_{15: 0} 2-\mathrm{OH}$ (Montero-Calasanz et al., 2014). The type strain is CCTCC AB $207182=$ NRRL B-51307 = TSBY 57.

Description of Chryseobacterium tenax, comb. nov.

C. te'nax (L. fem. adj. tenax sticky, holding firm).

Basonym: Epilithonimonas tenax O'Sullivan et al. 2006

The description is the same as for Epilithonimonas tenax (O'Sullivan et al., 2006). Lipids were not mentioned in the original description and thus the published corrections for Chryseobacterium (Montero-Calasanz et al., 2014) do not apply. The type strain is DSM $16811=$ EP105 = NCIMB 14026.

Description of Chryseobacterium xixisoli, comb. nov. C. xi.xi.so'li (N.L. n. xixi of Xixi, a geographical name; L. gen. n. soli of soil; N.L. fem. gen. n. xixisoli of soil from Xixi).

Basonym: Epilithonimonas xixisoli Feng et al. 2014

The description is the same as for Epilithonimonas xixisoli (Feng et al., 2014). The type strain is CGMCC $1.12802=$ NBRC $110387=$ S 31 .

\section{Emended Description of Flexibacter Soriano 1945}

The description is the same as for the species Flexibacter flexilis, as its known features, while scarce, already differentiate at the genus level.

On the basis of $16 \mathrm{~S}$ rRNA gene sequence analysis as well as previously published physiological and morphological data, the type species of the genus represents a separate branch within the order Cytophagales, and must be separated from all other species formerly classified in Flexibacter. The description of the genus must accordingly be restricted.

\section{Emended Description of Akkermansia muciniphila Derrien et al. 2004}

The description is as given by Derrien et al. (2004) with the following modification. The genomic $\mathrm{G}+\mathrm{C}$ content of the type strain is $55.8 \%$.

\section{Emended Description of Algoriphagus marincola} (Yoon et al. 2004) Nedashkovskaya et al. 2007

The description is as given by Nedashkovskaya et al. (2007b) with the following modification. The genomic $\mathrm{G}+\mathrm{C}$ content of the type strain is $41.9 \%$.

\section{Emended Description of Algoriphagus terrigena Yoon et al. 2006}

The description is as given by Yoon et al. (2006) with the following modification. The genomic $\mathrm{G}+\mathrm{C}$ content of the type strain is $47.8 \%$.

\section{Emended Description of Alistipes putredinis (Weinberg et al. 1937) Rautio et al. 2003}

The description is as given by Rautio et al. (2003) with the following modification. The genomic $\mathrm{G}+\mathrm{C}$ content of the type strain is $53.3 \%$.

\section{Emended Description of Alistipes shahii Song et al. 2006}

The description is as given by Song et al. (2006) with the following modification. The genomic G+C content of the type strain is $57.6 \%$.

\section{Emended Description of Alkaliflexus imshenetskii Zhilina et al. 2005}

The description is as given by Zhilina et al. (2004) with the following restriction. The genomic $\mathrm{G}+\mathrm{C}$ content of the type strain is $42.7 \%$.

\section{Emended Description of Alloprevotella tannerae (Moore et al. 1994) Downes et al. 2013}

The description is as given by Downes et al. (2013) with the following modification. The genomic $\mathrm{G}+\mathrm{C}$ content of the type strain is $46.6 \%$.

\section{Emended Description of Arcticibacter svalbardensis Prasad et al. 2013}

The description is as given by Prasad et al. (2013) with the following restriction. The genomic $\mathrm{G}+\mathrm{C}$ content of the type strain is $38.2 \%$.

\section{Emended Description of Arenibacter latericius Ivanova et al. 2001 emend. Nedashkovskaya et al. 2006}

The description is as given by Nedashkovskaya et al. (2006c) with the following modification. The genomic $\mathrm{G}+\mathrm{C}$ content of the type strain is $36.8 \%$.

\section{Emended Description of Bacteroides caccae Johnson et al. 1986}

The description is as given by Johnson et al. (1986) with the following modification. The genomic $\mathrm{G}+\mathrm{C}$ content of the type strain is $41.9 \%$. 


\section{Emended Description of Bacteroides cellulosilyticus}

Robert et al. 2007

The description is as given by Robert et al. (2007) with the following modification. The genomic $\mathrm{G}+\mathrm{C}$ content of the type strain is $42.7 \%$.

\section{Emended Description of Bacteroides coprophilus Hayashi et al. 2007}

The description is as given by Hayashi et al. (2007a) with the following modification. The genomic $\mathrm{G}+\mathrm{C}$ content of the type strain is $45.7 \%$.

\section{Emended description of Bacteroides coprosuis Whitehead et al. 2005}

The description is as given by Whitehead et al. (2005) with the following modification. The genomic $\mathrm{G}+\mathrm{C}$ content of the type strain is $35.0 \%$.

The genome sequence-derived $\mathrm{G}+\mathrm{C}$ content was reported earlier (Land et al., 2011) but no taxonomic consequences were drawn.

\section{Emended Description of Bacteroides dorei Bakir et al. 2006}

The description is as given by Bakir et al. (2006b) with the following modification. The genomic $\mathrm{G}+\mathrm{C}$ content of the type strain is $42.0 \%$.

\section{Emended Description of Bacteroides eggerthii Holdeman and Moore 1974}

The description is as given by Holdeman and Moore (1974) with the following modification. The genomic $\mathrm{G}+\mathrm{C}$ content of the type strain is $44.6 \%$.

\section{Emended Description of Bacteroides fragilis (Veillon} and Zuber 1898) Castellani and Chalmers 1919

The description is as given by Castellani and Chalmers (1919) with the following addition. The genomic $\mathrm{G}+\mathrm{C}$ content of the type strain is $43.1 \%$.

\section{Emended Description of Bacteroides graminisolvens Nishiyama et al. 2009 \\ The description is as given by Nishiyama et al. (2009) with the following modification. The genomic $\mathrm{G}+\mathrm{C}$ content of the type strain is $41.5 \%$.}

\section{Emended Description of Bacteroides helcogenes Benno et al. 1983}

The description is as given by Benno et al. (1983) with the following modification. The genomic $\mathrm{G}+\mathrm{C}$ content of the type strain is $44.7 \%$.

The genome sequence-derived $\mathrm{G}+\mathrm{C}$ content was reported earlier (Pati et al., 2011c) but no taxonomic consequences were drawn.

\section{Emended Description of Bacteroides intestinalis} Bakir et al. 2006

The description is as given by Bakir et al. (2006a) with the following modification. The genomic $\mathrm{G}+\mathrm{C}$ content of the type strain is $42.7 \%$.

\section{Emended Description of Bacteroides massiliensis Fenner et al. 2005}

The description is as given by Fenner et al. (2005) with the following modification. The genomic $\mathrm{G}+\mathrm{C}$ content of the type strain is $42.7 \%$.

\section{Emended Description of Bacteroides ovatus Eggerth and Gagnon 1932}

The description is as given by Eggerth and Gagnon (1932) with the following addition. The genomic $\mathrm{G}+\mathrm{C}$ content of the type strain is $41.9 \%$.

\section{Emended Description of Bacteroides}

propionicifaciens Ueki et al. 2008

The description is as given by Ueki et al. (2008) with the following restriction. The genomic $\mathrm{G}+\mathrm{C}$ content of the type strain is $38.0 \%$.

\section{Emended Description of Bacteroides thetaiotaomicron (Distaso 1912) Castellani and Chalmers 1919}

The description is as given by Castellani and Chalmers (1919) with the following addition. The genomic $\mathrm{G}+\mathrm{C}$ content of the type strain is $42.9 \%$.

\section{Emended Description of Bacteroides uniformis Eggerth and Gagnon 1932}

The description is as given by Eggerth and Gagnon (1932) with the following addition. The genomic $\mathrm{G}+\mathrm{C}$ content of the type strain is $46.4 \%$.

\section{Emended Description of Bacteroides vulgatus Eggerth and Gagnon 1932}

The description is as given by Eggerth and Gagnon (1932) with the following addition. The genomic $\mathrm{G}+\mathrm{C}$ content of the type strain is $42.2 \%$.

\section{Emended Description of Balneola vulgaris Urios et al. 2006}

The description is as given by Urios et al. (2006) with the following modification. The genomic $\mathrm{G}+\mathrm{C}$ content of the type strain is $39.8 \%$.

\section{Emended Description of Barnesiella intestinihominis Morotomi et al. 2008}

The description is as given by Morotomi et al. (2008) with the following modification. The genomic $\mathrm{G}+\mathrm{C}$ content of the type strain is $43.9 \%$. 
Emended Description of Belliella baltica Brettar et al. 2004

The description is as given by Brettar et al. (2004) with the following modification. The genomic $\mathrm{G}+\mathrm{C}$ content of the type strain is $36.8 \%$.

Emended description of Bergeyella zoohelcum (Holmes et al. 1987) Vandamme et al. 1994

The description is as given by Vandamme et al. (1994) with the following restriction. The genomic $\mathrm{G}+\mathrm{C}$ content of the type strain is $36.1 \%$.

\section{Emended Description of Blastopirellula marina} (Schlesner 1987) Schlesner et al. 2004

The description is as given by Schlesner et al. (2004) with the following restriction. The genomic $\mathrm{G}+\mathrm{C}$ content of the type strain is $57.0 \%$.

\section{Emended Description of Butyricimonas synergistica} Sakamoto et al. 2009 emend. Sakamoto et al. 2014 The description is as given by Sakamoto et al. (2014) with the following restriction. The genomic $\mathrm{G}+\mathrm{C}$ content of the type strain is $44.8 \%$.

\section{Emended Description of Butyricimonas virosa}

Sakamoto et al. 2009 emend. Sakamoto et al. 2014

The description is as given by Sakamoto et al. (2014) with the following restriction. The genomic $\mathrm{G}+\mathrm{C}$ content of the type strain is $42.3 \%$.

\section{Emended Description of Capnocytophaga gingivalis Leadbetter et al. 1982 emend. London et al. 1985}

The description is as given by London et al. (1985) with the following restriction. The genomic $\mathrm{G}+\mathrm{C}$ content of the type strain is $40.5 \%$.

\section{Emended Description of Capnocytophaga sputigena Leadbetter et al. 1982}

The description is as given by Leadbetter et al. (1979) with the following modification. The genomic $\mathrm{G}+\mathrm{C}$ content of the type strain is $38.4 \%$.

\section{Emended Description of Cellulophaga algicola Bowman 2000}

The description is as given by Bowman (2000) with the following restriction. The genomic $\mathrm{G}+\mathrm{C}$ content of the type strain is $33.8 \%$.

The genome sequence-derived $\mathrm{G}+\mathrm{C}$ content was reported earlier (Abt et al., 2011a) but no taxonomic consequences were drawn.

\section{Emended Description of Cellulophaga lytica (Lewin 1969) Johansen et al. 1999}

The description is as given by Johansen et al. (1999) with the following modification. The genomic $\mathrm{G}+\mathrm{C}$ content of the type strain is $32.1 \%$.

The genome sequence-derived $\mathrm{G}+\mathrm{C}$ content was reported earlier (Pati et al., 2011a) but no taxonomic consequences were drawn.
Emended Description of Chitinophaga japonensis (Fujita et al. 1997) Kämpfer et al. 2006

The description is as given by Kämpfer et al. (2006) with the following modification. The genomic $\mathrm{G}+\mathrm{C}$ content of the type strain is $53.0 \%$.

\section{Emended Description of Chitinophaga pinensis Sangkhobol and Skerman 1981}

The description is as given by Sangkhobol and Skerman (1981) with the following addition. The genomic $\mathrm{G}+\mathrm{C}$ content of the type strain is $45.2 \%$.

The genome sequence-derived $\mathrm{G}+\mathrm{C}$ content was reported earlier (Glavina Del Rio et al., 2010) but no taxonomic consequences were drawn.

\section{Emended Description of Chitinophaga sancti (Lewin 1969) Kämpfer et al. 2006}

The description is as given by Kämpfer et al. (2006) with the following modification. The genomic $\mathrm{G}+\mathrm{C}$ content of the type strain is $44.2 \%$.

\section{Emended Description of Chlorobium limicola Nadson 1906 emend. Imhoff 2003}

The description is as given by Imhoff (2003) with the following restriction. The genomic $\mathrm{G}+\mathrm{C}$ content of the type strain is $51.3 \%$.

\section{Emended Description of Chlorobium}

phaeobacteroides Pfennig 1968 emend. Imhoff 2003

The description is as given by Imhoff (2003) with the following modification. The genomic $\mathrm{G}+\mathrm{C}$ content of the type strain is $48.4 \%$.

\section{Emended Description of Chloroherpeton thalassium Gibson et al. 1985}

The description is as given by Gibson et al. (1984) with the following restriction. The genomic $\mathrm{G}+\mathrm{C}$ content of the type strain is $45.0 \%$.

\section{Emended Description of Chryseobacterium} antarcticum (Yi et al. 2005) Kämpfer et al. 2009

The description is as given by Kämpfer et al. (2009a) with the following modification. The genomic $\mathrm{G}+\mathrm{C}$ content of the type strain is $36.1 \%$.

\section{Emended Description of Chryseobacterium aquaticum Kim et al. 2008}

The description is as given by Kim et al. (2008) with the following modification. The genomic $\mathrm{G}+\mathrm{C}$ content of the type strain is $33.9 \%$.

\section{Emended Description of Chryseobacterium caeni Quan et al. 2007}

The description is as given by Quan et al. (2007) with the following modification. The genomic $\mathrm{G}+\mathrm{C}$ content of the type strain is $36.6 \%$. 


\section{Emended Description of Chryseobacterium}

formosense Young et al. 2005

The description is as given by Young et al. (2005) with the following addition. The genomic $\mathrm{G}+\mathrm{C}$ content of the type strain is $34.8 \%$.

\section{Emended Description of Chryseobacterium gallinarum Kämpfer et al. 2014}

The description is as given by Kämpfer et al. (2014) with the following addition. The genomic $\mathrm{G}+\mathrm{C}$ content of the type strain is $37.3 \%$.

\section{Emended Description of Chryseobacterium gleum (Holmes et al. 1984) Vandamme et al. 1994 emend. Montero-Calasanz et al. 2014}

The description is as given by Montero-Calasanz et al. (2014) with the following restriction. The genomic $\mathrm{G}+\mathrm{C}$ content of the type strain is $36.8 \%$.

\section{Emended Description of Chryseobacterium greenlandense Loveland-Curtze et al. 2009}

The description is as given by Loveland-Curtze et al. (2009) with the following restriction. The genomic $\mathrm{G}+\mathrm{C}$ content of the type strain is $34.1 \%$.

Emended Description of Chryseobacterium jeonii (Yi et al. 2005) Kämpfer et al. 2009

The description is as given by Kämpfer et al. (2009a) with the following modification. The genomic $\mathrm{G}+\mathrm{C}$ content of the type strain is $34.9 \%$.

\section{Emended Description of Chryseobacterium koreense} (Kim et al. 2004) Kämpfer et al. 2009

The description is as given by Kämpfer et al. (2009b) with the following modification. The genomic $\mathrm{G}+\mathrm{C}$ content of the type strain is $40.1 \%$.

\section{Emended Description of Chryseobacterium kwangjuense Sang et al. 2013}

The description is as given by Sang et al. (2013) with the following modification. The genomic G+C content of the type strain is $38.5 \%$.

\section{Emended Description of Chryseobacterium luteum} Behrendt et al. 2007 emend. Montero-Calasanz et al. 2014

The description is as given by Montero-Calasanz et al. (2014) with the following addition. The genomic $\mathrm{G}+\mathrm{C}$ content of the type strain is $37.3 \%$.

\section{Emended Description of Chryseobacterium palustre Pires et al. 2010 \\ The description is as given by Pires et al. (2010) with the following modification. The genomic $\mathrm{G}+\mathrm{C}$ content of the type strain is $41.5 \%$.}

\section{Emended Description of Chryseobacterium piperi} Strahan et al. 2011

The description is as given by Strahan et al. (2011) with the following modification. The genomic $\mathrm{G}+\mathrm{C}$ content of the type strain is $35.2 \%$.

\section{Emended Description of Chryseobacterium soli Weon et al. 2008}

The description is as given by Weon et al. (2008) with the following modification. The genomic $\mathrm{G}+\mathrm{C}$ content of the type strain is $36.4 \%$.

\section{Emended Description of Chryseobacterium solincola Benmalek et al. 2010}

The description is as given by Benmalek et al. (2010) with the following modification. The genomic $\mathrm{G}+\mathrm{C}$ content of the type strain is $39.5 \%$.

\section{Emended Description of Croceitalea dokdonensis Lee et al. 2008}

The description is as given by Lee et al. (2008) with the following modification. The genomic $\mathrm{G}+\mathrm{C}$ content of the type strain is $41.9 \%$.

\section{Emended Description of Cyclobacterium} amurskyense Nedashkovskaya et al. 2005

The description is as given by Nedashkovskaya et al. (2005a) with the following modification. The genomic $\mathrm{G}+\mathrm{C}$ content of the type strain is $38.3 \%$.

\section{Emended Description of Cyclobacterium marinum (Raj 1976) Raj and Maloy 1990}

The description is as given by Raj and Maloy (1990) with the following modification. The genomic $\mathrm{G}+\mathrm{C}$ content of the type strain is $38.1 \%$.

\section{Emended Description of Cyclobacterium qasimii} Shivaji et al. 2012

The description is as given by Shivaji et al. (2012) with the following modification. The genomic $\mathrm{G}+\mathrm{C}$ content of the type strain is $38.8 \%$.

\section{Emended Description of Cytophaga aurantiaca (ex Winogradsky 1929) Reichenbach 1989}

The description is as given by Reichenbach (1989b) with the following restriction. The genomic $\mathrm{G}+\mathrm{C}$ content of the type strain is $37.1 \%$.

\section{Emended Description of Cytophaga hutchinsonii Winogradsky 1929}

The description is as given by Winogradsky (1929) with the following addition. The genomic $\mathrm{G}+\mathrm{C}$ content of the type strain is $38.8 \%$. 


\section{Emended Description of Dyadobacter beijingensis Dong et al. 2007}

The description is as given by Dong et al. (2007) with the following modification. The genomic $\mathrm{G}+\mathrm{C}$ content of the type strain is $52.1 \%$.

\section{Emended Description of Dyadobacter crusticola Reddy and Garcia-Pichel 2005}

The description is as given by Reddy and Garcia-Pichel (2005) with the following modification. The genomic $\mathrm{G}+\mathrm{C}$ content of the type strain is $46.7 \%$.

\section{Emended Description of Dyadobacter fermentans Chelius and Triplett 2000}

The description is as given by Chelius and Triplett (2000) with the following modification. The genomic $\mathrm{G}+\mathrm{C}$ content of the type strain is $51.5 \%$.

The genome sequence-derived $\mathrm{G}+\mathrm{C}$ content was reported earlier (Lang et al., 2009) but no taxonomic consequences were drawn.

\section{Emended Description of Dyadobacter ginsengisoli \\ Liu et al. 2006}

The description is as given by Liu et al. (2006) with the following modification. The genomic $\mathrm{G}+\mathrm{C}$ content of the type strain is $49.0 \%$.

\section{Emended Description of Dysgonomonas gadei Hofstad et al. 2000}

The description is as given by Hofstad et al. (2000) with the following addition. The genomic $\mathrm{G}+\mathrm{C}$ content of the type strain is $39.6 \%$.

\section{Emended Description of Dysgonomonas mossii Lawson et al. 2002}

The description is as given by Lawson et al. (2002) with the following modification. The genomic $\mathrm{G}+\mathrm{C}$ content of the type strain is $37.5 \%$.

\section{Emended Description of Echinicola pacifica Nedashkovskaya et al. 2006}

The description is as given by Nedashkovskaya et al. (2006a) with the following modification. The genomic $\mathrm{G}+\mathrm{C}$ content of the type strain is $43.8 \%$.

\section{Emended Description of Echinicola vietnamensis Nedashkovskaya et al. 2007}

The description is as given by Nedashkovskaya et al. (2007a) with the following modification. The genomic $\mathrm{G}+\mathrm{C}$ content of the type strain is $44.8 \%$.

\section{Emended Description of Elizabethkingia anophelis Kämpfer et al. 2011 emend. Kämpfer et al. 2015}

The description is as given by Kämpfer et al. (2015) with the following addition. The genomic $\mathrm{G}+\mathrm{C}$ content of the type strain is $35.4 \%$.

\section{Emended Description of Empedobacter brevis} (Holmes and Owen 1982) Vandamme et al. 1994 emend. Zhang et al. 2014

The description is as given by Zhang et al. (2014) with the following restriction. The genomic $\mathrm{G}+\mathrm{C}$ content of the type strain is $32.8 \%$.

\section{Emended Description of Emticicia oligotrophica Saha} and Chakrabarti 2006

The description is as given by Saha and Chakrabarti (2006) with the following modification. The genomic $\mathrm{G}+\mathrm{C}$ content of the type strain is $35.6 \%$.

\section{Emended Description of Flavihumibacter petaseus} Zhang et al. 2010 emend. Zhang et al. 2013

The description is as given by Zhang et al. (2013) with the following modification. The genomic $\mathrm{G}+\mathrm{C}$ content of the type strain is $49.3 \%$.

\section{Emended Description of Flavihumibacter solisilvae Lee et al. 2014}

The description is as given by Lee et al. (2014) with the following modification. The genomic $\mathrm{G}+\mathrm{C}$ content of the type strain is $47.0 \%$.

\section{Emended Description of Flavisolibacter ginsengisoli Yoon and Im 2007}

The description is as given by Yoon and Im (2007) with the following modification. The genomic $\mathrm{G}+\mathrm{C}$ content of the type strain is $40.6 \%$.

\section{Emended Description of Flavisolibacter ginsengiterrae Yoon and Im 2007}

The description is as given by Yoon and Im (2007) with the following modification. The genomic $\mathrm{G}+\mathrm{C}$ content of the type strain is $41.3 \%$.

\section{Emended Description of Flavobacterium antarcticum Yi et al. 2005}

The description is as given by Yi et al. (2005) with the following modification. The genomic $\mathrm{G}+\mathrm{C}$ content of the type strain is $35.0 \%$.

\section{Emended Description of Flavobacterium aquatile (Frankland and Frankland 1889) Bergey et al. 1923} emend. Sheu et al. 2013

The description is as given by Sheu et al. (2013) with the following addition. The genomic $\mathrm{G}+\mathrm{C}$ content of the type strain is $32.2 \%$.

\section{Emended Description of Flavobacterium enshiense Dong et al. 2013}

The description is as given by Dong et al. (2013a) with the following modification. The genomic $\mathrm{G}+\mathrm{C}$ content of the type strain is $37.7 \%$. 


\section{Emended Description of Flavobacterium fryxellicola Van Trappen et al. 2005}

The description is as given by Van Trappen et al. (Van Trappen et al., 2005) with the following modification. The genomic $\mathrm{G}+\mathrm{C}$ content of the type strain is $34.6 \%$.

\section{Emended Description of Flavobacterium hydatis \\ Bernardet et al., 1996}

The description is as given by Bernardet et al. (1996) with the following modification. The genomic $\mathrm{G}+\mathrm{C}$ content of the type strain is $32.7 \%$.

\section{Emended Description of Flavobacterium saliperosum} Wang et al. 2006 emend. Dong et al. 2013

The description is as given by Dong et al. (2013a) with the following modification. The genomic $\mathrm{G}+\mathrm{C}$ content of the type strain is $39.6 \%$.

\section{Emended Description of Flavobacterium} subsaxonicum Ali et al. 2009 emend. Dong et al. 2013 The description is as given by Dong et al. (2013b) with the following modification. The genomic $\mathrm{G}+\mathrm{C}$ content of the type strain is $41.6 \%$.

\section{Emended Description of Flavobacterium terrigena} Yoon et al. 2007 emend. Fujii et al. 2014

The description is as given by Fujii et al. (2014) with the following modification. The genomic $\mathrm{G}+\mathrm{C}$ content of the type strain is $31.2 \%$.

\section{Emended Description of Flectobacillus major (Gromov 1963) Larkin et al. 1977}

The description is as given by Larkin et al. (1977) with the following modification. The genomic $\mathrm{G}+\mathrm{C}$ content of the type strain is $37.8 \%$.

\section{Emended Description of Flexibacter roseolus Lewin 1969}

The description is as given by Lewin (1969) with the following restriction. The genomic $\mathrm{G}+\mathrm{C}$ content of the type strain is $42.2 \%$.

\section{Emended Description of Formosa agariphila Nedashkovskaya et al. 2006}

The description is as given by Nedashkovskaya et al. (2006b) with the following modification. The genomic $\mathrm{G}+\mathrm{C}$ content of the type strain is $33.5 \%$.

\section{Emended Description of Gelidibacter mesophilus Macián et al. 2002}

The description is as given by Macián et al. (2002) with the following restriction. The genomic $\mathrm{G}+\mathrm{C}$ content of the type strain is $36.9 \%$.

\section{Emended Description of Gillisia limnaea Van Trappen} et al. 2004

The description is as given by Van Trappen et al. (2004) with the following restriction. The genomic $\mathrm{G}+\mathrm{C}$ content of the type strain is $37.6 \%$.
The genome sequence-derived $\mathrm{G}+\mathrm{C}$ content was reported earlier (Riedel et al., 2012a) but no taxonomic consequences were drawn.

\section{Emended Description of Haliscomenobacter hydrossis van Veen et al. 1973}

The description is as given by van Veen et al. (1973) with the following addition. The genomic $\mathrm{G}+\mathrm{C}$ content of the type strain is $47.1 \%$.

The genome sequence-derived $\mathrm{G}+\mathrm{C}$ content was reported earlier (Daligault et al., 2011) but no taxonomic consequences were drawn.

\section{Emended Description of Hallella seregens Moore and Moore 1994}

The description is as given by Moore and Moore (1994) with the following modification. The genomic $\mathrm{G}+\mathrm{C}$ content of the type strain is $56.0 \%$.

\section{Emended Description of Hymenobacter aerophilus} Buczolits et al. 2002

The description is as given by Buczolits et al. (2002) with the following restriction. The genomic $\mathrm{G}+\mathrm{C}$ content of the type strain is $62.1 \%$.

\section{Emended Description of Hymenobacter norwichensis} Buczolits et al. 2006

The description is as given by Buczolits et al. (2006) with the following addition. The genomic $\mathrm{G}+\mathrm{C}$ content of the type strain is $56.4 \%$.

\section{Emended Description of Hymenobacter} roseosalivarius Hirsch et al. 1999

The description is as given Hirsch et al. (1998) with the following restriction. The genomic G+C content of the type strain is $56.4 \%$.

\section{Emended Description of Imtechella halotolerans} Surendra et al. 2012

The description is as given by Surendra et al. (2012) with the following modification. The genomic $\mathrm{G}+\mathrm{C}$ content of the type strain is $35.5 \%$.

\section{Emended Description of Indibacter alkaliphilus}

Kumar et al. 2010

The description is as given by Kumar et al. (2010) with the following restriction. The genomic $\mathrm{G}+\mathrm{C}$ content of the type strain is $39.7 \%$.

\section{Emended Description of Joostella marina Quan et al. 2008}

The description is as given by Quan et al. (2008) with the following modification. The genomic $\mathrm{G}+\mathrm{C}$ content of the type strain is $33.6 \%$.

The genome sequence-derived $\mathrm{G}+\mathrm{C}$ content was reported earlier (Stackebrandt et al., 2013) but no taxonomic consequences were drawn. 


\section{Emended Description of Leadbetterella byssophila}

Weon et al. 2005

The description is as given by Weon et al. (2005) with the following modification. The genomic $\mathrm{G}+\mathrm{C}$ content of the type strain is $40.4 \%$.

The genome sequence-derived $\mathrm{G}+\mathrm{C}$ content was reported earlier (Abt et al., 2011b) but no taxonomic consequences were drawn.

\section{Emended Description of Leeuwenhoekiella blandensis Pinhassi et al. 2006}

The description is as given by Pinhassi et al. (2006) with the following modification. The genomic $\mathrm{G}+\mathrm{C}$ content of the type strain is $39.8 \%$.

\section{Emended Description of Lewinella persica (Lewin} 1970) Sly et al. 1998 emend. Khan et al. 2007

The description is as given by Khan et al. (2007) with the following modification. The genomic $\mathrm{G}+\mathrm{C}$ content of the type strain is $51.6 \%$.

\section{Emended Description of Mariniradius saccharolyticus} Bhumika et al. 2013

The description is as given by Bhumika et al. (2013) with the following modification. The genomic $\mathrm{G}+\mathrm{C}$ content of the type strain is $46.7 \%$.

\section{Emended Description of Microscilla marina (Pringsheim 1951) Lewin 1969}

The description is as given by Lewin (1969) with the following modification. The genomic $\mathrm{G}+\mathrm{C}$ content of the type strain is $40.6 \%$.

\section{Emended Description of Mucilaginibacter paludis \\ Pankratov et al. 2007}

The description is as given by Pankratov et al. (2007) with the following modification. The genomic $\mathrm{G}+\mathrm{C}$ content of the type strain is $42.9 \%$.

\section{Emended Description of Muricauda lutaonensis Arun} et al. 2009

The description is as given by Arun et al. (2009) with the following restriction. The genomic $\mathrm{G}+\mathrm{C}$ content of the type strain is $45.0 \%$.

\section{Emended Description of Myroides odoratus (Stutzer 1929) Vancanneyt et al. 1996}

The description is as given by Vancanneyt et al. (1996) with the following restriction. The genomic $\mathrm{G}+\mathrm{C}$ content of the type strain is $35.8 \%$.

\section{Emended Description of Niabella aurantiaca Kim} et al. 2007

The description is as given by Kim et al. (2007) with the following modification. The genomic $\mathrm{G}+\mathrm{C}$ content of the type strain is $48.6 \%$.

\section{Emended Description of Nonlabens marinus Park} et al. 2013 emend. Kwon et al. 2014

The description is as given by Kwon et al. (2014) with the following modification. The genomic $\mathrm{G}+\mathrm{C}$ content of the type strain is $39.7 \%$.

\section{Emended Description of Odoribacter laneus Nagai et al. 2010}

The description is as given by Nagai et al. (2010) with the following modification. The genomic $\mathrm{G}+\mathrm{C}$ content of the type strain is $40.5 \%$.

\section{Emended Description of Odoribacter splanchnicus} (Werner et al. 1975) Hardham et al. 2008

The description is as given by Hardham et al. (2008) with the following addition. The genomic $\mathrm{G}+\mathrm{C}$ content of the type strain is $43.4 \%$.

The genome sequence-derived $\mathrm{G}+\mathrm{C}$ content was reported earlier (Göker et al., 2011) but no taxonomic consequences were drawn.

\section{Emended Description of Opitutus terrae Chin et al. 2001}

The description is as given by Chin et al. (2001) with the following modification. The genomic G+C content of the type strain is $65.3 \%$.

\section{Emended Description of Owenweeksia} hongkongensis Lau et al. 2005 emend. Zhou et al. 2013

The description is as given by Zhou et al. (2013) with the following modification. The genomic $\mathrm{G}+\mathrm{C}$ content of the type strain is $40.2 \%$.

The genome sequence-derived $\mathrm{G}+\mathrm{C}$ content was reported earlier (Riedel et al., 2012b) but no taxonomic consequences were drawn.

\section{Emended Description of Parabacteroides distasonis (Eggerth and Gagnon 1932) Sakamoto and Benno 2006}

The description is as given by Sakamoto and Benno (2006) with the following modification. The genomic $\mathrm{G}+\mathrm{C}$ content of the type strain is $45.1 \%$.

\section{Emended Description of Parabacteroides johnsonii Sakamoto et al. 2007}

The description is as given by Sakamoto et al. (2007) with the following modification. The genomic $\mathrm{G}+\mathrm{C}$ content of the type strain is $45.2 \%$.

\section{Emended Description of Parabacteroides merdae (Johnson et al. 1986) Sakamoto and Benno 2006}

The description is as given by Sakamoto and Benno (2006) with the following modification. The genomic $\mathrm{G}+\mathrm{C}$ content of the type strain is $45.3 \%$. 
Emended Description of Pedobacter glucosidilyticus Luo et al. 2010 emend. Zhou et al. 2012

The description is as given by Zhou et al. (2012) with the following modification. The genomic $\mathrm{G}+\mathrm{C}$ content of the type strain is $34.4 \%$.

\section{Emended Description of Pedobacter kyungheensis Yang et al. 2015}

The description is as given by Yang et al. (2012) with the following modification. The genomic G+C content of the type strain is $40.5 \%$.

\section{Emended Description of Pirellula staleyi (Schlesner} and Hirsch 1984) Schlesner and Hirsch 1987

The description is as given by Schlesner and Hirsch (1987) with the following addition. The genomic $\mathrm{G}+\mathrm{C}$ content of the type strain is $57.5 \%$.

The genome sequence-derived $\mathrm{G}+\mathrm{C}$ content was reported earlier (Clum et al., 2009) but no taxonomic consequences were drawn.

\section{Emended Description of Polaribacter franzmannii Gosink et al. 1998}

The description is as given by Gosink et al. (1998) with the following restriction. The genomic $\mathrm{G}+\mathrm{C}$ content of the type strain is $32.5 \%$.

Emended Description of Polaribacter irgensii Gosink et al. 1998 emend. Kim et al. 2013

The description is as given by Kim et al. (2013) with the following modification. The genomic $\mathrm{G}+\mathrm{C}$ content of the type strain is $34.5 \%$.

\section{Emended Description of Pontibacter actiniarum} Nedashkovskaya et al. 2005

The description is as given by Nedashkovskaya et al. (2005c) with the following modification. The genomic $\mathrm{G}+\mathrm{C}$ content of the type strain is $53.1 \%$.

\section{Emended Description of Porphyromonas asaccharolytica (Holdeman and Moore 1970) Shah and Collins 1988}

The description is as given by Shah and Collins (1988) with the following restriction. The genomic $\mathrm{G}+\mathrm{C}$ content of the type strain is $52.5 \%$.

\section{Emended Description of Porphyromonas bennonis Summanen et al. 2009}

The description is as given by Summanen et al. (2009) with the following modification. The genomic $\mathrm{G}+\mathrm{C}$ content of the type strain is $56.3 \%$.

\section{Emended Description of Porphyromonas catoniae (Moore and Moore 1994) Willems and Collins 1995}

The description is as given by Willems and Collins (1995b) with the following modification. The genomic $\mathrm{G}+\mathrm{C}$ content of the type strain is $51.0 \%$.
Emended Description of Porphyromonas endodontalis (van Steenbergen et al. 1984) Shah and Collins 1988

The description is as given by Shah and Collins (1988) with the following restriction. The genomic $\mathrm{G}+\mathrm{C}$ content of the type strain is $47.5 \%$.

\section{Emended Description of Porphyromonas gingivalis (Coykendall et al. 1980) Shah and Collins 1988}

The description is as given by Shah and Collins (1988) with the following modification. The genomic $\mathrm{G}+\mathrm{C}$ content of the type strain is $48.4 \%$.

\section{Emended Description of Porphyromonas gulae}

\section{Fournier et al. 2001}

The description is as given by Fournier et al. (2001) with the following modification. The genomic $\mathrm{G}+\mathrm{C}$ content of the type strain is $48.6 \%$.

\section{Emended Description of Porphyromonas levii} (Johnson and Holdeman 1983) Shah et al. 1995

The description is as given by Shah et al. (1995) with the following restriction. The genomic $\mathrm{G}+\mathrm{C}$ content of the type strain is $45.7 \%$.

\section{Emended Description of Porphyromonas somerae} Summanen et al. 2006

The description is as given by Summanen et al. (2005) with the following addition. The genomic $\mathrm{G}+\mathrm{C}$ content of the type strain is $47.1 \%$.

\section{Emended Description of Prevotella albensis Avgustin et al. 1997}

The description is as given by Avgustin et al. (1997) with the following restriction. The genomic $\mathrm{G}+\mathrm{C}$ content of the type strain is $41.2 \%$.

\section{Emended Description of Prevotella amnii Lawson et al. 2008}

The description is as given by Lawson et al. (2008) with the following addition. The genomic $\mathrm{G}+\mathrm{C}$ content of the type strain is $36.6 \%$.

\section{Emended Description of Prevotella baroniae Downes} et al. 2005

The description is as given by Downes et al. (2005) with the following modification. The genomic $\mathrm{G}+\mathrm{C}$ content of the type strain is $53.0 \%$.

\section{Emended Description of Prevotella brevis (Bryant} et al. 1958) Avgustin et al. 1997

The description is as given by Avgustin et al. (1997) with the following restriction. The genomic $\mathrm{G}+\mathrm{C}$ content of the type strain is $48.7 \%$. 
Emended Description of Prevotella bryantii Avgustin et al. 1997

The description is as given by Avgustin et al. (1997) with the following restriction. The genomic $\mathrm{G}+\mathrm{C}$ content of the type strain is $39.1 \%$.

\section{Emended Description of Prevotella buccae (Holdeman et al. 1982) Shah and Collins 1990}

The description is as given by Shah and Collins (1990) with the following modification. The genomic $\mathrm{G}+\mathrm{C}$ content of the type strain is $51.0 \%$.

\section{Emended Description of Prevotella copri Hayashi} et al. 2007

The description is as given by Hayashi et al. (2007b) with the following restriction. The genomic $\mathrm{G}+\mathrm{C}$ content of the type strain is $44.8 \%$.

Emended Description of Prevotella corporis (Johnson and Holdeman 1983) Shah and Collins 1990

The description is as given by Shah and Collins (1990) with the following restriction. The genomic $\mathrm{G}+\mathrm{C}$ content of the type strain is $44.1 \%$.

\section{Emended Description of Prevotella dentalis} (Haapasalo et al. 1986) Willems and Collins 1995

The description is as given by Willems and Collins (1995a) with the following restriction. The genomic $\mathrm{G}+\mathrm{C}$ content of the type strain is $55.9 \%$.

\section{Emended Description of Prevotella denticola (Shah} and Collins 1982) Shah and Collins 1990 emend. Wu et al. 1992

The description is as given by Wu et al. (1992) with the following restriction. The genomic $\mathrm{G}+\mathrm{C}$ content of the type strain is $50.1 \%$.

\section{Emended Description of Prevotella histicola Downes et al. 2008}

The description is as given by Downes et al. (2008) with the following modification. The genomic $\mathrm{G}+\mathrm{C}$ content of the type strain is $41.2 \%$.

\section{Emended Description of Prevotella intermedia (Holdeman and Moore 1970) Shah and Collins 1990}

The description is as given by Shah and Collins (1990) with the following restriction. The genomic $\mathrm{G}+\mathrm{C}$ content of the type strain is $43.3 \%$.

\section{Emended Description of Prevotella loescheii} (Holdeman and Johnson 1982) Shah and Collins 1990 emend. Wu et al. 1992

The description is as given by Wu et al. (1992) with the following restriction. The genomic $\mathrm{G}+\mathrm{C}$ content of the type strain is $46.6 \%$.

\section{Emended Description of Prevotella marshii Downes} et al. 2005

The description is as given by Downes et al. (2005) with the following modification. The genomic $\mathrm{G}+\mathrm{C}$ content of the type strain is $47.5 \%$.

\section{Emended Description of Prevotella melaninogenica (Oliver and Wherry 1921) Wu et al. 1992}

The description is as given by Wu et al. (1992) with the following addition. The genomic $\mathrm{G}+\mathrm{C}$ content of the type strain is $41.0 \%$.

\section{Emended Description of Prevotella}

multisaccharivorax Sakamoto et al. 2005

The description is as given by Sakamoto et al. (2005) with the following modification. The genomic $\mathrm{G}+\mathrm{C}$ content of the type strain is $48.3 \%$.

The genome sequence-derived $\mathrm{G}+\mathrm{C}$ content was reported earlier (Pati et al., 2011b) but no taxonomic consequences were drawn.

\section{Emended Description of Prevotella nanceiensis}

Alauzet et al. 2007

The description is as given by Alauzet et al. (2007) with the following modification. The genomic $\mathrm{G}+\mathrm{C}$ content of the type strain is $38.4 \%$.

\section{Emended Description of Prevotella nigrescens Shah and Gharbia 1992}

The description is as given by Shah and Gharbia (1992) with the following restriction. The genomic $\mathrm{G}+\mathrm{C}$ content of the type strain is $42.6 \%$.

\section{Emended Description of Prevotella oralis (Loesche et al. 1964) Shah and Collins 1990}

The description is as given by Shah and Collins (1990) with the following addition. The genomic $\mathrm{G}+\mathrm{C}$ content of the type strain is $44.5 \%$.

\section{Emended Description of Prevotella oris (Holdeman et al. 1982) Shah and Collins 1990}

The description is as given by Shah and Collins (1990) with the following restriction. The genomic $\mathrm{G}+\mathrm{C}$ content of the type strain is $43.8 \%$.

\section{Emended Description of Prevotella pallens Könönen et al., 1998}

The description is as given by Könönen et al. (1998) with the following addition. The genomic $\mathrm{G}+\mathrm{C}$ content of the type strain is $37.4 \%$.

\section{Emended Description of Prevotella paludivivens Ueki et al. 2007}

The description is as given by Ueki et al. (2007) with the following modification. The genomic G+C content of the type strain is $37.3 \%$. 


\section{Emended Description of Prevotella timonensis Glazunova et al. 2007}

The description is as given by Glazunova et al. (2007) with the following addition. The genomic $\mathrm{G}+\mathrm{C}$ content of the type strain is $42.4 \%$.

\section{Emended Description of Prosthecochloris aestuarii Gorlenko 1970 emend. Imhoff 2003}

The description is as given by Imhoff (2003) with the following addition. The genomic G+C content of the type strain is $50.1 \%$.

\section{Emended description of Proteiniphilum acetatigenes Chen and Dong 2005}

The description is as given by Chen and Dong (2005) with the following restriction. The genomic $\mathrm{G}+\mathrm{C}$ content of the type strain is $43.1 \%$.

\section{Emended Description of Pseudopedobacter saltans} (Steyn et al. 1998) Cao et al. 2014

The description is as given by Cao et al. (2014) with the following restriction. The genomic $\mathrm{G}+\mathrm{C}$ content of the type strain is $36.6 \%$.

\section{Emended Description of Pseudosphingobacterium domesticum Vaz-Moreira et al. 2007}

The description is as given by Vaz-Moreira et al. (2007) with the following modification. The genomic $\mathrm{G}+\mathrm{C}$ content of the type strain is $38.9 \%$.

\section{Emended Description of Psychroflexus gondwanensis (Dobson et al. 1993) Bowman et al. 1999}

The description is as given by Bowman et al. (1998) with the following modification. The genomic $\mathrm{G}+\mathrm{C}$ content of the type strain is $35.8 \%$.

\section{Emended Description of Psychroflexus torquis Bowman et al. 1999}

The description is as given by Bowman et al. (1998) with the following modification. The genomic $\mathrm{G}+\mathrm{C}$ content of the type strain is $34.5 \%$.

\section{Emended Description of Psychroflexus tropicus Donachie et al. 2004}

The description is as given by Donachie et al. (2004) with the following restriction. The genomic $\mathrm{G}+\mathrm{C}$ content of the type strain is $36.5 \%$.

\section{Emended Description of Psychroserpens burtonensis Bowman et al. 1997}

The description is as given by Bowman et al. (1997) with the following restriction. The genomic $\mathrm{G}+\mathrm{C}$ content of the type strain is $33.4 \%$.

\section{Emended Description of Rhodonellum psychrophilum Schmidt et al. 2006}

The description is as given by Schmidt et al. (2006) with the following modification. The genomic $\mathrm{G}+\mathrm{C}$ content of the type strain is $41.8 \%$.

\section{Emended Description of Rikenella microfusus} (Kaneuchi and Mitsuoka 1978) Collins et al. 1985

The description is as given by Collins et al. (1985) with the following restriction. The genomic $\mathrm{G}+\mathrm{C}$ content of the type strain is $57.0 \%$.

Emended Description of Robiginitalea biformata Cho and Giovannoni 2004

The description is as given by Cho and Giovannoni (2004) with the following modification. The genomic $\mathrm{G}+\mathrm{C}$ content of the type strain is $55.3 \%$.

\section{Emended Description of Roseivirga echinicomitans} Nedashkovskaya et al. 2005

The description is as given by Nedashkovskaya et al. (2005b) with the following modification. The genomic $\mathrm{G}+\mathrm{C}$ content of the type strain is $40.0 \%$.

\section{Emended Description of Roseivirga ehrenbergii Nedashkovskaya et al. 2005 emend. \\ Nedashkovskaya et al. 2008}

The description is as given by Nedashkovskaya et al. (2008) with the following modification. The genomic $\mathrm{G}+\mathrm{C}$ content of the type strain is $39.3 \%$.

\section{Emended Description of Roseivirga spongicola Lau} et al. 2006

The description is as given by Lau et al. (2006) with the following modification. The genomic $\mathrm{G}+\mathrm{C}$ content of the type strain is $40.2 \%$.

\section{Emended Description of Runella limosa Ryu et al. 2006}

The description is as given by Ryu et al. (2006) with the following modification. The genomic $\mathrm{G}+\mathrm{C}$ content of the type strain is $44.3 \%$.

\section{Emended Description of Runella slithyformis Larkin} and Williams 1978

The description is as given by Larkin and Williams (1978) with the following modification. The genomic $\mathrm{G}+\mathrm{C}$ content of the type strain is $46.6 \%$.

The genome sequence-derived $\mathrm{G}+\mathrm{C}$ content was reported earlier (Copeland et al., 2012) but no taxonomic consequences were drawn.

Emended Description of Runella zeae Chelius et al. 2002

The description is as given by Chelius et al. (2002) with the following modification. The genomic $\mathrm{G}+\mathrm{C}$ content of the type strain is $42.1 \%$.

\section{Emended Description of Salegentibacter flavus Ivanova et al. 2006}

The description is as given by Ivanova et al. (2006) with the following modification. The genomic $\mathrm{G}+\mathrm{C}$ content of the type strain is $39.8 \%$. 
Emended Description of Salinimicrobium terrae Chen et al. 2008

The description is as given by Chen et al. (2008) with the following modification. The genomic $\mathrm{G}+\mathrm{C}$ content of the type strain is $40.4 \%$.

\section{Emended Description of Segetibacter koreensis An} et al. 2007

The description is as given by An et al. (2007) with the following modification. The genomic $\mathrm{G}+\mathrm{C}$ content of the type strain is $37.4 \%$.

\section{Emended Description of Sphingobacterium} multivorum (Holmes et al. 1981) Yabuuchi et al. 1983

The description is as given by Yabuuchi et al. (1983) with the following modification. The genomic $\mathrm{G}+\mathrm{C}$ content of the type strain is $39.9 \%$.

\section{Emended Description of Sphingobacterium thalpophilum (Holmes et al. 1983) Takeuchi and Yokota 1993}

The description is as given by Takeuchi and Yokota (1992) with the following modification. The genomic $\mathrm{G}+\mathrm{C}$ content of the type strain is $43.6 \%$.

\section{Emended Description of Spirosoma linguale Migula 1894}

The description is as given by Migula (1894) with the following restriction. The genomic $\mathrm{G}+\mathrm{C}$ content of the type strain is $50.1 \%$.

The genome sequence-derived $\mathrm{G}+\mathrm{C}$ content was reported earlier (Lail et al., 2010) but no taxonomic consequences were drawn.

\section{Emended Description of Spirosoma panaciterrae Ten et al. 2009}

The description is as given by Ten et al. (2009) with the following modification. The genomic G+C content of the type strain is $48.9 \%$.

\section{Emended Description of Spirosoma spitsbergense Finster et al. 2009 \\ The description is as given by Finster et al. (2009) with the following modification. The genomic $\mathrm{G}+\mathrm{C}$ content of the type strain is $50.4 \%$.}

\section{Emended Description of Sporocytophaga myxococcoides (Krzemieniewska 1933) Stanier 1940}

The description is as given by Stanier (1940) with the following addition. The genomic $\mathrm{G}+\mathrm{C}$ content of the type strain is $36.2 \%$.

\section{Emended Description of Tamlana sedimentorum Romanenko et al. 2014}

The description is as given by Romanenko et al. (2014) with the following modification. The genomic $\mathrm{G}+\mathrm{C}$ content of the type strain is $32.9 \%$.

\section{Emended Description of Terrimicrobium} sacchariphilum Qiu et al. 2014

The description is as given by Qiu et al. (2014) with the following modification. The genomic $\mathrm{G}+\mathrm{C}$ content of the type strain is $60.2 \%$.

\section{Emended Description of Thermonema rossianum Nobre et al. 1997}

The description is as given by Nobre et al. (Tenreiro et al., 1997) with the following modification. The genomic $\mathrm{G}+\mathrm{C}$ content of the type strain is $48.8 \%$.

\section{Emended Description of Weeksella virosa Holmes} et al. 1987 emend. Zhang et al. 2014

The description is as given by Zhang et al. (2014) with the following modification. The genomic $\mathrm{G}+\mathrm{C}$ content of the type strain is $35.9 \%$.

The genome sequence-derived $\mathrm{G}+\mathrm{C}$ content was reported earlier (Lang et al., 2011) but no taxonomic consequences were drawn.

\section{Emended Description of Winogradskyella psychrotolerans Begum et al. 2013}

The description is as given by Begum et al. (2013) with the following restriction. The genomic $\mathrm{G}+\mathrm{C}$ content of the type strain is $33.5 \%$.

\section{AUTHOR CONTRIBUTIONS}

HK prepared genomic DNA. TW sequenced the genomes. $\mathrm{MH}, \mathrm{NI}, \mathrm{NK}$, and SM annotated the genomes. JM and MG phylogenetically analyzed the data. MGL and MG collected the $\mathrm{G}+\mathrm{C}$ content information. $\mathrm{RH}, \mathrm{MGL}$, and MG collected the phenotypic information. RH, JM, MGL, and MG interpreted the results. All authors read and approved the final manuscript.

\section{FUNDING}

This work was performed under the auspices of the US Department of Energy's Office of Science, Biological and Environmental Research Program, and by the University of California, Lawrence Berkeley National Laboratory under contract No. DE-AC02-05CH11231. RH was supported by the German Bundesministerium für Ernährung und Landwirtschaft, grant No. 22016812 for Brian J. Tindall.

\section{ACKNOWLEDGMENTS}

We are grateful to Brian J. Tindall, Sabine Gronow, Cathrin Spröer (all DSMZ) and Maria del Carmen Montero Calasanz (Newcastle University) for helpful comments, as well as to Evelyne Brambilla, Beatrice Trümper, and Meike Döppner (all DSMZ) for technical assistance.

\section{SUPPLEMENTARY MATERIAL}

The Supplementary Material for this article can be found online at: $\quad$ http://journal.frontiersin.org/article/10.3389/fmicb.2016. 02003/full\#supplementary-material 


\section{REFERENCES}

ABAS (2015). Classification of Prokaryotes (Bacteria and Archaea) into Risk Groups (TRBA 466). Bundesarbeitsblatt. Available online at: http://www.baua.de, 19.

ABSA (2016). Risk Group Database. American Biological Safety Association. Available online at: http://www.absa.org/

Abt, B., Lu, M., Misra, M., Han, C., Nolan, M., Lucas, S., et al. (2011a). Complete genome sequence of Cellulophaga algicola type strain (IC166). Stand. Genomic Sci. 4, 72-80. doi: 10.4056/sigs. 1543845

Abt, B., Teshima, H., Lucas, S., Lapidus, A., Del Rio, T. G., Nolan, M., et al. (2011b). Complete genome sequence of Leadbetterella byssophila type strain (4M15). Stand. Genomic Sci. 4, 2-12. doi: 10.4056/sigs. 1413518

Acinas, S. G., Ferrera, I., Sarmento, H., Díez-Vives, C., Forn, I., Ruiz-González, C., et al. (2015). Validation of a new catalysed reporter deposition-fluorescence in situ hybridization probe for the accurate quantification of marine Bacteroidetes populations. Environ. Microbiol. 17, 3557-3569. doi: 10.1111/1462-2920.12517

Alauzet, C., Mory, F., Carlier, J. P., Marchandin, H., Jumas-Bilak, E., and Lozniewski, A. (2007). Prevotella nanceiensis sp. nov., isolated from human clinical samples. Int. J. Syst. Evol. Microbiol. 57, 2216-2220. doi: 10.1099/ijs.0.65173-0

Alfredsson, G. A., Kristjansson, J. K., Hjorleifsdottir, S., and Stetter, K. O. (1988). Rhodothermus marinus, gen. nov., sp. nov., a Thermohilic, Halophilic Bacterium from Submarine Hot Springs in Iceland. J. Gen. Microbiol. 134, 299-306. doi: 10.1099/00221287-134-2-299

An, D.-S., Lee, H. G., Im, W.-T., Liu, Q.-M., and Lee, S.-T. (2007). Segetibacter koreensis gen. nov., sp. nov., a novel member of the phylum Bacteroidetes, isolated from the soil of a ginseng field in South Korea. Int. J. Syst. Evol. Microbiol. 57, 1828-1833. doi: 10.1099/ijs.0.64803-0

Antón, J., Oren, A., Benlloch, S., Rodríguez-Valera, F., Amann, R., and RossellóMora, R. (2002). Salinibacter ruber gen. nov., sp. nov., a novel, extremely halophilic member of the Bacteria from saltern crystallizer ponds. Int. J. Syst. Evol. Microbiol. 52, 485-491. doi: 10.1099/ijs.0.01913-0

Arun, A. B., Chen, W. M., Lai, W. A., Chao, J. H., Rekha, P. D., Shen, F. T., et al. (2009). Muricauda lutaonensis sp. nov., a moderate thermophile isolated from a coastal hot spring. Int. J. Syst. Evol. Microbiol. 59, 2738-2742. doi: 10.1099/ijs.0.007930-0

Auch, A. F., Henz, S. R., Holland, B. R., and Göker, M. (2006). Genome BLAST distance phylogenies inferred from whole plastid and whole mitochondrion genome sequences. BMC Bioinformatics 7:350. doi: 10.1186/1471-2105-7-350

Auch, A. F., von Jan, M., Klenk, H.-P., and Göker, M. (2010). Digital DNA-DNA hybridization for microbial species delineation by means of genome-to-genome sequence comparison. Stand. Genomic Sci. 2, 117-134. doi: 10.4056/sigs.531120

Avgustin, G., Wallace, R. J., and Flint, H. J. (1997). Phenotypic diversity among ruminal isolates of Prevotella ruminicola: proposal of Prevotella brevis sp. nov., Prevotella bryantii sp. nov., and Prevotella albensis sp. nov. and redefinition of Prevotella ruminicola. Int. J. Syst. Bacteriol. 47, 284-288. doi: 10.1099/00207713-47-2-284

Baati, H., Guermazi, S., Gharsallah, N., Sghir, A., and Ammar, E. (2010). Novel prokaryotic diversity in sediments of Tunisian multipond solar saltern. Res. Microbiol. 161, 573-582. doi: 10.1016/j.resmic.2010.05.009

Bakermans, C. (2015). Microbial Evolution under Extreme Conditions. Berlin, Boston, MA: De Gruyter.

Bakir, M. A., Kitahara, M., Sakamoto, M., Matsumoto, M., and Benno, Y. (2006a). Bacteroides intestinalis sp. nov., isolated from human faeces. Int. J. Syst. Evol. Microbiol. 56, 151-154. doi: 10.1099/ijs.0.63914-0

Bakir, M. A., Sakamoto, M., Kitahara, M., Matsumoto, M., and Benno, Y. (2006b). Bacteroides dorei sp. nov., isolated from human faeces. Int. J. Syst. Evol. Microbiol. 56, 1639-1643. doi: 10.1099/ijs.0.64257-0

Bapteste, E., and Boucher, Y. (2009). Epistemological impacts of horizontal gene transfer on classification in microbiology. Methods Mol. Biol. 532, 55. doi: 10.1007/978-1-60327-853-9

Baronio, M., Lattanzio, V. M. T., Vaisman, N., Oren, A., and Corcelli, A. (2010). The acylhalocapnines of halophilic bacteria: structural details of unusual sulfonate sphingoids. J. Lipid Res. 51, 1878-1885. doi: 10.1194/jlr.M004804

Begum, Z., Srinivas, T. N. R., Manasa, P., Sailaja, B., Sunil, B., Prasad, S., et al. (2013). Winogradskyella psychrotolerans sp. nov., a marine bacterium of the family Flavobacteriaceae isolated from Arctic sediment. Int. J. Syst. Evol. Microbiol. 63, 1646-1652. doi: 10.1099/ijs.0.044669-0
Behrendt, U., Ulrich, A., and Schumann, P. (2008). Chryseobacterium gregarium sp. nov., isolated from decaying plant material. Int. J. Syst. Evol. Microbiol. 58, 1069-1074. doi: 10.1099/ijs.0.65544-0

Behrendt, U., Ulrich, A., Spröer, C., and Schumann, P. (2007). Chryseobacterium luteum sp. nov., associated with the phyllosphere of grasses. Int. J. Syst. Evol. Microbiol. 57, 1881-1885. doi: 10.1099/ijs.0.65104-0

Benmalek, Y., Cayol, J.-L., Bouanane, N. A., Hacene, H., Fauque, G., and Fardeau, M.-L. (2010). Chryseobacterium solincola sp. nov., isolated from soil. Int. J. Syst. Evol. Microbiol. 60, 1876-1880. doi: 10.1099/ijs.0.008631-0

Benno, Y., Watabe, J., and Mitsuoka, T. (1983). Bacteroides pyogenes sp. nov., Bacteroides suis sp. nov., and Bacteroides helcogenes sp. nov., new species from abscesses and feces of pigs. Syst. Appl. Microbiol. 4, 396-407. doi: 10.1016/S0723-2020(83)80024-1

Bernardet, J. F. (2011). "Family I. Flavobacteriaceae Reichenbach 1992b, 327VP (Effective publication: Reichenbach 1989b, 2013.) emend. Bernardet, Segers, Vancanneyt, Berthe, Kersters, and Vandamme 1996, 145 emend. Bernardet, Nakagawa and Holmes 2002, 1057," in Bergey's Manual of Systematic Bacteriology, eds J. T. Krieg and N. R. Staley (New York, NY: Springer), 106-314.

Bernardet, J.-F. (2010). “Class II. Flavobacteriia class. nov."” in Bergey's Manual of Systematic Bacteriology, Vol. 4, 2nd Edn., The Bacteroidetes, Spirochaetes, Tenericutes (Mollicutes), Acidobacteria, Fibrobacteres, Fusobacteria, Dictyoglomi, Gemmatimonadetes, Lentisphaerae, Verrucomicrobia, Chlamydiae, and Planctomycetes, eds W. W. B. Krieg, N. R. Staley, J. T. Brown, D. R. Hedlund, B. P. Paster, B. J. Ward, and W. Ludwig (New York, NY: Springer), 106-314.

Bernardet, J.-F., Segers, P., Vancanneyt, M., Berthe, F., Kersters, K., and Vandamme, P. (1996). Cutting a gordian knot: emended classification and description of the genus Flavobacterium, emended description of the family Flavobacteriaceae, and proposal of Flavobacterium hydatis nom. nov. (Basonym, Cytophaga aquatilis Strohl and Tait 1978). Int. J. Syst. Bacteriol. 46, 128-148. doi: 10.1099/00207713-46-1-128

Bernardet, J. F., Nakagawa, Y., and Holmes, B. (2002). Proposed minimal standards for describing new taxa of the family Flavobacteriaceae and emended description of the family. Int. J. Syst. Evol. Microbiol. 52, 1049-1070. doi: 10.1099/ijs.0.02136-0.02136

Bhumika, V., Srinivas, T. N. R., Ravinder, K., and Anil Kumar, P. (2013). Mariniradius saccharolyticus gen. nov., sp. nov., a member of the family Cyclobacteriaceae isolated from marine aquaculture pond water, and emended descriptions of the genus Aquiflexum and Aquiflexum balticum. Int. J. Syst. Evol. Microbiol. 63, 2088-2094. doi: 10.1099/ijs.0.043919-0

Bowman, J. P. (2000). Description of Cellulophaga algicola sp. nov., isolated from the surfaces of Antarctic algae, and reclassification of Cytophaga uliginosa (ZoBell and Upham 1944) Reichenbach 1989 as Cellulophaga uliginosa comb. nov. Int. J. Syst. Evol. Microbiol. 50, 1861-1868. doi: $10.1099 / 00207713-50-5-1861$

Bowman, J. P. (2006). "The marine clade of the family Flavobacteriaceae: the Genera Aequorivita, Arenibacter, Cellulophaga, Croceibacter, Formosa, Gelidibacter, Gillisia, Maribacter, Mesonia, Muricauda," in The Prokaryotes, eds M. Dworkin, S. Falkow, E. Rosenberg, K. H. Schleifer, and E. Stackebrandt (New York, NY: Springer), 677-694.

Bowman, J. P., McCammon, S. A., Brown, J. L., Nichols, P. D., and McMeekinl, T. A. (1997). Psychrosepens burtonensis gen. nov., sp. nov., and Gelidibacter algens gen. nov., sp. nov., psychrophilic bacteria isolated from Antarctic lacustrine and sea ice habitats. Int. J. Syst. Bacteriol. 47, 670-677.

Bowman, J. P., McCammon, S. A., Lewis, T., Skerratt, J. H., Brown, J. L., Nichols, D. S., et al. (1998). Psychroflexus torquis gen. nov., sp. nov., a psychrophilic species from Antarctic sea ice, and reclassification of Flavobacterium gondwanense (Dobson et al. 1993) as Psychroflexus gondwanense gen. nov., comb. nov. Microbiology 144, 1601-1609. doi: 10.1099/00221287-144-6-1601

Bowman, J. P., Nichols, C. M., and Gibson, J. A. E. (2003). Algoriphagus ratkowskyi gen. nov., sp. nov., Brumimicrobium glaciale gen. nov., sp. nov., Cryomorpha ignava gen. nov., sp. nov. and Crocinitomix catalasitica gen. nov., sp. nov., novel flavobacteria isolated from various polar habitats. Int. J. Syst. Evol. Microbiol. 53, 1343-1355. doi: 10.1099/ijs.0.02553-0

Bowman, J. P., and Nichols, D. S. (2002). Aequorivita gen. nov., a member of the family Flavobacteriaceae isolated from terrestrial and marine Antarctic habitats. Int. J. Syst. Evol. Microbiol. 52, 1533-1541. doi: 10.1099/ijs.0.01976-0 
Breider, S., Scheuner, C., Schumann, P., Fiebig, A., Petersen, J., Pradella, S., et al. (2014). Genome-scale data suggest reclassifications in the Leisingera-Phaeobacter cluster including proposals for Sedimentitalea gen. nov. and Pseudophaeobacter gen. nov. J. Comput. Biol. 5:416. doi: 10.3389/fmicb.2014.00416

Brettar, I., Christen, R., and Höfle, M. G. (2004). Belliella baltica gen. nov., sp. nov., a novel marine bacterium of the Cytophaga-Flavobacterium-Bacteroides group isolated from surface water of the central Baltic Sea. Int. J. Syst. Evol. Microbiol. 54, 65-70. doi: 10.1099/ijs.0.02752-0

Buczolits, S., Denner, E. B. M., Kämpfer, P., and Busse, H. J. (2006). Proposal of Hymenobacter norwichensis sp. nov., classification of "Taxeobacter ocellatus," "Taxeobacter gelupurpurascens" and "Taxeobacter chitinovorans" as Hymenobacter ocellatus sp. nov., Hymenobacter gelipurpurascen. Int. J. Syst. Evol. Microbiol. 56, 2071-2078. doi: 10.1099/ijs.0.64371-0

Buczolits, S., Denner, E. B. M., Vybiral, D., Wieser, M., Kämpfer, P., and Busse, H. J. (2002). Classification of three airborne bacteria and proposal of Hymenobacter aerophilus sp. nov. Int. J. Syst. Evol. Microbiol. 52, 445-446. doi: 10.1099/00207713-52-2-445

Camacho, C., Coulouris, G., Avagyan, V., Ma, N., Papadopoulos, J., Bealer, K., et al. (2009). BLAST+: architecture and applications. BMC Bioinformatics 10:421. doi: 10.1186/1471-2105-10-421

Cantarel, B. L., Coutinho, P. M., Rancurel, C., Bernard, T., Lombard, V., and Henrissat, B. (2009). The Carbohydrate-Active EnZymes database (CAZy): an expert resource for glycogenomics. Nucleic Acids Res. 37, D233-D238. doi: 10.1093/nar/gkn663

Cao, J., Lai, Q., Li, G., and Shao, Z. (2014). Pseudopedobacter beijingensis gen. nov., sp. nov., isolated from coking wastewater activated sludge, and reclassification of Pedobacter saltans as Pseudopedobacter saltans comb. nov. Int. J. Syst. Evol. Microbiol. 64, 1853-1858. doi: 10.1099/ijs.0.053991-0

Castellani, A., and Chalmers, A. J. (1919). Manual of Tropical Medicine, $3 r d$ Edn. New York, NY: William Wood and company.

Chelius, M. K., Henn, J. A., and Triplett, E. W. (2002). Runella zeae sp. nov., a novel Gram-negative bacterium from the stems of surface-sterilized Zea mays. Int. J. Syst. Evol. Microbiol. 52, 2061-2063. doi: 10.1099/ijs.0.02203-0

Chelius, M. K., and Triplett, E. W. (2000). Dyadobacter fermentans gen. nov., sp. nov., a novel Gram-negative bacterium isolated from surfacesterilized Zea mays stems. Int. J. Syst. Evol. Microbiol. 50, 751-758. doi: 10.1099/00207713-52-6-2061

Chen, S., and Dong, X. (2005). Proteiniphilum acetatigenes gen. nov., sp. nov., from a UASB reactor treating brewery wastewater. Int. J. Syst. Evol. Microbiol. 55, 2257-2261. doi: 10.1099/ijs.0.63807-0

Chen, Y.-G., Cui, X.-L., Zhang, Y.-Q., Li, W.-J., Wang, Y.-X., Kim, C.-J., et al. (2008). Salinimicrobium terrae sp. nov., isolated from saline soil, and emended description of the genus Salinimicrobium. Int. J. Syst. Evol. Microbiol. 58, 2501-2504. doi: 10.1099/ijs.0.65860-0

Chin, K. J., Liesack, W., and Janssen, P. H. (2001). Opitutus terrae gen. nov., sp. nov., to accommodate novel strains of the division "Verrucomicrobia" isolated from rice paddy soil. Int. J. Syst. Evol. Microbiol. 51, 1965-1968. doi: 10.1099/00207713-51-6-1965

Cho, J.-C., and Giovannoni, S. J. (2004). Robiginitalea biformata gen. nov., sp. nov., a novel marine bacterium in the family Flavobacteriaceae with a higher G+C content. Int. J. Syst. Evol. Microbiol. 54, 1101-1106. doi: 10.1099/ijs.0. 03023-0

Cho, Y., Chung, H., Jang, G. I., Choi., D. H., Noh, J. H., and Cho, B. C. (2013). Gracilimonas rosea sp. nov., isolated from tropical seawater, and emended description of the genus Gracilimonas. Int. J. Syst. Evol. Microbiol. 63, 4006-4011. doi: 10.1099/ijs.0.052340-0

Choi, D. H., Zhang, G. I., Noh, J. H., Kim, W. S., and Cho, B. C. (2009). Gracilimonas tropica gen. nov., sp. nov., isolated from a Synechococcus culture. Int. J. Syst. Evol. Microbiol. 59, 1167-1172. doi: 10.1099/ijs.0.005512-0

Çınar, S., and Mutlu, M. B. (2016). Comparative analysis of prokaryotic diversity in solar salterns in eastern Anatolia (Turkey). Extremophiles 20, 589-601. doi: 10.1007/s00792-016-0845-7

Clum, A., Tindall, B. J., Sikorski, J., Ivanova, N., Mavrommatis, K., Lucas, S., et al. (2009). Complete genome sequence of Pirellula staleyi type strain (ATCC 27377). Stand. Genomic Sci. 1, 308-316. doi: 10.4056/sigs.51657

Collins, M. D., Shah, H. N., and Mitsuoka, T. (1985). Reclassification of Bacteroides microfusus (Kaneuchi and Mitsuoka) in a New Genus
Rikenella, as Rikenella microfusus comb. nov. Syst. Appl. Microbiol. 6, 79-81. doi: 10.1016/S0723-2020(85)80015-1

Copeland, A., Zhang, X., Misra, M., Lapidus, A., Nolan, M., Lucas, S., et al. (2012). Complete genome sequence of the aquatic bacterium Runella slithyformis type strain (LSU $4^{\mathrm{T}}$ ). Stand. Genomic Sci. 6, 145-154. doi: 10.4056/sigs.2475579

Corcelli, A., Lattanzio, V. M. T., Mascolo, G., Babudri, F., Oren, A., Mascolo, G., et al. (2004). Novel sulfonolipid in the extremely halophilic bacterium Salinibacter ruber. Society 70, 6678-6685. doi: 10.1128/AEM.70.11.6678

Cowan, S. T. (1971). Sense and nonsense in bacterial taxonomy. J. Gen. Microbiol. 67, 1-8. doi: 10.1099/00221287-67-1-1

Daligault, H., Lapidus, A., Zeytun, A., Nolan, M., Lucas, S., Del Rio, T. G., et al. (2011). Complete genome sequence of Haliscomenobacter hydrossis type strain (O). Stand. Genomic Sci. 4, 352-360. doi: 10.4056/sigs.1964579

Derrien, M., Vaughan, E. E., Plugge, C. M., and de Vos, W. M. (2004). Akkermansia municiphila gen. nov., sp. nov., a human intestinal mucin-degrading bacterium. Int. J. Syst. Evol. Microbiol. 54, 1469-1476. doi: 10.1099/ijs.0.02873-0

Donachie, S. P., Bowman, J. P., and Alam, M. (2004). Psychroflexus tropicus sp. nov., an obligately halophilic Cytophaga-Flavobacterium-Bacteroides group bacterium from an Hawaiian hypersaline lake. Int. J. Syst. Evol. Microbiol. 54, 935-940. doi: 10.1099/ijs.0.02733-0

Dong, K., Chen, F., Du, Y., and Wang, G. (2013a). Flavobacterium enshiense sp. nov., isolated from soil, and emended descriptions of the genus Flavobacterium and Flavobacterium cauense, Flavobacterium saliperosum and Flavobacterium suncheonense. Int. J. Syst. Evol. Microbiol. 63, 886-892. doi: 10.1099/ijs.0.039974-0

Dong, K., Xu, B., Zhu, F., and Wang, G. (2013b). Flavobacterium hauense sp. nov., isolated from soil and emended descriptions of Flavobacterium subsaxonicum, Flavobacterium beibuense, and Flavobacterium rivuli. Int. J. Syst. Evol. Microbiol. 63, 3237-3242. doi: 10.1099/ijs.0.048652-0

Dong, Z., Guo, X., Zhang, X., Qiu, F., Sun, L., Gong, H., et al. (2007). Dyadobacter beijingensis sp. nov., isolated from the rhizosphere of turf grasses in China. Int. J. Syst. Evol. Microbiol. 57, 862-865. doi: 10.1099/ijs.0.64754-0

Downes, J., Dewhirst, F. E., Tanner, A. C. R., and Wade, W. G. (2013). Description of Alloprevotella rava gen. nov., sp. nov., isolated from the human oral cavity, and reclassification of Prevotella tannerae Moore et al. 1994 as Alloprevotella tannerae gen. nov., comb. nov. Int. J. Syst. Evol. Microbiol. 63, 1214-1218. doi: 10.1099/ijs.0.041376-0

Downes, J., Hooper, S. J., Wilson, M. J., and Wade, W. G. (2008). Prevotella histicola sp. nov., isolated from the human oral cavity. Int. J. Syst. Evol. Microbiol. 58, 1788-1791. doi: 10.1099/ijs.0.65656-0

Downes, J., Sutcliffe, I., Tanner, A. C. R., and Wade, W. G. (2005). Prevotella marshii sp. nov. and Prevotella baroniae sp. nov., isolated from the human oral cavity. Int. J. Syst. Evol. Microbiol. 55, 1551-1555. doi: 10.1099/ijs.0.63634-0

Eggerth, A. H., and Gagnon, B. H. (1932). The Bacteroides of human feces. J. Bacteriol. 25, 389-413.

Farris, J. S. (1974). Formal definitions of paraphyly and polyphyly. Syst. Zool. 23, 548-554. doi: 10.2307/2412474

Felsenstein, J. (2004). Inferring Phylogenies. Sunderland, MA: Sinauer Associates.

Feng, H., Zeng, Y., and Huang, Y. (2014). Epilithonimonas xixisoli sp. nov., isolated from wetland bank-side soil. Int. J. Syst. Evol. Microbiol. 64, 4155-4159. doi: 10.1099/ijs.0.065771-0

Fenner, L., Roux, V., Mallet, M.-N., and Raoult, D. (2005). Bacteroides massiliensis sp. nov., isolated from blood culture of a newborn. Int. J. Syst. Evol. Microbiol. 55, 1335-1337. doi: 10.1099/ijs.0.63350-0

Fernández-Gómez, B., Richter, M., Schüler, M., Pinhassi, J., Acinas, S. G., González, J. M., et al. (2013). Ecology of marine Bacteroidetes: a comparative genomics approach. ISME J. 7, 1026-1037. doi: 10.1038/ismej.2012.169

Finster, K. W., Herbert, R. A., and Lomstein, B. A. (2009). Spirosoma spitsbergense sp. nov. and Spirosoma luteum sp. nov., isolated from a high Arctic permafrost soil, and emended description of the genus Spirosoma. Int. J. Syst. Evol. Microbiol. 59, 839-844. doi: 10.1099/ijs.0.002725-0

Fournier, D., Mouton, C., Lapierre, P., Kato, T., Okuda, K., and Ménard, C. (2001). Porphyromonas gulae sp. nov., an anaerobic, gram-negative coccobacillus from the gingival sulcus of various animal hosts. Int. J. Syst. Evol. Microbiol. 51, 1179-1189. doi: 10.1099/00207713-51-3-1179

Fujii, D., Nagai, F., Watanabe, Y., and Shirasawa, Y. (2014). Flavobacterium longum sp. nov. and Flavobacterium urocaniciphilum sp. nov., isolated from a wastewater treatment plant, and emended descriptions of Flavobacterium 
caeni and Flavobacterium terrigena. Int. J. Syst. Evol. Microbiol. 64, 1488-1494. doi: 10.1099/ijs.0.054312-0

Garrity, G. M., and Holt, J. G. (2001). "Taxonomic outline of the archaea and bacteria," in Bergey's Manual of Systematic Bacteriology, Vol. 1, 2nd Edn., eds G. M. Garrity, D. R. Boone, and R. W. Castenholz (New York, NY: Springer), 155-166.

Ge, L., Zhao, Q., Sheng, H., Wu, J., and An, L. (2015). Epilithonimonas psychrotolerans sp. nov., isolated from alpine permafrost. Int. J. Syst. Evol. Microbiol. 65, 3777-3781. doi: 10.1099/ijsem.0.000489

Gibson, J., Pfennig, N., and Waterbury, J. B. (1984). Chloroherpeton thalassium gen. nov. et spec. nov., a non-filamentous, flexing and gliding green sulfur bacterium. Arch. Microbiol. 138, 96-101. doi: 10.1007/BF00413007

Glavina Del Rio, T., Abt, B., Spring, S., Lapidus, A., Nolan, M., Tice, H., et al. (2010). Complete genome sequence of Chitinophaga pinensis type strain (UQM 2034). Stand. Genomic Sci. 2, 87-95. doi: 10.4056/sigs.661199

Glazunova, O. O., Launay, T., Raoult, D., and Roux, V. (2007). Prevotella timonensis sp. nov., isolated from a human breast abscess. Int. J. Syst. Evol. Microbiol. 57, 883-886. doi: 10.1099/ijs.0.64609-0

Göker, M., Gronow, S., Zeytun, A., Nolan, M., Lucas, S., Lapidus, A., et al. (2011). Complete genome sequence of Odoribacter splanchnicus type strain (1651/6). Stand. Genomic Sci. 4, 200-209. doi: 10.4056/sigs.1714269

Göker, M., and Klenk, H.-P. (2013). Phylogeny-driven target selection for largescale genome-sequencing (and other) projects. Stand. Genomic Sci. 8, 360-374. doi: 10.4056/sigs.3446951

Goloboff, P. A., Farris, J. S., and Nixon, K. C. (2008). TNT, a free program for phylogenetic analysis. Cladistics 24, 774-786. doi: 10.1111/j.1096-0031.2008. 00217.x

Goloboff, P. A., Mattoni, C. I., and Quinteros, A. S. (2006). Continuous characters analyzed as such. Cladistics 22, 589-601. doi: 10.1111/j.1096-0031.2006.00122.x

Gosink, J. J., Woese, C. R., and Staley, J. T. (1998). Polaribacter gen. nov., with three new species, $P$. irgensii sp. nov., $P$. franzmannii sp. nov. and $P$. filamentus sp. nov., gas vacuolate polar marine bacteria of the Cytophaga-FlavobacteriumBacteroides group and reclassification of "Flectobacillus glomeratus" as Polaribacter glomeratus comb. nov. Int. J. Syst. Bacteriol. 48, 223-235. doi: 10.1099/00207713-48-1-223

Grabowski, A., Tindall, B. J., Bardin, V., Blanchet, D., and Jeanthon, C. (2005). Petrimonas sulfuriphila gen. nov., sp. nov., a mesophilic fermentative bacterium isolated from a biodegraded oil reservoir. Int. J. Syst. Evol. Microbiol. 55, 1113-1121. doi: 10.1099/ijs.0.63426-0

Hantsis-Zacharov, E., and Halpern, M. (2007). Chryseobacterium haifense sp. nov., a psychrotolerant bacterium isolated from raw milk. Int. J. Syst. Evol. Microbiol. 57, 2344-2348. doi: 10.1099/ijs.0.65115-0

Hardham, J. M., King, K. W., Dreier, K., Wong, J., Strietzel, C., Eversole, R. R., et al. (2008). Transfer of Bacteroides splanchnicus to Odoribacter gen. nov. as Odoribacter splanchnicus comb. nov., and description of Odoribacter denticanis sp. nov., isolated from the crevicular spaces of canine periodontitis patients. Int. J. Syst. Evol. Microbiol. 58, 103-109. doi: 10.1099/ijs.0.63458-0

Hayashi, H., Shibata, K., Abdul Bakir, M., Sakamoto, M., Tomita, S., and Benno, Y. (2007a). Bacteroides coprophilus sp. nov., isolated from human faeces. Int. J. Syst. Evol. Microbiol. 57, 1323-1326. doi: 10.1099/ijs.0.64979-0

Hayashi, H., Shibata, K., Sakamoto, M., Tomita, S., and Benno, Y. (2007b). Prevotella copri sp. nov. and Prevotella stercorea sp. nov., isolated from human faeces. Int. J. Syst. Evol. Microbiol. 57, 941-946. doi: 10.1099/ijs.0.64778-0

Hennig, W. (1965). Phylogenetic systematics. Annu. Rev. Ecol. Syst. 10, 97-116.

Henz, S. R., Huson, D. H., Auch, A. F., Nieselt-Struwe, K., and Schuster, S. C. (2005). Whole genome-based prokaryotic phylogeny. Bioinformatics 21, 2329-2335. doi: 10.1093/bioinformatics/bth324

Hirsch, P., Ludwig, W., Hethke, C., Sittig, M., Hoffmann, B., and Gallikowski, C. A. (1998). Hymenobacter roseosalivarius gen. nov., sp. nov. from continental Antartica soils and sandstone: bacteria of the Cytophaga/Flavobacterium/Bacteroides line of phylogenetic descent. Syst. Appl. Microbiol. 21, 374-383. doi: 10.1016/S0723-2020(98)80047-7

Hoang, V. A., Kim, Y. J., Ponnuraj, S. P., Nguyen, N. L., Hwang, K. H., and Yang, D. C. (2015). Epilithonimonas ginsengisoli sp. nov., isolated from soil of a ginseng field. Int. J. Syst. Evol. Microbiol. 65, 122-128. doi: 10.1099/ijs.0.065466-0

Hofstad, T., Olsen, I., Eribe, E. R., Falsen, E., Collins, M. D., and Lawson, P. A. (2000). Dysgonomonas gen. nov. to accommodate Dysgonomonas gadei sp. nov., an organism isolated from a human gall bladder, and Dysgonomonas capnocytophagoides (formerly CDC group DF-3). Int. J. Syst. Evol. Microbiol. 50, 2189-2195. doi: 10.1099/00207713-50-6-2189

Holdeman, L. V., and Moore, W. E. C. (1974). New genus, Coprococcus, twelve new species, and emended descrptions of four previously described species of Bacteria from human feces. Int. J. Syst. Bacteriol. 24, 260-277.

Hugo, C. J., Segers, P., Hoste, B., Vancanneyt, M., and Kersters, K. (2003). Chryseobacterium joostei sp. nov., isolated from the dairy environment. Int. J. Syst. Evol. Microbiol. 53, 771-777. doi: 10.1099/ijs.0.02232-0

Iino, T., Mori, K., Uchino, Y., Nakagawa, T., Harayama, S., and Suzuki, K. I. (2010). Ignavibacterium album gen. nov., sp. nov., a moderately thermophilic anaerobic bacterium isolated from microbial mats at a terrestrial hot spring and proposal of Ignavibacteria classis nov., for a novel lineage at the periphery of green sulf. Int. J. Syst. Evol. Microbiol. 60, 1376-1382. doi: 10.1099/ijs.0.012484-0

Ilardi, P., Fernández, J., and Avendaño-Herrera, R. (2009). Chryseobacterium piscicola sp. nov., isolated from diseased salmonid fish. Int. J. Syst. Evol. Microbiol. 59, 3001-3005. doi: 10.1099/ijs.0.007021-0

Imhoff, J. F. (2003). Phylogenetic taxonomy of the family Chlorobiaceae on the basis of $16 \mathrm{~S}$ rRNA and fmo (Fenna-Matthews-Olson protein) gene sequences. Int. J. Syst. Evol. Microbiol. 53, 941-951. doi: 10.1099/ijs.0.02403-0

Ivanova, E. P., Bowman, J. P., Christen, R., Zhukova, N. V., Lysenko, A. M., Gorshkova, N. M., et al. (2006). Salegentibacter flavus sp. nov. Int. J. Syst. Evol. Microbiol. 56, 583-586. doi: 10.1099/ijs.0.64087-0

Jabari, L., Gannoun, H., Cayol, J. L., Hedi, A., Sakamoto, M., Falsen, E., et al. (2012). Macellibacteroides fermentans gen. nov., sp. nov., a member of the family Porphyromonadaceae isolated from an upflow anaerobic filter treating abattoir wastewaters. Int. J. Syst. Evol. Microbiol. 62, 2522-2527. doi: 10.1099/ijs.0.032508-0

Jeffroy, O., Brinkmann, H., Delsuc, F., and Philippe, H. (2006). Phylogenomics: the beginning of incongruence? Trends Genet. 22, 225-231. doi: 10.1016/j.tig.2006. 02.003

Johansen, J. E., Nielsen, P., and Sjoholm, C. (1999). Description of Cellulophaga baltica gen. nov., sp. nov. and Cellulophaga fucicola gen. nov., sp. nov. and reclassification of [Cytophaga] lytica to Cellulophaga lytica gen. nov., comb. nov. Int. J. Syst. Bacteriol. 49, 1231-1240.

Johnson, J. L., Moore, W. E. C., and Moore, L. V. H. (1986). Bacteroides caccae sp. nov., Bacteroides merdae sp. nov., and Bacteroides stercoris sp. nov. isolated from human feces. Int. J. Syst. Bacteriol. 36, 499-501.

Kämpfer, P., Busse, H. J., McInroy, J. A., and Glaeser, S. P. (2015). Elizabethkingia endophytica sp. nov., isolated from Zea mays and emended description of Elizabethkingia anophelis Kämpfer et al. 2011. Int. J. Syst. Evol. Microbiol. 65, 2187-2193. doi: 10.1099/ijs.0.000236

Kämpfer, P., Dreyer, U., Neef, A., Dott, W., and Busse, H. J. (2003). Chryseobacterium defluvii sp. nov., isolated from wastewater. Int. J. Syst. Evol. Microbiol. 53, 93-97. doi: 10.1099/ijs.0.02073-0

Kämpfer, P., Fallschissel, K., and Avendaño-Herrera, R. (2011). Chryseobacterium chaponense sp. nov., isolated from farmed Atlantic salmon (Salmo salar). Int. J. Syst. Evol. Microbiol. 61, 497-501. doi: 10.1099/ijs.0.022004-0

Kämpfer, P., Lodders, N., Veneechoutte, M., and Wauters, G. (2009a). Transfer of Sejongia antarctica, Sejongia jeonii and Sejongia marina to the genus Chryseobacterium as Chryseobacterium antarcticum comb. nov., Chryseobacterium jeonii comb. nov. and Chryseobacterium marinum comb. nov. Int. J. Syst. Evol. Microbiol. 59, 2238-2240. doi: 10.1099/ijs.0.009142-0

Kämpfer, P., Poppel, M. T., Wilharm, G., Busse, H. J., McInroy, J. A., and Glaeser, S. P. (2014). Chryseobacterium gallinarum sp. nov., isolated from a chicken, and Chryseobacterium contaminans sp. nov., isolated as a contaminant from a rhizosphere sample. Int. J. Syst. Evol. Microbiol. 64, 1419-1427. doi: 10.1099/ijs.0.058933-0

Kämpfer, P., Vaneechoutte, M., Lodders, N., De Baere, T., Avesani, V., Janssens, M., et al. (2009b). Description of Chryseobacterium anthropi sp. nov. to accommodate clinical isolates biochemically similar to Kaistella koreensis and Chryseobacterium haifense, proposal to reclassify Kaistella koreensis as Chryseobacterium koreense comb. nov. and emended description of the genus Chryseobacterium. Int. J. Syst. Evol. Microbiol. 59, 2421-2428. doi: 10.1099/ijs.0.008250-0

Kämpfer, P., Young, C. C., Sridhar, K. R., Arun, A. B., Lai, W. A., Shen, F. T., et al. (2006). Transfer of [Flexibacter] sancti, [Flexibacter] filiformis, [Flexibacter] japonensis and [Cytophaga] arvensicola to the genus Chitinophaga 
and description of Chitinophaga skermanii sp. nov. Int. J. Syst. Evol. Microbiol. 56, 2223-2228. doi: 10.1099/ijs.0.64359-0

Khan, S. T., Fukunaga, Y., Nakagawa, Y., and Harayama, S. (2007). Emended descriptions of the genus Lewinella and of Lewinella cohaerens, Lewinella nigricans and Lewinella persica, and description of Lewinella lutea sp. nov. and Lewinella marina sp. nov. Int. J. Syst. Evol. Microbiol. 57, 2946-2951. doi: $10.1099 /$ ijs.0.65308-0

Kim, B. C., Oh, H. W., Kim, H., Park, D.-S. S., Hong, S. G., Lee, H. K., et al. (2013). Polaribacter sejongensis sp. nov., isolated from Antarctic soil, and emended descriptions of the genus Polaribacter, Polaribacter butkevichii and Polaribacter irgensii. Int. J. Syst. Evol. Microbiol. 63, 4000-4005. doi: 10.1099/ijs.0.047100-0

Kim, B. S., Kim, O. S., Moon, E. Y., and Chun, J. (2010). Vitellibacter aestuarii sp. nov., isolated from tidalflat sediment, and an emended description of the genus Vitellibacter. Int. J. Syst. Evol. Microbiol. 60, 1989-1992. doi: 10.1099/ijs.0.019034-0

Kim, B. Y., Weon, H. Y., Yoo, S. H., Hong, S. B., Kwon, S. W., Stackebrandt, E., et al. (2007). Niabella aurantiaca gen. nov., sp. nov., isolated from a greenhouse soil in Korea. Int. J. Syst. Evol. Microbiol. 57, 538-541. doi: 10.1099/ijs.0.64614-0

Kim, K. K., Bae, H.-S., Schumann, P., and Lee, S.-T. (2005). Chryseobacterium daecheongense sp. nov., isolated from freshwater lake sediment. Int. J. Syst. Evol. Microbiol. 55, 133-138. doi: 10.1099/ijs.0.02931-0

Kim, K. K., Lee, K. C., Oh, H. M., and Lee, J. S. (2008). Chryseobacterium aquaticum sp. nov., isolated from a water reservoir. Int. J. Syst. Evol. Microbiol. 58, 533-537. doi: 10.1099/ijs.0.65491-0

Kirchman, D. L. (2002). The ecology of Cytophaga-Flavobacteria in aquatic environments. FEMS Microbiol. Ecol. 39, 91-100. doi: 10.1111/j.1574-6941. 2002.tb00910.x

Klenk, H.-P., and Göker, M. (2010). En route to a genome-based classification of Archaea and Bacteria? Syst. Appl. Microbiol. 33, 175-182. doi: 10.1016/j.syapm.2010.03.003

Könönen, E., Eerola, E., Frandsen, E. V., Jalava, J., Mättö, J., Salmenlinna, S., et al. (1998). Phylogenetic characterization and proposal of a new pigmented species to the genus Prevotella: Prevotella pallens sp. nov. Int. J. Syst. Bacteriol. 48( $\mathrm{Pt} 1)$, 47-51. doi: 10.1099/00207713-48-1-47

Krieg, N. R., Ludwig, W., Euzéby, J., and Whitman, W. B. (2010). "Phylum XIV. Bacteroidetes phyl. nov.," in in Bergey's Manual of Systematic Bacteriology, Vol. 4, 2nd Edn., The Bacteroidetes, Spirochaetes, Tenericutes (Mollicutes), Acidobacteria, Fibrobacteres, Fusobacteria, Dictyoglomi, Gemmatimonadetes, Lentisphaerae, Verrucomicrobia, Chlamydiae, and Planctomycetes, eds N. R. Krieg, J. T. Staley, D. R. Brown, B. P. Hedlund, B. J. Paster, N. L. Ward, et al. (New York, NY: Springer), 25-469.

Krieg, N. R., Staley, J. T., Brown, D. R., Hedlund, B. P., Paster, B. J., Ward, N. L., et al. (2012). "Family III. Saprospiraceae fam. nov.", in Bergey's Manual of Systematic Bacteriology, Vol. 4, 2nd Edn., The Bacteroidetes, Spirochaetes, Tenericutes (Mollicutes), Acidobacteria, Fibrobacteres, Fusobacteria, Dictyoglomi, Gemmatimonadetes, Lentisphaerae, Verrucomicrobia, Chlamydiae, and Planctomycetes, eds N. R. Krieg, J. T. Staley, D. R. Brown, B. P. Hedlund, B. J. Paster, N. L. Ward, et al. (New York, NY: Springer), 358.

Kumar, P. A., Srinivas, T. N. R., Madhu, S., Manorama, R., and Shivaji, S. (2010). Alkaliphilic bacterium isolated from a haloalkaline lake. Int. J. Syst. Evol. Microbiol. 60, 721-726. doi: 10.1099/ijs.0.014076-0

Kwon, Y. M., Yang, S. H., Kwon, K. K., and Kim, S. J. (2014). Nonlabens antarcticus sp. nov., a psychrophilic bacterium isolated from glacier ice, and emended descriptions of Nonlabens marinus Park et al. 2012 and Nonlabens agnitus Yi and Chun 2012. Int. J. Syst. Evol. Microbiol. 64, 400-405. doi: 10.1099/ijs.0.056606-0

Kyrpides, N. C., Hugenholtz, P., Eisen, J. A., Woyke, T., Göker, M., Parker, C. T., et al. (2014). Genomic encyclopedia of bacteria and archaea: sequencing a myriad of type strains. PLoS Biol. 12:e1001920. doi: 10.1371/journal.pbio.1001920

Lail, K., Sikorski, J., Saunders, E., Lapidus, A., Glavina Del Rio, T., Copeland, A., et al. (2010). Complete genome sequence of Spirosoma linguale type strain (1). Stand. Genomic Sci. 2, 176-185. doi: 10.4056/sigs.741334

Land, M., Held, B., Gronow, S., Abt, B., Lucas, S., Del Rio, T. G., et al. (2011). Non-contiguous finished genome sequence of Bacteroides coprosuis type strain $\left(\mathrm{PC}_{139}{ }^{\mathrm{T}}\right)$. Stand. Genomic Sci. 4, 233-243. doi: 10.4056/sigs.1784330
Lang, E., Lapidus, A., Chertkov, O., Brettin, T., Detter, J. J. C., Han, C., et al. (2009). Complete genome sequence of Dyadobacter fermentans type strain $\left(\mathrm{NS}_{11} 4^{\mathrm{T}}\right)$. Stand. Genomic Sci. 1, 133-140. doi: 10.4056/sigs. 19262

Lang, E., Teshima, H., Lucas, S., Lapidus, A., Hammon, N., Deshpande, S., et al. (2011). Complete genome sequence of Weeksella virosa type strain $\left(9751^{\mathrm{T}}\right)$. Stand. Genomic Sci. 4, 81-90. doi: 10.4056/sigs.1603927

Larkin, J. M., and Williams, P. M. (1978). Runella slithyfurmis gen. nov., sp. nov., a curved, nonflexible, pink bacterium. Int. J. Syst. Bacteriol. 28, 32-36. doi: 10.1099/00207713-28-1-32

Larkin, J. M., Williams, P. M., and Taylor, R. (1977). Taxonomy of the genus Microcyclus Ørskov 1928: reintroduction and emendation of the genus Spirosoma Migula 1894 and proposal of a new genus, Flectobacillus. Int. J. Syst. Bacteriol. 27, 147-156. doi: 10.1099/00207713-27-2-147

Lau, S. C. K., Tsoi, M. M. Y., Li, X., Plakhotnikova, I., Dobretsov, S., Wu, M., et al. (2006). Description of Fabibacter halotolerans gen. nov., sp. nov. and Roseivirga spongicola sp. nov., and reclassification of [Marinicola] seohaensis as Roseivirga seohaensis comb. nov. Int. J. Syst. Evol. Microbiol. 56, 1059-1065. doi: 10.1099/ijs.0.64104-0

Lawson, P. A., Falsen, E., Inganäs, E., Weyant, R. S., and Collins, M. D. (2002). Dysgonomonas mossii sp. nov., from human sources. Syst. Appl. Microbiol. 25, 194-197. doi: 10.1078/0723-2020-00107

Lawson, P. A., Moore, E., and Falsen, E. (2008). Prevotella amnii sp. nov., isolated from human amniotic fluid. Int. J. Syst. Evol. Microbiol. 58, 89-92. doi: $10.1099 /$ ijs. $0.65118-0$

Leadbetter, E. R., Holt, S. C., and Socransky, S. S. (1979). Capnocytophaga: new genus of gram-negative gliding bacteria I. General characteristics, taxonomic considerations and significance. Arch. Microbiol. 122, 9-16. doi: 10.1007/BF00408040

Lee, C., Grasso, C., and Sharlow, M. F. (2002). Multiple sequence alignment using partial order graphs. Bioinformatics 18, 452-464. doi: 10.1093/bioinformatics/18.3.452

Lee, H. J., Jeong, S. E., Cho, M. S., Kim, S., Lee, S. S., Lee, B. H., et al. (2014). Flavihumibacter solisilvae sp. nov., isolated from forest soil. Int. J. Syst. Evol. Microbiol. 64, 2897-2901. doi: 10.1099/ijs.0.063669-0

Lee, H. S., Kwon, K. K., Yang, S. H., Bae, S. S., Park, C. H., Kim, S. J., et al. (2008). Description of Croceitalea gen. nov. in the family Flavobacteriaceae with two species, Croceitalea eckloniae sp. nov. and Croceitalea dokdonensis sp. nov., isolated from the rhizosphere of the marine alga Ecklonia kurome. Int. J. Syst. Evol. Microbiol. 58, 2505-2510. doi: 10.1099/ijs.0.65697-0

Lefort, V., Desper, R., and Gascuel, O. (2015). FastME 2.0: a comprehensive, accurate, and fast distance-based phylogeny inference program. Mol. Biol. Evol. 32, 2798-2800. doi: 10.1093/molbev/msv150

Letunic, I., and Bork, P. (2011). Interactive Tree Of Life v2: online annotation and display of phylogenetic trees made easy. Nucleic Acids Res. 39, W475-W478. doi: 10.1093/nar/gkr201

Lewin, R. A. (1974). Flexibacter polymorphus, a new marine species. J. Gen. Microbiol. 82, 393-403.

Lewin, R. A. A. (1969). A classification of Flexibacteria. J. Gen. Microbiol. 58, 189-206. doi: 10.1099/00221287-58-2-189

Ley, R. E., Hamady, M., Lozupone, C., Turnbaugh, P., Ramey, R. R., Bircher, J. S., et al. (2009). Evolution of mammals and their gut microbes. Science 320, 1647-1651. doi: 10.1126/science. 1155725

Li, Y., Kawamura, Y., Fujiwara, N., Naka, T., Liu, H., Huang, X., et al. (2003). Chryseobacterium miricola sp. nov., a novel species isolated from condensation water of space station Mir. Syst. Appl. Microbiol. 26, 523-528. doi: $10.1078 / 072320203770865828$

Lienau, E. K., and DeSalle, R. (2009). Evidence, content and corroboration and the tree of life. Acta Biotheor. 57, 187-199. doi: 10.1007/s10441-008-9066-5

Lin, C.-Y., Zhang, X.-Y., Liu, A., Liu, C., Song, X.-Y., Su, H.-N., et al. (2015). Marivirga atlantica sp. nov., isolated from seawater and emended description of the genus Marivirga. Int. J. Syst. Evol. Microbiol. 65, 1515-1519. doi: 10.1099/ijs.0.000126

Lin, S. -Y., Hameed, A., Wen, C. Z., Liu, Y. C., Hsu, Y. H., Shen, F. T., et al. (2015). Vitellibacter echinoideorum sp. nov., isolated from a sea urchin (Tripneustes gratilla). Int. J. Syst. Evol. Microbiol. 65, 2320-2325. doi: 10.1099/ijs.0.000258

Liu, J. J., Zhang, X. Q., Pan, J., Sun, C., Zhang, Y., Li, C. Q., et al. (2013). Aequorivita viscosa sp. nov., isolated from an intertidal zone, and emended 
descriptions of Aequorivita antarctica and Aequorivita capsosiphonis. Int. J. Syst. Evol. Microbiol. 63, 3192-3196. doi: 10.1099/ijs.0.049635-0

Liu, L., Li, Y., Li, S., Hu, N., He, Y., Pong, R., et al. (2012). Comparison of next-generation sequencing systems. J. Biomed. Biotechnol. 2012:251364. doi: $10.1155 / 2012 / 251364$

Liu, Q. M., Im, W. T., Lee, M., Yang, D. C., and Lee, S. T. (2006). Dyadobacter ginsengisoli sp. nov., isolated from soil of a ginseng field. Int. J. Syst. Evol. Microbiol. 56, 1939-1944. doi: 10.1099/ijs.0.64322-0

Liu, X.-Z., Wang, Q.-M., Göker, M., Groenewald, M., Kachalkin, A. V., Lumbsch, H. T., et al. (2015). Towards an integrated phylogenetic classification of the Tremellomycetes. Stud. Mycol. 81, 85-147. doi: 10.1016/j.simyco.2015.12.001

London, J., Celesk, R. A., Kagermeier, A., and Johnson, J. L. (1985). Emended description of Capnocytophaga gingivalis. Int. J. Syst. Bacteriol. 35, 369-370. doi: 10.1099/00207713-35-3-369

Loveland-Curtze, J., Miteva, V., and Brenchley, J. (2009). Novel ultramicrobacterial isolates from a deep Greenland ice core represent a proposed new species, Chryseobacterium greenlandense sp. nov. Extremophiles 14, 61-69. doi: 10.1007/s00792-009-0287-6

Ludwig, W., Euzeby, J., and Whitman, W. B. (2012). "Family I. Rhodothermaceae fam. nov.", in Bergey's Manual of Systematic Bacteriology, Vol. 4, 2nd Edn., The Bacteroidetes, Spirochaetes, Tenericutes (Mollicutes), Acidobacteria, Fibrobacteres, Fusobacteria, Dictyoglomi, Gemmatimonadetes, Lentisphaerae, Verrucomicrobia, Chlamydiae, and Planctomycetes, eds N. R. Krieg, J. T. Staley, D. R. Brown, B. P. Hedlund, B. J. Paster, N. L. Ward, et al. (New York, NY: Springer), 457

Macián, M. C., Pujalte, M. J., Márquez, M. C., Ludwig, W., Ventosa, A., Garay, E., et al. (2002). Gelidibacter mesophilus sp. nov., a novel marine bacterium in the family Flavobacteriaceae. Int. J. Syst. Evol. Microbiol. 52, 1325-1329. doi: 10.1099/00207713-52-4-1325

Makhdoumi-Kakhki, A., Amoozegar, M. A., and Ventosa, A. (2012). Salinibacter iranicus sp. nov. and Salinibacter luteus sp. nov., isolated from a salt lake, and emended descriptions of the genus Salinibacter and of Salinibacter ruber. Int. J. Syst. Evol. Microbiol. 62, 1521-1527. doi: 10.1099/ijs.0.031971-0

Manz, W., Amann, R., Ludwig, W., Vancanneyt, M., and Schleifer, K. H. (1996). Application of a suite of $16 \mathrm{~S}$ rRNA-specific oligonucleotide probes designed to investigate bacteria of the phylum cytophaga-flavobacterbacteroides in the natural environment. Microbiology 142, 1097-1106. doi: 10.1099/13500872-142-5-1097

Markowitz, V. M., Mavromatis, K., Ivanova, N. N., Chen, I.-M. A., Chu, K., and Kyrpides, N. C. (2009). IMG ER: a system for microbial genome annotation expert review and curation. Bioinformatics 25, 2271-2278. doi: 10.1093/bioinformatics/btp393

Marteinsson, V. T., Bjornsdottir, S. H., Bienvenu, N., Kristjansson, J. K., and Birrien, J. L. (2010). Rhodothermus profundi sp. nov., a thermophilic bacterium isolated from a deep-sea hydrothermal vent in the Pacific Ocean. Int. J. Syst. Evol. Microbiol. 60, 2729-2734. doi: 10.1099/ijs.0.012724-0

Martens, E. C., Koropatkin, N. M., Smith, T. J., and Gordon, J. I. (2009). Complex glycan catabolism by the human gut microbiota: the Bacteroidetes Sus-like paradigm. J. Biol. Chem. 284, 24673-24677. doi: 10.1074/jbc.R109.022848

Mavromatis, K., Land, M. L., Brettin, T. S., Quest, D. J., Copeland, A., Clum, A., et al. (2012). The fast changing landscape of sequencing technologies and their impact on microbial genome assemblies and annotation. PLOS ONE 7:e48837. doi: 10.1371/journal.pone.0048837

Mayberry, W. R. (1980). Hydrooxy fatty acids in bacteroides species: d-(-)-3 hydroxy-15-methylhexadecanoate and its homologs. J. Gen. Bact. 143, 582-587.

McBride, M. J., and Zhu, Y. (2013). Gliding motility and Por secretion system genes are widespread among members of the phylum Bacteroidetes. J. Bacteriol. 195, 270-278. doi: 10.1128/JB.01962-12

Meier-Kolthoff, J. P., Auch, A. F., Klenk, H.-P., and Göker, M. (2013a). Genome sequence-based species delimitation with confidence intervals and improved distance functions. BMC Bioinformatics 14:60. doi: 10.1186/1471-2105-14-60

Meier-Kolthoff, J. P., Auch, A. F., Klenk, H.-P., and Göker, M. (2014a). Highly parallelized inference of large genome-based phylogenies. Concurr. Comput. Pract. Exp. 26, 1715-1729. doi: 10.1002/cpe.3112

Meier-Kolthoff, J. P., Göker, M., Spröer, C., and Klenk, H.-P. (2013b). When should a DDH experiment be mandatory in microbial taxonomy? Arch. Microbiol. 195, 413-418. doi: 10.1007/s00203-013-0888-4
Meier-Kolthoff, J. P., Hahnke, R. L., Petersen, J., Scheuner, C., Michael, V., Fiebig, A., et al. (2014b). Complete genome sequence of DSM $30083^{\mathrm{T}}$, the type strain $\left(\mathrm{U} 5 / 41^{\mathrm{T}}\right)$ of Escherichia coli, and a proposal for delineating subspecies in microbial taxonomy. Stand. Genomic Sci. 9:2. doi: 10.1186/1944-3277-9-2

Meier-Kolthoff, J. P., Klenk, H.-P., and Göker, M. (2014c). Taxonomic use of DNA $\mathrm{G}+\mathrm{C}$ content and DNA-DNA hybridization in the genomic age. Int. J. Syst. Evol. Microbiol. 64, 352-356. doi: 10.1099/ijs.0.056994-0

Mesbah, M., Premachandran, U., and Whitman, W. B. (1989). Precise measurement of the $\mathrm{G}+\mathrm{C}$ content of deoxyribonucleic acid by highperformance liquid chromatography. Int. J. Syst. Bacteriol. 39, 159-167. doi: 10.1099/00207713-39-2-159

Migula, W. (1894). "Über ein neues System der Bakterien," in Arbeiten aus dem Bakteriologischen Institut der Technischen Hochschule zu Karlsruhe (Karlsruhe: Nemnich), 235-238.

Montero-Calasanz, M., Göker, M., Rohde, M., Spröer, C., Schumann, P., Busse, H.-J., et al. (2014). Chryseobacterium oleae sp. nov., an efficient plant growth promoting bacterium in the rooting induction of olive tree (Olea europaea L.) cuttings and emended descriptions of the genus Chryseobacterium, C. daecheongense, C. gambrini. Syst. Appl. Microbiol. 37, 342-350. doi: 10.1016/j.syapm.2014.04.004

Moore, L. V. H., and Moore, W. E. C. (1994). Oribaculum catoniae gen. nov., sp. nov.; Catonella morbi gen. nov., sp. nov.; Hallella seregens gen. nov., sp. nov.; Johnsonella ignava gen. nov., sp. nov.; and Dialister pneumosintes gen. nov., comb. nov., nom. rev., Anaerobic Gram-Negative Bacilli from the Human Gingival Crevice. An. Int. J. Syst. Bacteriol. J. 44, 187-192. doi: 10.1099/00207713-44-2-187

Moreira, A. P. B., Pereira, N. Jr., and Thompson, F. L. (2011). Usefulness of a real-time PCR platform for $\mathrm{G}+\mathrm{C}$ content and DNA-DNA hybridization estimations in vibrios. Int. J. Syst. Evol. Microbiol. 61, 2379-2383. doi: 10.1099/ijs.0.023606-0

Morotomi, M., Nagai, F., Sakon, H., and Tanaka, R. (2008). Dialister succinatiphilus sp. nov. and Barnesiella intestinihominis sp. nov., isolated from human faeces. Int. J. Syst. Evol. Microbiol. 58, 2716-2720. doi: 10.1099/ijs.0.2008/000810-0

Munoz, R., Rosselló-Móra, R., and Amann, R. (2016). Revised phylogeny of Bacteroidetes and proposal of sixteen new taxa and two new combinations including Rhodothermaeota phyl. nov. Syst. Appl. Microbiol. 39, 281-296. doi: 10.1016/j.syapm.2016.04.004

Nagai, F., Morotomi, M., Watanabe, Y., Sakon, H., and Tanaka, R. (2010). Alistipes indistinctus sp. nov. and Odoribacter laneus sp. nov., common members of the human intestinal microbiota isolated from faeces. Int. J. Syst. Evol. Microbiol. 60, 1296-1302. doi: 10.1099/ijs.0.014571-0

Nakagawa, Y. (2011a). "Class IV. Cytophagia class. nov."” in Bergey's Manual of Systematic Bacteriology, Vol. 4, 2nd Edn., The Bacteroidetes, Spirochaetes, Tenericutes (Mollicutes), Acidobacteria, Fibrobacteres, Fusobacteria, Dictyoglomi, Gemmatimonadetes, Lentisphaerae, Verrucomicrobia, Chlamydiae, and Planctomycetes, eds N. R. Krieg, J. T. Staley, D. R. Brown, B. P. Hedlund, B. J. Paster, N. L. Ward et al., (New York, NY: Springer), 370.

Nakagawa, Y. (2011b). "Family I. Cytophagaceae Stanier 1940, 630AL," in Bergey's Manual of Systematic Bacteriology, Vol. 4, 2nd Edn., The Bacteroidetes, Spirochaetes, Tenericutes (Mollicutes), Acidobacteria, Fibrobacteres, Fusobacteria, Dictyoglomi, Gemmatimonadetes, Lentisphaerae, Verrucomicrobia, Chlamydiae, and Planctomycetes, eds N. R. Krieg, J. T. Staley, D. R. Brown, B. P. Hedlund, B. J. Paster, N. L. Ward et al., (New York, NY: Springer), 371.

Nakagawa, Y. (2011c). "Genus VIII. Flexibacter Soriano 1945, 92AL," in Bergey's Manual of Systematic Bacteriology, Vol. 4, 2nd Edn., The Bacteroidetes, Spirochaetes, Tenericutes (Mollicutes), Acidobacteria, Fibrobacteres, Fusobacteria, Dictyoglomi, Gemmatimonadetes, Lentisphaerae, Verrucomicrobia, Chlamydiae, and Planctomycetes, eds N. R. Krieg, J. T. Staley, D. R. Brown, B. P. Hedlund, B. J. Paster, N. L. Ward et al., (New York, NY: Springer), 392-397.

Nakagawa, Y., Sakane, T., Suzuki, M., and Hatano, K. (2002). Phylogenetic structure of the genera Flexibacter, Flexithrix, and Microscilla deduced from 16S rRNA sequence analysis. J. Gen. Appl. Microbiol. 48, 155-165. doi: 10.2323/jgam.48.155

Nedashkovskaya, O. I., Kim, S. B., Hoste, B., Shin, D. S., Beleneva, I. A., Vancanneyt, M., et al. (2007a). Echinicola vietnamensis sp. nov., a member of 
the phylum Bacteroidetes isolated from seawater. Int. J. Syst. Evol. Microbiol. 57, 761-763. doi: 10.1099/ijs.0.64546-0

Nedashkovskaya, O. I., Kim, S. B., Lee, M. S., Park, M. S., Lee, K. H., Lysenko, A. M., et al. (2005a). Cyclobacterium amurskyense sp. nov., a novel marine bacterium isolated from sea water. Int. J. Syst. Evol. Microbiol. 55, 2391-2394. doi: 10.1099/ijs.0.63781-0

Nedashkovskaya, O. I., Kim, S. B., Lysenko, A. M., Kalinovskaya, N. I., and Mikhailov, V. V. (2008). Reclassification of Roseivirga seohaensis (Yoon et al. 2005) Lau et al. 2006 as a later synonym of Roseivirga ehrenbergii Nedashkovskaya et al. 2005 and emendation of the species description. Int. J. Syst. Evol. Microbiol. 58, 1194-1197. doi: 10.1099/ijs.0.65686-0

Nedashkovskaya, O. I., Kim, S. B., Lysenko, A. M., Park, M. S., Mikhailov, V. V., Bae, K. S., et al. (2005b). Roseivirga echinicomitans sp. nov., a novel marine bacterium isolated from the sea urchin Strongylocentrotus intermedius, and emended description of the genus Roseivirga. Int. J. Syst. Evol. Microbiol. 55, 1797-1800. doi: 10.1099/ijs.0.63621-0

Nedashkovskaya, O. I., Kim, S. B., Suzuki, M., Shevchenko, L. S., Lee, M. S., Lee, K. H., et al. (2005c). Pontibacter actiniarum gen. nov., sp. nov., a novel member of the phylum "Bacteroidetes", and proposal of Reichenbachiella gen. nov. as a replacement for the illegitimate prokaryotic generic name Reichenbachia Nedashkovskaya et al. 2003. Int. J. Syst. Evol. Microbiol. 55, 2583-2588. doi: 10.1099/ijs.0.63819-0

Nedashkovskaya, O. I., Kim, S. B., Vancanneyt, M., Lysenko, A. M., Shin, D. S., Park, M. S., et al. (2006a). Echinicola pacifica gen. nov., sp. nov., a novel Flexibacterium isolated from the sea urchin Strongylocentrotus intermedius. Int. J. Syst. Evol. Microbiol. 56, 953-958. doi: 10.1099/ijs.0.64156-0

Nedashkovskaya, O. I., Kim, S. B., Vancanneyt, M., Snauwaert, C., Lysenko, A. M., Rohde, M., et al. (2006b). Formosa agariphila sp. nov., a budding bacterium of the family Flavobacteriaceae isolated from marine environments, and emended description of the genus Formosa. Int. J. Syst. Evol. Microbiol. 56, 161-167. doi: 10.1099/ijs.0.63875-0

Nedashkovskaya, O. I., Kim, S. J. S. B., Kwon, K. K., Shin, D. S., Luo, X., Kim, S. J. S. B., et al. (2007b). Proposal of Algoriphagus vanfongensis sp. nov., transfer of members of the genera Hongiella Yi and Chun 2004 emend. Nedashkovskaya et al. 2004 and Chimaereicella Tiago et al. 2006 to the genus Algoriphagus, and emended description of the genus Algoriphagus Bowman et al. 2003 emend. Nedashkovskaya et al. 2004. Int. J. Syst. Evol. Microbiol. 57, 1988-1994. doi: 10.1099/ijs.0.65073-0

Nedashkovskaya, O. I., Suzuki, M., Vysotskii, M. V., and Mikhailov, V. V. (2003). Vitellibacter vladivostokensis gen. nov., sp. nov., a new member of the phylum Cytophaga-Flavobacterium-Bacteroides. Int. J. Syst. Evol. Microbiol. 53, 1281-1286. doi: 10.1099/ijs.0.02302-0

Nedashkovskaya, O. I., Vancanneyt, M., Cleenwerck, I., Snauwaert, C., Kim, S. B., Lysenko, A. M., et al. (2006c). Arenibacter palladensis sp. nov., a novel marine bacterium isolated from the green alga Ulva fenestrata, and emended description of the genus Arenibacter. Int. J. Syst. Evol. Microbiol. 56, 155-160. doi: 10.1099/ijs.0.63893-0

Nedashkovskaya, O. I., Vancanneyt, M., Kim, S. B., and Bae, K. S. (2010). Reclassification of Flexibacter tractuosus (Lewin 1969) Leadbetter 1974 and "Microscilla sericea" Lewin 1969 in the genus Marivirga gen. nov. as Marivirga tractuosa comb. nov. and Marivirga sericea nom. rev., comb. nov. Int. J. Syst. Evol. Microbiol. 60, 1858-1863. doi: 10.1099/ijs.0.016121-0

Nelson-Sathi, S., Sousa, F. L., Roettger, M., Lozada-Chávez, N., Thiergart, T., Janssen, A., et al. (2015). Origins of major archaeal clades correspond to gene acquisitions from bacteria. Nature 517, 77-80. doi: 10.1038/nature13805

Nishiyama, T., Ueki, A., Kaku, N., Watanabe, K., and Ueki, K. (2009). Bacteroides graminisolvens sp. nov., a xylanolytic anaerobe isolated from a methanogenic reactor treating cattle waste. Int. J. Syst. Evol. Microbiol. 59, 1901-1907. doi: 10.1099/ijs.0.008268-0

Nolan, M., Tindall, B. J., Pomrenke, H., Lapidus, A., Copeland, A., Glavina Del Rio, T., et al. (2009). Complete genome sequence of Rhodothermus marinus type strain (R-10). Stand. Genomic Sci. 1, 283-290. doi: 10.4056/sigs.46736

O'Sullivan, L. A., Rinna, J., Humphreys, G., Weightman, A. J., and Fry, J. C. (2006). Culturable phylogenetic diversity of the phylum "Bacteroidetes" from river epilithon and coastal water and description of novel members of the family Flavobacteriaceae: Epilithonimonas tenax gen. nov., sp. nov. and Persicivirga xylanidelens gen. nov., sp. Int. J. Syst. Evol. Microbiol. 56, 169-180. doi: 10.1099/ijs.0.63941-0
Oren, A. (2002). Molecular ecology of extremely halophilic Archaea and Bacteria FEMS Microbiol. Ecol. 39, 1-7. doi: 10.1016/S0168-6496(01)00200-8

Oren, A. (2008). Microbial life at high salt concentrations: phylogenetic and metabolic diversity. Saline Syst. 4:2. doi: 10.1186/1746-1448-4-2

Oren, A., Da Costa, M. S., Garrity, G. M., Rainey, F. A., Rosselló-Móra, R., Schink, B., et al. (2015). Proposal to include the rank of phylum in the international code of nomenclature of prokaryotes. Int. J. Syst. Evol. Microbiol. 65, 4284-4287. doi: 10.1099/ijsem.0.000664

Pankratov, T. A., Tindall, B. J., Liesack, W., and Dedysh, S. N. (2007). Mucilaginibacter paludis gen. nov., sp. nov. and Mucilaginibacter gracilis sp. nov., pectin-, xylan and laminarin-degrading members of the family Sphingobacteriaceae from acidic Sphagnum peat bog. Int. J. Syst. Evol. Microbiol. 57, 2349-2354. doi: 10.1099/ijs.0.65100-0

Panschin, I., Huang, S., Meier-kolthoff, J. P., Tindall, B. J., Rohde, M., Verbarg, S., et al. (2016). Comparing polysaccharide decomposition between the type strains Gramella echinicola KMM $6050^{\mathrm{T}}$ (DSM $19838^{\mathrm{T}}$ ) and Gramella portivictoriae UST040801-001 ${ }^{\mathrm{T}}$ (DSM $23547^{\mathrm{T}}$ ), and emended description of Gramella echinicola Nedashkovskaya et al. 2005 emend. Shahina et al. 2014 and Gramella portivictoriae Lau et al. 2005. Stand. Genomic Sci. 11, 1-16. doi: 10.1186/s40793-016-0163-9

Park, M. S., Jung, S. R., Lee, K. H., Lee, M. S., Do, J. O., Kim, S. B., et al. (2006). Chryseobacterium soldanellicola sp. nov. and Chryseobacterium taeanense sp. nov., isolated from roots of sand-dune plants. Int. J. Syst. Evol. Microbiol. 56, 433-438. doi: 10.1099/ijs.0.63825-0

Park, S. C., Baik, K. S., Kim, M. S., Kim, S. S., Kim, S. R., Oh, M. J., et al. (2009). Aequorivita capsosiphonis sp. nov., isolated from the green alga Capsosiphon fulvescens, and emended description of the genus Aequorivita. Int. J. Syst. Evol. Microbiol. 59, 724-728. doi: 10.1099/ijs.0.004119-0

Park, S., Lee, K. C., Bae, K. S., and Yoon, J. H. (2014). Vitellibacter soesokkakensis sp. nov., isolated from the junction between the ocean and a freshwater spring and emended description of the genus Vitellibacter. Int. J. Syst. Evol. Microbiol. 64, 588-593. doi: 10.1099/ijs.0.056713-0

Park, S., Song, J., Yoshizawa, S., Choi, A., Cho, J. C., and Kogure, K. (2013). Rubrivirga marina gen. nov., sp. nov., a member of the family Rhodothermaceae isolated from deep seawater. Int. J. Syst. Evol. Microbiol. 63, 2229-2233. doi: 10.1099/ijs.0.046318-0

Park, S., Yoshizawa, S., Kogure, K., and Yokota, A. (2011). Rubricoccus marinus gen. nov., sp. nov., of the family "Rhodothermaceae", isolated from seawater. Int. J. Syst. Evol. Microbiol. 61, 2069-2072. doi: 10.1099/ijs.0. 026294-0

Paster, B. J., Dewhirst, F. E., Olsen, I., and Fraser, G. J. (1994). Phylogeny of Bacteroides, Prevotella, and Porphyromonas spp. and related bacteria. J. Bacteriol. 176, 725-732.

Paster, B. J., Ludwig, W., Weisburg, W. G., Stackebrandt, E., Hespell, R. B., Hahn, C. M., et al. (1985). A phylogenetic grouping of the Bacteroides, Cytophagas, and certain Flavobacteria. Syst. Appl. Microbiol. 6, 34-42. doi: 10.1016/S0723-2020(85)80008-4

Pati, A., Abt, B., Teshima, H., Nolan, M., Lapidus, A., Lucas, S., et al. (2011a). Complete genome sequence of Cellulophaga lytica type strain (LIM-21). Stand. Genomic Sci. 4, 221-232. doi: 10.4056/sigs. 1774329

Pati, A., Gronow, S., Lu, M., Lapidus, A., Nolan, M., Lucas, S., et al. (2011b). Non-contiguous finished genome sequence of the opportunistic oral pathogen Prevotella multisaccharivorax type strain (PPPA20). Stand. Genomic Sci. 5, 41-49. doi: 10.4056/sigs.2164949

Pati, A., Gronow, S., Zeytun, A., Lapidus, A., Nolan, M., Hammon, N., et al. (2011c). Complete genome sequence of Bacteroides helcogenes type strain ( $\mathrm{P}$ 36-108). Stand. Genomic Sci. 4, 45-53. doi: 10.4056/sigs.1513795

Pattengale, N. D., Alipour, M., Bininda-Emonds, O. R. P., Moret, B. M. E., and Stamatakis, A. (2010). How many bootstrap replicates are necessary? J. Comput. Biol. 17, 337-354. doi: 10.1089/cmb.2009.0179

Pinhassi, J., Bowman, J. P., Nedashkovskaya, O. I., Lekunberri, I., GomezConsarnau, L., and Pedrós-Alió, C. (2006). Leeuwenhoekiella blandensis sp. nov., a genome-sequenced marine member of the family Flavobacteriaceae. Int. J. Syst. Evol. Microbiol. 56, 1489-1493. doi: 10.1099/ijs.0.64232-0

Pires, C., Carvalho, M. F., De Marco, P., Magan, N., and Castro, P. M. L. (2010). Chryseobacterium palustre sp. nov. and Chryseobacterium humi sp. nov., isolated from industrially contaminated sediments. Int. J. Syst. Evol. Microbiol. 60, 402-407. doi: 10.1099/ijs.0.010348-0 
Podosokorskaya, O. A., Kadnikov, V. V., Gavrilov, S. N., Mardanov, A. V., Merkel, A. Y., Karnachuk, O. V., et al. (2013). Characterization of Melioribacter roseus gen. nov., sp. nov., a novel facultatively anaerobic thermophilic cellulolytic bacterium from the class Ignavibacteria, and a proposal of a novel bacterial phylum Ignavibacteriae. Environ. Microbiol. 15, 1759-1771. doi: 10.1111/1462-2920.12067

Prasad, S., Poorna Manasa, B., Buddhi, S., Pratibha, M. S., Begum, Z., Bandi, S., et al. (2013). Arcticibacter svalbardensis gen. nov., sp. nov., of the family Sphingobacteriaceae in the phylum Bacteroidetes, isolated from Arctic soil. Int. J. Syst. Evol. Microbiol. 63, 1627-1632. doi: 10.1099/ijs.0.044420-0

Qiu, Y. L., Kuang, X. Z., Shi, X. S., Yuan, X. Z., and Guo, R. B. (2014). Terrimicrobium sacchariphilum gen. nov., sp. nov., an anaerobic bacterium of the class "Spartobacteria" in the phylum Verrucomicrobia, isolated from a rice paddy field. Int. J. Syst. Evol. Microbiol. 64, 1718-1723. doi: 10.1099/ijs.0.060244-0

Quan, Z. X., Kim, K. K., Kim, M. K., Jin, L., and Lee, S. T. (2007). Chryseobacterium caeni sp. nov., isolated from bioreactor sludge. Int. J. Syst. Evol. Microbiol. 57, 141-145. doi: 10.1099/ijs.0.64599-0

Quan, Z.-X., Xiao, Y.-P., Roh, S. W., Nam, Y.-D., Chang, H.-W., Shin, K.-S., et al. (2008). Joostella marina gen. nov., sp. nov., a novel member of the family Flavobacteriaceae isolated from the East Sea. Int. J. Syst. Evol. Microbiol. 58, 1388-1392. doi: 10.1099/ijs.0.65611-0

Raj, H. D., and Maloy, S. R. (1990). Proposal of Cyclobacterium marinus gen. nov., comb. nov. for a marine bacterium previously assigned to the genus Flectobacillus. Int. J. Syst. Bacteriol. 40, 337-347.

Rajasabapathy, R., Mohandass, C., Yoon, J. H., Dastager, S. G., Liu, Q., Khieu, T. N., et al. (2015). Vitellibacter nionensis sp. nov., isolated from a shallow water hydrothermal vent. Int. J. Syst. Evol. Microbiol. 65, 692-697. doi: 10.1099/ijs.0.070805-0

Rautio, M., Eerola, E., Väisänen-Tunkelrott, M.-L., Molitoris, D., Lawson, P., Collins, M. D., et al. (2003). Reclassification of Bacteroides putredinis (Weinberg et al., 1937) in a new genus Alistipes gen. nov., as Alistipes putredinis comb. nov., and description of Alistipes finegoldii sp. nov., from human sources. Syst. Appl. Microbiol. 26, 182-188. doi: 10.1078/072320203322346029

R Development Core Team (2015). R: A Language and Environment for Statistical Computing. Vienna: R Development Core Team.

Reddy, G. S. N., and Garcia-Pichel, F. (2005). Dyadobacter crusticola sp. nov., from biological soil crusts in the Colorado Plateau, USA, and an emended description of the genus Dyadobacter Chelius and Triplett 2000. Int. J. Syst. Evol. Microbiol. 55, 1295-1299. doi: 10.1099/ijs.0.63498-0

Reichenbach, H. (1989a). "Genus Flexibacter Soriano 1945, 92AL, emend," in Bergey's Manual of Systematic Bacteriology, Vol. 3, 1st Edn., eds J. T. Staley, M. P. Bryant, N. Pfennig, and J. G. Holt (Baltimore: The Williams \& Wilkins Co.), 2061-2071.

Reichenbach, H. (1989b). "Genus I. Cytophaga Winogradsky 1929 emend," in Bergey's Manual of Systematic Bacteriology, Vol. 3, 1st Edn., eds J. T. Staley, M. P. Bryant, N. Pfennig, and J. G. Holt (Baltimore: The Williams \& Wilkins Co.), 2015-2050.

Reichenbach, H. (1989c). "Order 1. Cytophagales Leadbetter 1974, 99AL," in Bergey's Manual of Systematic Bacteriology, Vol. 3, 1st Edn, eds J. T. Staley, M. P., Bryant, N., Pfennig, and J. G. Holt (New York, NY: Springer), 2011-2013.

Riedel, T., Held, B., Nolan, M., Lucas, S., Lapidus, A., Tice, H., et al. (2012a). Genome sequence of the Antarctic rhodopsins-containing Flavobacterium gillisia limnaea type strain $\left(\mathrm{R}-8282^{\mathrm{T}}\right)$. Stand. Genomic Sci. 7, 107-119. doi: 10.4056/sigs.3216895

Riedel, T., Held, B., Nolan, M., Lucas, S., Lapidus, A., Tice, H., et al. (2012b). Genome sequence of the orange-pigmented seawater bacterium Owenweeksia hongkongensis type strain $\left(\mathrm{UST} 20020801^{\mathrm{T}}\right.$ ). Stand. Genomic Sci. 7, 120-130. doi: 10.4056/sigs.3216895

Riedel, T., Spring, S., Fiebig, A., Petersen, J., Göker, M., and Klenk, H.-P. (2014). Genome sequence of the pink to light reddish-pigmented Rubellimicrobium mesophilum type strain (DSM $19309^{\mathrm{T}}$ ), a representative of the Roseobacter group isolated from soil, and emended description of the species. Stand. Genomic Sci. 9, 902-913. doi: 10.4056/sigs.5621012

Riley, R., Haridas, S., Wolfe, K. H., Lopes, M. R., Hittinger, C. T., Göker, M., et al. (2016). Comparative genomics of biotechnologically important yeasts. Proc. Natl. Acad. Sci. U.S.A. 113, 9882-9887. doi: 10.1073/pnas.1603941113
Robert, C., Chassard, C., Lawson, P. A., and Bernalier-Donadille, A. (2007). Bacteroides cellulosilyticus sp. nov., a cellulolytic bacterium from the human gut microbial community. Int. J. Syst. Evol. Microbiol. 57, 1516-1520. doi: 10.1099/ijs.0.64998-0

Romanenko, L. A., Tanaka, N., Kurilenko, V. V., and Svetashev, V. I. (2014). Tamlana sedimentorum sp. nov., isolated from shallow sand sediments of the Sea of Japan. Int. J. Syst. Evol. Microbiol. 64, 2891-2896. doi: $10.1099 /$ ijs. $0.061812-0$

Rosselló-Mora, R., and Amann, R. (2001). The species concept for prokaryotes. FEMS Microbiol. Rev. 25, 39-67. doi: 10.1016/S0168-6445(00)00040-1

Ryu, S. H., Nguyen, T. T. H., Park, W., Kim, C. J., and Jeon, C. O. (2006). Runella limosa sp. nov., isolated from activated sludge. Int. J. Syst. Evol. Microbiol. 56, 2757-2760. doi: 10.1099/ijs.0.64460-0

Saha, P., and Chakrabarti, T. (2006). Emticicia oligotrophicagen. nov., sp. nov., a new member of the family "Flexibacteraceae", phylum Bacteroidetes. Int. J. Syst. Evol. Microbiol. 56, 991-995. doi: 10.1099/ijs.0.64086-0

Sakamoto, M., and Benno, Y. (2006). Reclassification of Bacteroides distasonis, Bacteroides goldsteinii and Bacteroides merdae as Parabacteroides distasonis gen. nov., comb. nov., Parabacteroides goldsteinii comb. nov and Parabacteroides merdae comb. Int. J. Syst. Evol. Microbiol. 56, 1599-1605. doi: 10.1099/ijs.0.64192-0

Sakamoto, M., Kitahara, M., and Benno, Y. (2007). Parabacteroides johnsonii sp. nov., isolated from human faeces. Int. J. Syst. Evol. Microbiol. 57, 293-296. doi: $10.1099 /$ ijs.0.64588-0

Sakamoto, M., and Ohkuma, M. (2012). Reclassification of Xylanibacter oryzae Ueki et al. 2006 as Prevotella oryzae comb. nov., with an emended description of the genus Prevotella. Int. J. Syst. Evol. Microbiol. 62, 2637-2642. doi: $10.1099 /$ ijs.0.038638-0

Sakamoto, M., Takagaki, A., Matsumoto, K., Kato, Y., Goto, K., and Benno, Y. (2009). Butyricimonas synergistica gen. nov., sp. nov. and Butyricimonas virosa sp. nov., butyric acid-producing bacteria in the family "Porphyromonadaceae" isolated from rat faeces. Int. J. Syst. Evol. Microbiol. 59, 1748-1753. doi: 10.1099/ijs.0.007674-0

Sakamoto, M., Tanaka, Y., Benno, Y., and Ohkuma, M. (2014). Butyricimonas faecihominis sp. nov. and Butyricimonas paravirosa sp. nov., isolated from human faeces, and emended description of the genus Butyricimonas. Int. J. Syst. Evol. Microbiol. 64, 2992-2997. doi: 10.1099/ijs.0.065318-0

Sakamoto, M., Umeda, M., Ishikawa, I., and Benno, Y. (2005). Prevotella multisaccharivorax sp. nov., isolated from human subgingival plaque. Int. J. Syst. Evol. Microbiol. 55, 1839-1843. doi: 10.1099/ijs.0.63739-0

Sang, M. K., Kim, H.-S., Myung, I.-S., Ryu, C.-M., Kim, B. S., and Kim, K. D. (2013). Chryseobacterium kwangjuense sp. nov., isolated from pepper (Capsicum annuum L.) root. Int. J. Syst. Evol. Microbiol. 63, 2835-2840. doi: 10.1099/ijs.0.048496-0

Sangkhobol, V., and Skerman, V. B. D. (1981). Chitinophaga, a new genus of chitinolytic myxobacteria. Int. J. Syst. Bacteriol. 31, 285-293. doi: 10.1099/00207713-31-3-285

Scheuner, C., Tindall, B. J., Lu, M., Nolan, M., Lapidus, A., Cheng, J.F., et al. (2014). Complete genome sequence of Planctomyces brasiliensis type strain (DSM $5305^{\mathrm{T}}$ ), phylogenomic analysis and reclassification of Planctomycetes including the descriptions of Gimesia gen. nov., Planctopirus gen. nov. and Rubinisphaera gen. nov. and emended descriptions of the order Planctomycetales and the family Planctomycetaceae. Stand. Genomic Sci. 9:10. doi: $10.1186 / 1944-3277-9-10$

Schlesner, H., and Hirsch, P. (1987). Rejection of the Genus Name Pirella for pearshaped budding bacteria and proposal to create the genus Pirellula gen. nov. Int. J. Syst. Bacteriol. 37, 441-441. doi: 10.1099/00207713-37-4-441

Schlesner, H., Rensmann, C., Tindall, B. J., Gade, D., Rabus, R., Pfeiffer, S., et al. (2004). Taxonomic heterogeneity within the Planctomycetales as derived by DNA-DNA hybridization, description of Rhodopirellula baltica gen. nov., sp. nov., transfer of Perillula marina to the genus Blastopirellula gen. nov. as Blastopirellula marina comb. nov. and emended description of the genus Pirellula. Int. J. Syst. Evol. Microbiol. 54, 1567-1580. doi: 10.1099/ijs.0.63113-0

Schmidt, M., Priemé, A., and Stougaard, P. (2006). Rhodonellum psychrophilum gen. nov., sp. nov., a novel psychrophilic and alkaliphilic bacterium of the phylum Bacteroidetes isolated from Greenland. Int. J. Syst. Evol. Microbiol. 56, 2887-2892. doi: 10.1099/ijs.0.64450-0 
Shah, H. N., and Collins, D. M. (1990). Prevotella, a new genus to include Bacteroides melaninogenicus and related species formerly classified in the genus Bacteroides. Int. J. Syst. Bacteriol. 40, 205-208. doi: 10.1099/00207713-40-2-205

Shah, H. N., and Collins, M. D. (1988). Proposal for reclassification of Bacteroides asaccharolyticus, Bacteroides gingivalis, and Bacteroides endodontalis in a new genus, Porphyromonas. Int. J. Syst. Bacteriol. 38, 128-131. doi: 10.1099/00207713-38-1-128

Shah, H. N., Collins, M. D., Olsen, I., Paster, B. J., and Dewhirst, F. E. (1995). Reclassification of Bacteroides levii (Holdeman, Cato, and Moore) in the genus Polphyromonas, as Porphyromonas levii comb. nov. Int. J. Syst. Bacteriol. 45, 586-588. doi: 10.1099/00207713-45-3-586

Shah, H. N., and Gharbia, S. E. (1992). Biochemical and chemical studies on strains designated Prevotella intermedia and proposal of a new pigmented species, Prevotella nigrescens sp. nov. Int J Syst Bacteriol 42, 542-546. doi: 10.1099/00207713-42-4-542

Shakéd, T., Hantsis-Zacharov, E., and Halpern, M. (2010). Epilithonimonas lactis sp. nov., isolated from raw cow's milk. Int. J. Syst. Evol. Microbiol. 60, 675-679. doi: 10.1099/ijs.0.012575-0

Shen, F. T., Kämpfer, P., Young, C. C., Lai, W. A., and Arun, A. B. (2005). Chryseobacterium taichungense sp. nov., isolated from contaminated soil. Int. J. Syst. Evol. Microbiol. 55, 1301-1304. doi: 10.1099/ijs.0.63514-0

Sheu, S. Y., Lin, Y. S., and Chen, W. M. (2013). Flavobacterium squillarum sp. nov., isolated from a freshwater shrimp culture pond, and emended descriptions of Flavobacterium haoranii, Flavobacterium cauense, Flavobacterium terrae and Flavobacterium aquatile. Int. J. Syst. Evol. Microbiol. 63, 2239-2247. doi: 10.1099/ijs.0.046425-0

Shivaji, S., Vishnu Vardhan Reddy, P., Nageshwara Rao, S. S. S., Begum, Z., Manasa, P., and Srinivas, T. N. R. (2012). Cyclobacterium qasimii sp. nov., a psychrotolerant bacterium isolated from arctic marine sediment. Int. J. Syst. Evol. Microbiol. 62, 2133-2139. doi: 10.1099/ijs.0.038661-0

Siddall, M. E. (2010). Unringing a bell: metazoan phylogenomics and the partition bootstrap. Cladistics 26, 444-452. doi: 10.1111/j.1096-0031.2009.00295.x

Smith, C. J., Rocha, E. R., and Paster, B. J. (2006). "The medically important Bacteroides spp. in health and disease," in The Prokaryotes, eds M. Dworkin, S. Falkow, E. Rosenberg, K. H. Schleifer, and E. Stackebrandt (Berlin, Germany: Springer Verlag), 381-427.

Song, Y., Könönen, E., Rautio, M., Liu, C., Bryk, A., Eerola, E., et al. (2006). Alistipes onderdonkii sp. nov. and Alistipes shahii sp. nov., of human origin. Int. J. Syst. Evol. Microbiol. 56, 1985-1990. doi: 10.1099/ijs.0.64318-0

Sonnenburg, E. D., Zheng, H., Joglekar, P., Higginbottom, S. K., Firbank, S. J., Bolam, D. N., et al. (2010). Specificity of polysaccharide use in intestinal Bacteroides species determines diet-induced microbiota alterations. Cell 141, 1241-1252. doi: 10.1016/j.cell.2010.05.005

Stackebrandt, E., Chertkov, O., Lapidus, A., Nolan, M., Lucas, S., Han, C., et al. (2013). High-quality-draft genome sequence of the yellow-pigmented flavobacterium Joostella marina type strain $\left(\mathrm{En} 5^{\mathrm{T}}\right)$. Stand. Genomic Sci. 8, 37-46. doi: 10.4056/sigs.3537045

Stamatakis, A. (2014). RAxML Version 8: a tool for phylogenetic analysis and post-analysis of large phylogenies. Bioinformatics 30, 1312-1313. doi: 10.1093/bioinformatics/btu033

Stanier, R. Y. (1940). Studies on the Cytophagas. J. Bacteriol. 40, 619-635.

Strahan, B. L., Failor, K. C., Batties, A. M., Hayes, P. S., Cicconi, K. M., Mason, C. T., et al. (2011). Chryseobacterium piperi sp. nov., isolated from a freshwater creek. Int. J. Syst. Evol. Microbiol. 61, 2162-2166. doi: 10.1099/ijs.0.027805-0

Summanen, P. H., Durmaz, B., Väisänen, M. L., Liu, C., Molitoris, D., Eerola, E., et al. (2005). Porphyromonas somerae sp. nov., a pathogen isolated from humans and distinct from Porphyromonas levii. J. Clin. Microbiol. 43, 4455-4459. doi: 10.1128/JCM.43.9.4455-4459.2005

Summanen, P. H., Lawson, P. A., and Finegold, S. M. (2009). Porphyromonas bennonis sp. nov., isolated from human clinical specimens. Int. J. Syst. Evol. Microbiol. 59, 1727-1732. doi: 10.1099/ijs.0.001909-0

Surendra, V., Bhawana, P., Suresh, K., Srinivas, T. N. R., and Anil Kumar, P. (2012). Imtechella halotolerans gen. nov., sp. nov., a member of the family Flavobacteriaceae isolated from estuarine water. Int. J. Syst. Evol. Microbiol. 62, 2624-2630. doi: 10.1099/ijs.0.038356-0

Szoboszlay, S., Atzél, B., Kukolya, J., Tóth, E. M., Márialigeti, K., Schumann, P., et al. (2008). Chryseobacterium hungaricum sp. nov., isolated from hydrocarbon-contaminated soil. Int. J. Syst. Evol. Microbiol. 58, 2748-2754. doi: 10.1099/ijs.0.65847-0
Takeuchi, M., and Yokota, A. (1992). Proposals of Sphingobacterium faecium sp. nov., Sphingobacterium piscium sp.nov., Sphingobacterium heparinum comb. nov., Sphingobacterium thalpophilum comb. nov. and two genospecies of the genus Sphingobacterium, and syn. J. Gen. Micriobiol. 38, 465-482. doi: 10.2323 /jgam.38.465

Taylor, D. J., and Piel, W. H. (2004). An assessment of accuracy, error, and conflict with support values from genome-scale phylogenetic data. Mol. Biol. Evol. 21, 1534-1537. doi: 10.1093/molbev/msh156

Ten, L. N., Xu, J.-L. L., Jin, F.-X. X., Im, W.-T. T., Oh, H.-M. M., and Lee, S.-T. T. (2009). Spirosoma panaciterrae sp. nov., isolated from soil. Int. J. Syst. Evol. Microbiol. 59, 331-335. doi: 10.1099/ijs.0.002436-0

Tenreiro, S., Nobre, M. F., Rainey, F. A., Miguel, C., and Da Costa, M. S. (1997). Thermonema rossianum sp. nov., a new thermophilic and slightly halophilic species from saline hot springs in Naples, Italy. Int. J. Syst. Bacteriol. 47, 122-126. doi: 10.1099/00207713-47-1-122

Thomas, F., Hehemann, J.-H., Rebuffet, E., Czjzek, M., and Michel, G. (2011). Environmental and gut Bacteroidetes: the food connection. Front. Microbiol. 2:93. doi: 10.3389/fmicb.2011.00093

Tsiamis, G., Katsaveli, K., Ntougias, S., Kyrpides, N., Andersen, G., Piceno, Y., et al. (2008). Prokaryotic community profiles at different operational stages of a Greek solar saltern. Res. Microbiol. 159, 609-627. doi: 10.1016/j.resmic.2008.09.007

Ueki, A., Abe, K., Kaku, N., Watanabe, K., and Ueki, K. (2008). Bacteroides propionicifaciens sp. nov., isolated from rice-straw residue in a methanogenic reactor treating waste from cattle farms. Int. J. Syst. Evol. Microbiol. 58, 346-352. doi: 10.1099/ijs.0.65486-0

Ueki, A., Akasaka, H., Satoh, A., Suzuki, D., and Ueki, K. (2007). Prevotella paludivivens sp. nov., a novel strictly anaerobic, Gram-negative, hemicellulosedecomposing bacterium isolated from plant residue and rice roots in irrigated rice-field soil. Int. J. Syst. Evol. Microbiol. 57, 1803-1809. doi: 10.1099/ijs.0.64914-0

Urios, L., Agogué, H., Lesongeur, F., Stackebrandt, E., and Lebaron, P. (2006). Balneola vulgaris gen. nov., sp. nov., a member of the phylum Bacteroidetes from the north-western Mediterranean Sea. Int. J. Syst. Evol. Microbiol. 56, 1883-1887. doi: 10.1099/ijs.0.64285-0

Urios, L., Intertaglia, L., Lesongeur, F., and Lebaron, P. (2008). Balneola alkaliphila sp. nov., a marine bacterium isolated from the Mediterranean Sea. Int. J. Syst. Evol. Microbiol. 58, 1288-1291. doi: 10.1099/ijs.0.65555-0

Vaas, L. A. I., Sikorski, J., Hofner, B., Fiebig, A., Buddruhs, N., Klenk, H. P., et al. (2013). Opm: an R package for analysing OmniLog ${ }^{\circledR}$ phenotype microarray data. Bioinformatics 29, 1823-1824. doi: 10.1093/bioinformatics/btt291

Vaisman, N., and Oren, A. (2009). Salisaeta longa gen. nov., sp. nov., a red, halophilic member of the Bacteroidetes. Int. J. Syst. Evol. Microbiol. 59, 2571-2574. doi: 10.1099/ijs.0.010892-0

Vancanneyt, M., Segers, P., Torck, U., Hoste, B., Bernardet, J. F., Vandamme, P., et al. (1996). Reclassification of Flavobacterium odoratum (Stutzer 1929) strains to a new genus, Myroides, as Myroides odoratus comb. nov. and Myroides odoratimimus sp. nov. Int. J. Syst. Bacteriol. 46, 926-932. doi: 10.1099/00207713-46-4-926

Vandamme, P., Bernardet, J. F., Segers, P., Kersters, K., and Holmes, B. (1994). New perspectives in the classification of the Flavobacteria: description of Chryseobacterium gen. nov., Bergeyella gen. nov., and Empedobacter nom. rev. Int. J. Syst. Bacteriol. 44, 827-831. doi: 10.1099/00207713-44-4-827

Vaneechoutte, M., Kämpfer, P., De Baere, T., Avesani, V., Janssens, M., and Wauters, G. (2007). Chryseobacterium hominis sp. nov., to accommodate clinical isolates biochemically similar to CDC groups II-h and II-c. Int. J. Syst. Evol. Microbiol. 57, 2623-2628. doi: 10.1099/ijs.0.65158-0

Van Trappen, S., Vandecandelaere, I., Mergaert, J., and Swings, J. (2004). Gillisia limnaea gen. nov., sp. nov., a new member of the family Flavobacteriaceae isolated from a microbial mat in Lake Fryxell, Antartica. Int. J. Syst. Evol. Microbiol. 54, 445-448. doi: 10.1099/ijs.0.02922-0

Van Trappen, S., Vandecandelaere, I., Mergaert, J., and Swings, J. (2005). Flavobacterium fryxellicola sp. nov. and Flavobacterium psychrolimnae sp. nov., novel psychrophilic bacteria isolated from microbial mats in Antarctic lakes. Int. J. Syst. Evol. Microbiol. 55, 769-772. doi: 10.1099/ijs.0.03056-0

van Veen, W. L., van der Kooij, D., Geuze, E. C. W. A., and van der Vlies, A. W. (1973). Investigations on the sheathed bacterium Haliscomenobacter hydrossis gen.n., sp.n., isolated from activated sludge. Antonie Van Leeuwenhoek 39, 207-216. doi: 10.1007/BF02578853 
Vaz-Moreira, I., Nobre, M. F., Nunes, O. C., and Manaia, C. M. (2007). Pseudosphingobacterium domesticum gen. nov., sp. nov., isolated from home-made compost. Int. J. Syst. Evol. Microbiol. 57, 1535-1538. doi: 10.1099/ijs.0.64950-0

Wagener, K., Drillich, M., Baumgardt, S., Kämpfer, P., Busse, H. J., and EhlingSchulz, M. (2014). Falsiporphyromonas endometrii gen. nov., sp. nov., isolated from the post-partum bovine uterus, and emended description of the genus Porphyromonas Shah and Collins 1988. Int. J. Syst. Evol. Microbiol. 64, 642-649. doi: 10.1099/ijs.0.057307-0

Wang, Y.-X., Liu, J.-H., Xiao, W., Ma, X.-L., Lai, Y.-H., Li, Z.-Y., et al. (2013a). Aliifodinibius roseus gen. nov., sp. nov., and Aliifodinibius sediminis sp. nov., two moderately halophilic bacteria isolated from salt mine samples. Int. J. Syst. Evol. Microbiol. 63, 2907-2913. doi: 10.1099/ijs.0.043869-0

Wang, Y.-X., Liu, J.-H., Xiao, W., Zhang, X.-X., Li, Y.-Q., Lai, Y.-H., et al. (2012). Fodinibius salinus gen. nov., sp. nov., a moderately halophilic bacterium isolated from a salt mine. Int. J. Syst. Evol. Microbiol. 62, 390-396. doi: 10.1099/ijs.0.025502-0

Wang, Y. X., Li, Y. P., Liu, J. H., Xiao, W., Lai, Y. H., Li, Z. Y., et al. (2013b). Gracilimonas mengyeensis sp. nov., a moderately halophilic bacterium isolated from a salt mine in Yunnan, south-western China. Int. J. Syst. Evol. Microbiol. 63, 3989-3993. doi: 10.1099/ijs.0.052043-0

Wardle, H. M., Drucker, D. B., and Joseph, L. A. (1996). Phospholipid molecular species of Bacteroides. J. Appl. Bacteriol. 80, 551-556. doi: 10.1111/j.1365-2672.1996.tb03256.x

Weisburg, W. G., Oyaizu, Y., Oyaizu, H., and Woese, C. R. (1985). Natural relationship between bacteroides and flavobacteria. J. Bacteriol. 164, 230-236.

Weon, H. Y., Kim, B. Y., Kwon, S. W., Park, I. C., Cha, I. B., Tindall, B. J., et al. (2005). Leadbetterella byssophila gen. nov., sp. nov., isolated from cotton-waste composts for the cultivation of oyster mushroom. Int. J. Syst. Evol. Microbiol. 55, 2297-2302. doi: 10.1099/ijs.0.63741-0

Weon, H. Y., Kim, B. Y., Yoo, S. H., Kwon, S. W., Stackebrandt, E., and Go, S. J. (2008). Chryseobacterium soli sp. nov. and Chryseobacterium jejuense sp. nov., isolated from soil samples from Jeju, Korea. Int. J. Syst. Evol. Microbiol. 58, 470-473. doi: 10.1099/ijs.0.65295-0

Whitehead, T. R., Cotta, M. A., Collins, M. D., Falsen, E., and Lawson, P. A. (2005). Bacteroides coprosuis sp. nov., isolated from swine-manure storage pits. Int. J. Syst. Evol. Microbiol. 55, 2515-2518. doi: 10.1099/ijs.0.63869-0

Wickham, H. (2009). Ggplot2: Elegant Graphics for Data Analysis, 2nd Edn. New York, NY: Springer.

Wiley, E., and Lieberman, B. (2011). Phylogenetics: Theory and Practice of Phylogenetic Systematics. Hoboken, NJ: John Wiley \& Sons, Inc.

Willems, A., and Collins, M. D. (1995a). 16S rRNA Gene similarities indicate that Hallella seregens (Moore and Moore) and Mitsuokella dentalis (Haapasalo et al.) are genealogically highly related and are members of the genus prevotella: emended description of the genus Prevotella (Shah and Collins) and Description of Prevotella dentalis comb. nov. Int. J. Syst. Bacteriol. 45, 832-836. doi: 10.1099/00207713-45-4-832

Willems, A., and Collins, M. D. (1995b). Reclassification of Oribaculum catoniae (Moore and Moore 1994) as Porphyromonas catoniae comb. nov. and emendation of the genus Porphyromonas. Int. J. Syst. Bacteriol. 45, 578-581. doi: 10.1099/00207713-45-3-578

Winogradsky, S. (1929). Études sur la microbiologie du sol - sur la dégradation de la cellulose dans le sol. Ann. l'Institut Pasteur 43, 549-633.

Woese, C. R. (1987). Bacterial evolution. Microbiol. Rev. 51, 221-271.

Wood, S. (1994). Monophyly and comparison between trees. Cladistics 10, 339-346.

Wu, C., Johnson, J. L., Moore, W. E. C., and Moore, L. V. H. (1992). Emended Descriptions of Prevotella denticola, Prevotella loescheii, Prevotella veroralis, and Prevotella melaninogenica. Int. J. Syst. Bacteriol. 42, 536-541. doi: 10.1099/00207713-42-4-536

Wu, Y. F., Wu, Q.-L. L., and Liu, S.-J. J. (2013). Chryseobacterium taihuense sp. nov., isolated from a eutrophic lake, and emended descriptions of the genus Chryseobacterium, Chryseobacterium taiwanense, Chryseobacterium jejuense and Chryseobacterium indoltheticum. Int. J. Syst. Evol. Microbiol. 63, 913-919. doi: 10.1099/ijs.0.040337-0

Xu, Y., Zhang, R., Li, Q., Liu, K., and Jiao, N. (2015). Marivirga lumbricoides sp. nov., a marine bacterium isolated from the South China Sea. Int. J. Syst. Evol. Microbiol. 65, 452-456. doi: 10.1099/ijs.0.066027-0
Yabuuchi, E., Kaneko, T., Yano, I., Moss, W., and Miyoshi, N. (1983). Sphingobacterium gen. nov., Sphingobacterium spiritivorum comb. nov., Sphingobacterium multivorum comb. nov., Sphingobacterium mizutae sp. nov., and Flavobacterium indologenes sp. nov.: glucose-nonfermenting gramnegative rods in CDC groups IIK-2 and IIb. Int. J. Syst. Bacteriol. 33, 580-598. doi: 10.1099/00207713-33-3-580

Yang, J. E., Shin, J. Y., Park, S. Y., T Mavlonov G., Yi, E. J., Lee, E. H., et al. (2012). Pedobacter kyungheensis sp. nov., with ginsenoside converting activity. J. Gen. Appl. Microbiol. 58, 309-316. doi: 10.2323/jgam.58.309

Yang, S.-H., Seo, H.-S., Woo, J.-H., Oh, H.-M., Jang, H., Lee, J.-H., et al. (2014). Carboxylicivirga gen. nov. in the family Marinilabiliaceae with two novel species, Carboxylicivirga mesophila sp. nov. and Carboxylicivirga taeanensis sp. nov., and reclassification of Cytophaga fermentans as Saccharicrinis fermentans gen. nov., comb. nov. Int. J. Syst. Evol. Microbiol. 64, 1351-1358. doi: 10.1099/ijs.0.053462-0

Yarza, P., Richter, M., Peplies, J., Euzeby, J., Amann, R., Schleifer, K.-H., et al. (2008). The All-Species Living Tree project: a 16S rRNA-based phylogenetic tree of all sequenced type strains. Syst. Appl. Microbiol. 31, 241-250. doi: 10.1016/j.syapm.2008.07.001

Yi, H., Oh, H. M., Lee, J. H., Kim, S. J., and Chun, J. (2005). Flavobacterium antarcticum sp. nov., a novel psychrotolerant bacterium isolated from the Antarctic. Int. J. Syst. Evol. Microbiol. 55, 637-641. doi: 10.1099/ijs.0.63423-0

Yoon, J.-H. H., Lee, M.-H. H., Kang, S.-J. J., and Oh, T.-K. K. (2006). Algoriphagus terrigena sp. nov., isolated from soil. Int. J. Syst. Evol. Microbiol. 56, 777-780. doi: 10.1099/ijs.0.64092-0

Yoon, M. H., and Im, W.-T. T. (2007). Flavisolibacter ginsengiterrae gen. nov., sp. nov. and Flavisolibacter ginsengisoli sp. nov., isolated from ginseng cultivating soil. Int. J. Syst. Evol. Microbiol. 57, 1834-1839. doi: 10.1099/ijs.0.65011-0

Young, C. C., Kämpfer, P., Shen, F. T., Lai, W. A., and Arun, A. B. (2005). Chryseobacterium formosense sp. nov., isolated from the rhizosphere of Lactuca sativa L. (garden lettuce). Int. J. Syst. Evol. Microbiol. 55, 423-426. doi: 10.1099/ijs.0.63331-0

Zhang, L., Wang, Y., Wei, L., Wang, Y., Shen, X., and Li, S. (2013). Taibaiella smilacinae gen. nov., sp. nov., an endophytic member of the family Chitinophagaceae isolated from the stem of Smilacina japonica, and emended description of Flavihumibacter petaseus. Int. J. Syst. Evol. Microbiol. 63, 3769-3776. doi: 10.1099/ijs.0.051607-0

Zhang, R. G., Tan, X., Zhao, X. M., Deng, J., and Lv, J. (2014). Moheibacter sediminis gen. nov., sp. nov., a member of the family Flavobacteriaceae isolated from sediment, and emended descriptions of Empedobacter brevis, Wautersiella falsenii and Weeksella virosa. Int. J. Syst. Evol. Microbiol. 64, 1481-1487. doi: 10.1099/ijs.0.060178-0

Zhilina, T. N., Appel, R., Probian, C., Brossa, E. L., Harder, J., Widdel, F., et al. (2004). Alkaliflexus imshenetskii gen. nov. sp. nov., a new alkaliphilic gliding carbohydrate-fermenting bacterium with propionate formation from a soda lake. Arch. Microbiol. 182, 244-253. doi: 10.1007/s00203-004-0722-0

Zhou, Y., Su, J., Lai, Q., Li, X., Yang, X., Dong, P., et al. (2013). Phaeocystidibacter luteus gen. nov., sp. nov., a member of the family Cryomorphaceae isolated from the marine alga Phaeocystis globosa, and emended description of Owenweeksia hongkongensis. Int. J. Syst. Evol. Microbiol. 63, 1143-1148. doi: 10.1099/ijs.0.030254-0

Zhou, Z., Jiang, F., Wang, S., Peng, F., Dai, J., Li, W., et al. (2012). Pedobacter arcticus sp. nov., a facultative psychrophile isolated from Arctic soil, and emended descriptions of the genus Pedobacter, Pedobacter heparinus, Pedobacter daechungensis, Pedobacter terricola, Pedobacter glucosidilyticus and Pedobacter lentus. Int. J. Syst. Evol. Microbiol. 62, 1963-1969. doi: 10.1099/ijs.0.031104-0

Conflict of Interest Statement: The authors declare that the research was conducted in the absence of any commercial or financial relationships that could be construed as a potential conflict of interest.

Copyright (C) 2016 Hahnke, Meier-Kolthoff, García-López, Mukherjee, Huntemann, Ivanova, Woyke, Kyrpides, Klenk and Göker. This is an open-access article distributed under the terms of the Creative Commons Attribution License (CC BY). The use, distribution or reproduction in other forums is permitted, provided the original author(s) or licensor are credited and that the original publication in this journal is cited, in accordance with accepted academic practice. No use, distribution or reproduction is permitted which does not comply with these terms. 